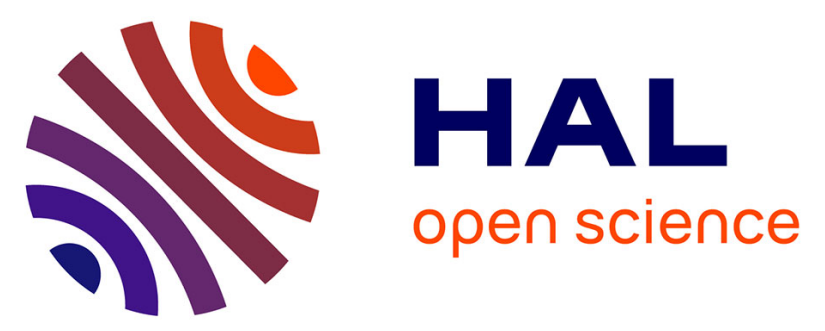

\title{
The sensitivity of gas hydrate reservoirs to climate change: Perspectives from a new combined model for permafrost-related and marine settings
}

Thomas Mestdagh, Jeffrey Poort, Marc de Batist

\section{- To cite this version:}

Thomas Mestdagh, Jeffrey Poort, Marc de Batist. The sensitivity of gas hydrate reservoirs to climate change: Perspectives from a new combined model for permafrost-related and marine settings. EarthScience Reviews, 2017, 169, pp.104-131. 10.1016/j.earscirev.2017.04.013 . hal-01521071

\section{HAL Id: hal-01521071 \\ https: / hal.sorbonne-universite.fr/hal-01521071}

Submitted on 11 May 2017

HAL is a multi-disciplinary open access archive for the deposit and dissemination of scientific research documents, whether they are published or not. The documents may come from teaching and research institutions in France or abroad, or from public or private research centers.
L'archive ouverte pluridisciplinaire HAL, est destinée au dépôt et à la diffusion de documents scientifiques de niveau recherche, publiés ou non, émanant des établissements d'enseignement et de recherche français ou étrangers, des laboratoires publics ou privés. 


\section{The sensitivity of gas hydrate reservoirs to climate change: perspectives from a new combined model for permafrost-related and marine settings}

Thomas Mestdagh ${ }^{\mathrm{a},}{ }^{,}$, Jeffrey Poort ${ }^{\mathrm{b}}$, Marc De Batist ${ }^{\mathrm{a}}$

${ }^{a}$ Renard Centre of Marine Geology, Department of Geology, Ghent University, Krijgslaan 281 (S8), 9000 Ghent, Belgium

${ }^{b}$ Institut des Sciences de la Terre de Paris, Université Pierre et Marie Curie, Case courrier 129-4, place Jussieu, 75252 Paris, France

*Corresponding author: Thomas.Mestdagh@UGent.be

\section{Abstract}

Gas hydrate reservoirs store large quantities of gas in sediments on continental margins, in deep lakes, and in continental and relic sub-shelf permafrost. The gas hydrate structure is only stable at sufficiently low temperature and high pressure, and may therefore collapse under changing climatic conditions. If a temperature rise or pressure drop (e.g. through falling sea level) is effective enough to dissociate hydrate deposits, methane (the most common gas component in hydrates and a potent greenhouse gas) is released from the hydrate structure and may eventually enter into the atmosphere. This may generate a positive feedback effect, as resulting enhanced greenhouse gas levels would additionally warm the atmosphere and hence maintain or reinforce hydrate dissociation. The significance of this mechanism has been debated over the past decades, often within the framework of geologically rapid Quaternary climatic oscillations and present-day climate warming. An extensive set of studies has addressed the climate-sensitivity of gas hydrate reservoirs in various study areas and geological settings, and by means of various approaches. No real consensus has yet been reached on the matter. In this study, we seek to evaluate the sensitivity of gas hydrate reservoirs to changes in global climate from a more general perspective, by firstly reviewing the available literature, and secondly developing a new numerical model to quantify gas hydrate destabilization under changing environmental conditions. Qualities of the model include the wide applicability to both marine and permafrost-related hydrate reservoirs and the integrative 
approach, combining existing hydrate formation models with a dissocation model that accounts for the consumption of latent heat during hydrate dissociation. To determine which settings are most vulnerable, and to acquire insight into the extent, fashion and rates of hydrate dissociation, we apply the model to four distinct types of hydrate reservoirs across a hypothetic high-latitude continental margin under two specific cases of climate change: the last deglaciation following the Last Glacial Maximum and present-day climate warming. The simulations indicate that hydrates on the upper continental slope and in association with thin, sub-shelf permafrost are most sensitive to the imposed climatic variations, whereas deepwater and onshore permafrost-related reservoirs react in a more stable way. However, the deep (i.e. at several tens to hundreds of meters subsurface depth) stratigraphic-type hydrates considered in this study constitute by far the largest fraction of the global gas hydrate volume, but dissociate on slow timescales of thousands to hunderds of thousands of years, even in the most sensitive environments. In contrast, shallow (i.e. at, or a few meters below the surface or seafloor) structural-type hydrates are able to respond to climatic variations on submillennial timescales, but the volumes of gas they may release are probably insignificant to the global carbon cycle and climate. Quaternary and present-day climate change do affect the stability of gas hydrate reservoirs, but at long timescales where hydrate volumes are large, and on short timescales where hydrate volumes are small. Consequently, gas hydrates dissociate to an extent that is too small or at a pace that is too slow to create a strong positive feedback effect. While the release of methane from the disintegration of gas hydrates is observed on different margins today, it is not likely to have played a leading role in Quaternary climatic variations or to become a significant process in the coming centuries as a result of present-day rising temperatures.

Keywords: gas hydrate; climate change; methane; modeling; marine; permafrost 


\section{Introduction}

Gas hydrates are ice-like crystalline compounds of water and gas (in nature predominantly methane), that occupy the pore space of sediments if low temperature and high pressure conditions prevail, and if a sufficiently large volume of gas is available (Davie and Buffett, 2001). Natural gas hydrates have been discovered in marine sediments on continental margins, in the sedimentary infill of deep lake basins, as well as in association with continental and relic sub-shelf permafrost (Collett et al., 2009). Milkov (2004) estimates the global volume of natural gas contained in submarine hydrate reservoirs to be in the range of 1 to $5 \times 10^{15} \mathrm{~m}^{3}$ (equivalent to $\pm 500-2500$ Gton of methane carbon). In addition to this, about 20 Gton of carbon is estimated to be stored in Arctic permafrost-related hydrate deposits (Ruppel, 2015). This vast amount of methane, locked up in hydrate reservoirs at relatively shallow depths in the geosphere (compared to regular natural gas accumulations), has drawn the attention of the research community because it may constitute a potential energy resource (Koh et al., 2012), and because it may play a role in the global carbon cycle and influence the Earth's climate (e.g. Nisbet, 1990; Dickens et al., 1995; Kvenvolden, 2002; Kennett et al., 2003; Archer, 2007; Archer et al., 2009; Ruppel, 2011; Ruppel and Kessler, 2017). Awareness of the latter issue originated in the 1980's, with a.o. Kvenvolden (1988) realizing that gas hydrate reservoirs may release significant amounts of methane $\left(\mathrm{CH}_{4}\right)$ and its oxidation product carbon dioxide $\left(\mathrm{CO}_{2}\right)$, both greenhouse gases, to the atmosphere, when hydrates decompose as a result of global warming. The subsequent increase in atmospheric greenhouse gas levels would contribute to already warming temperatures and thus maintain or even amplify the dissociation of the hydrates. As such, this positive feedback mechanism would mark a close interrelationship between geologically rapid climate change and fluctuations in atmospheric greenhouse gas levels on the one hand, and variations in the size of the global gas hydrate reservoir on the other (figure 1). Hydrate reservoirs in high-latitude areas are believed to be most sensitive to this process, because climatic changes are most pronounced here (e.g. IPCC, 2013) and hydrates exist below shallower water depths. Hypotheses relying on this hydrate-climate coupling have been formulated within the framework of 
Quaternary 'glacial to interglacial' transitions (e.g. Nisbet, 1990; Paull et al., 1991; Loehle, 1993; Poort et al., 2005) and higher-frequency 'stadial to interstadial' climatic oscillations (Kennett et al., 2003), in the debate of present-day climate change (e.g. Westbrook et al., 2009; Biastoch et al., 2011; Hunter et al., 2013; Marín-Moreno et al., 2013; Ruppel and Kessler, 2017), as well as in the context of the Paleocene-Eocene thermal maximum (PETM) and other past hyperthermal events (Dickens et al., 1995).

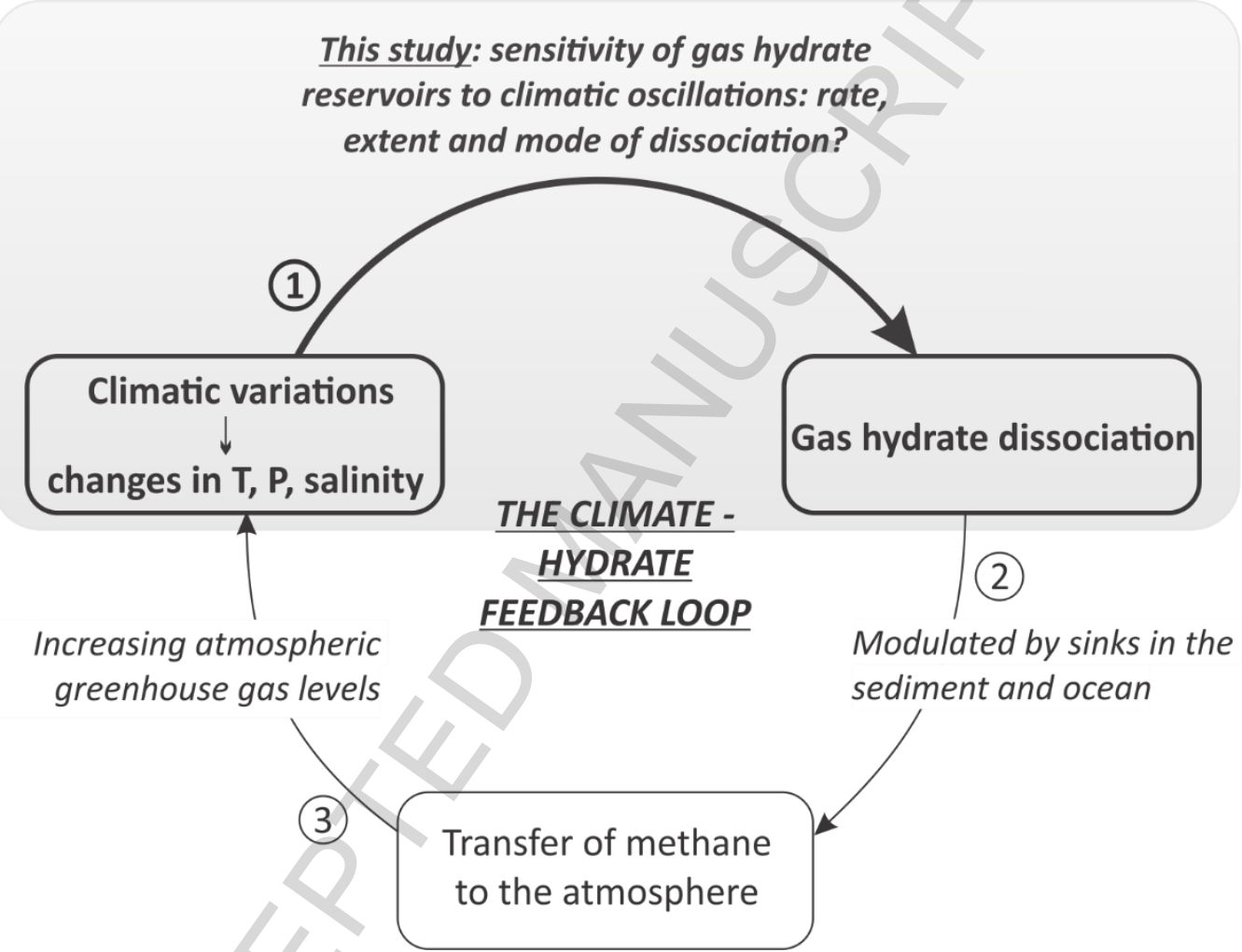

Figure 1. The feedback interaction between climate change and gas hydrate dissociation: an initial change in climatic conditions (temperature, pressure or salinity) can cause hydrate dissociation. If the liberated gas (predominantly methane) eventually reaches the atmosphere, the increase in atmospheric greenhouse gas concentrations can lead to an additional warming, and maintain or reinforce further dissociation of hydrates. The present work reviews the first step in this cycle, which can be considered as the sensitivity of gas hydrate reservoirs to climate change.

However, the role of gas hydrates in the carbon cycle and global climate, although being suggestive, remains controversial. A wide range of studies have contributed to the debate, presenting either field observations, measurements and/or quantitative modelling results in favor of or against a significant role for gas hydrates in controlling Earth's climate. The discussion is complex because gas hydrate systems are governed by the interplay of geological, chemical, physical and biological 
processes, each working in a certain direction, at a specific rate, and according to a small or large set of imposed parameters (Xu and Ruppel, 1999). Many studies have focused on only one single aspect of the gas hydrate system, hereby ignoring the potential impact of interrelated processes on the presented results. Moreover, many studies focus on one specific study area and one specific hydratebearing geological setting, with permafrost-related hydrate settings being strongly underrepresented. As a result, a general consensus has not yet been reached.

Obviously, a more integrated approach and general perspective are necessary. A recent study by Ruppel and Kessler (2017) reviews the full climate - hydrate feedback cycle shown in figure 1, with the main focus on present-day, anthropogenically forced climate change. The here presented study concentrates more deeply on the first step in this cycle and reviews how gas hydrate reservoirs react when they are subjected to changing climatic conditions. Specifically, the objectives of this work are to: (1) provide a concise overview of key studies and examples, to illustrate the available tools and above-outlined issues when evaluating the sensitivity of gas hydrate reservoirs to climate change; and (2) complement this review with a new, simple one-dimensional hydrate dissociation model, though based on a large and critically chosen set of parameters and processes, in order to thoroughly evaluate where, how fast, in what fashion and to what extent gas hydrates can dissociate when climatic oscillations disturb hydrate stability conditions. In this study, we specifically focus on the case of Quaternary and present-day climate variability. The environmental changes associated with the PETM took place on different timescales and within a different palaeogeographical context. Hence the discussion on the role of hydrate decomposition in the PETM is not addressed here, but is for example reviewed by Dickens (2011). Importantly, the here presented model is applicable to both permafrost and marine environments, which allows to assess and compare four distinct hydratebearing settings across a hypothetic high-latitude continental margin (i.e. i) thick onshore permafrost, ii) relic sub-shelf permafrost, iii) upper continental slope and iv) lower continental slope/continental rise; see figure 2). By means of a sensitivity analysis we illustrate how variations in certain model parameters affect the model outcome. Changes in temperature and pressure (through 
sea level variations) representative for the last deglaciation following the Last Glacial Maximum (LGM) and for contemporary climate change are then simulated, in order to determine the climatesensitivity of gas hydrate reservoirs in these two case studies. The model incorporates a number of important factors that have not always been fully considered in previous studies, such as i) the rates of the involved processes, especially the dissociation rate, but also the (re-)formation rate of hydrates, and ii) the effective occurrence of hydrate in the subsurface, as the sedimentary column in which gas hydrates can theoretically occur is not necessarily entirely filled with hydrates.

\section{Gas released from destabilizing hydrate reservoirs, potentially transferred to the atmosphere}

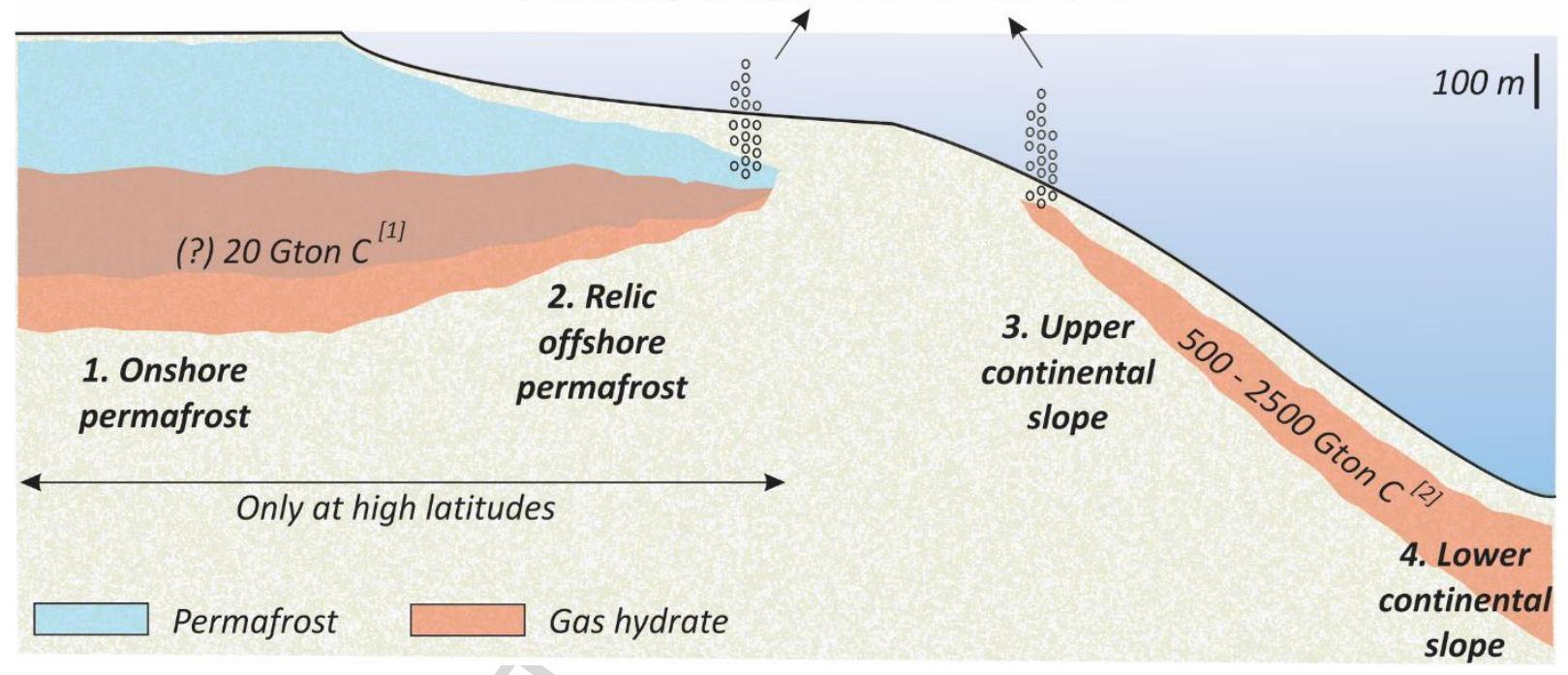

Figure 2. Schematic profile across a hypothetic continental margin, showing gas hydrates in four distinct geographic settings: (1) thick onshore permafrost (only at high latitudes); (2) relic subsea permafrost below the shelf (only at high latitudes); (3) feathering upper edge of the hydrate stability zone on the upper continental slope; (4) deepwater setting on the lower continental slope or rise. ${ }^{[1]}$ Estimate of the amount of Arctic permafrost-associated gas hydrate by Ruppel (2015), however remaining highly uncertain; ${ }^{[2]}$ Estimate of the global amount of submarine gas hydrate by Milkov (2004). 


\section{Review of studies on the sensitivity of gas hydrates to climate change}

Natural gas hydrate reservoirs were discovered and recognized as a major pool of carbon in the shallow geosphere during the 1960's and 1970's. Soon, scientists started to realize that changes in the size of the global hydrate inventory could interfere with the Earth's carbon cycle and climate (e.g. Kvenvolden, 1988; MacDonald, 1990; Kvenvolden, 1993). Early studies have primarily focused on the role of melting methane hydrates in Quaternary 'glacial to interglacial' transitions. For example, the hydrocarbon pump hypothesis, which states that methane can be rapidly released from decomposing (high-latitude) hydrate reservoirs after a small triggering event with subsequent rising temperatures, has been invoked to explain the observed increase in atmospheric methane and carbon dioxide levels at the end of the last and penultimate glaciation (Nisbet, 1990; Loehle, 1993). Paull et al. (1991) suggest that gas hydrates already start to destabilize as the glaciation progresses, because of falling sea level and the subsequent decrease in pressure. The resulting warming (because of the gradual buildup of atmospheric methane) would thus limit the extent of glaciations. Another pressure effect has been described by Smith et al. (2001) and Crémière et al. (2016), who suggest that melting of ice sheets during the last deglaciation has led to thinning of the underlying hydrate stability zone and methane release, on the East Greenland shelf and the Norwegian margin respectively. The clathrate gun hypothesis (Kennett et al., 2003) adopts similar ideas as the hydrocarbon pump hypothesis, and additionally applies them to higher-frequency 'stadial to interstadial' climatic oscillations. During the past two decades the debate has increasingly centered around the potential effect of contemporary anthropogenic climate forcing on the stability of (Arctic) gas hydrates. Archer et al. (2009) conclude that the stability of oceanic methane hydrates may constitute a slow tipping point in the global carbon cycle. Others argue that hydrate reservoirs are already actively destabilizing today, for example on the upper continental slope West of Svalbard (Westbrook et al., 2009).

The straightforward logic of the above hypotheses is appealing. It is, however, important to establish on which observations they are based, and how they can be corroborated. Generally, three types of 
tools are available: (1) isotopic measurements; (2) analysis of features that can be indicative of hydrate dissociation, and (3) modelling. Their application to, and implications for the gas hydrate debate are discussed below, and summarized in table 1.

\subsection{Isotopic measurements}

Methane in gas hydrate systems either has a biogenic (microbial) or thermogenic origin (Milkov, 2005). Biogenic methane is generally strongly depleted in ${ }^{13} \mathrm{C}$, with present-day $\delta^{13} \mathrm{C}$ values typically $<-60 \%$ (Milkov, 2005). Negative $\delta^{13} \mathrm{C}$ excursions in marine isotopic records can therefore be an indication of methane release from destabilizing hydrate reservoirs, for example during the last deglaciation (Loehle, 1993; Smith et al., 2001). Millennial-scale oscillations in carbon isotopic values from benthic and planktonic foraminiferal assemblages in the Santa Barbara basin constitute the base of the clathrate gun hypothesis (Kennett et al., 2003). However, deuterium/hydrogen (D/H) isotope ratios measured on atmospheric methane trapped in ice cores, do not support the presumed methane outgassing from a marine methane hydrate source during abrupt Late Quaternary warming episodes (Sowers, 2006; Bock et al., 2010).

\subsection{Analysis of potential hydrate dissociation features}

A second category of frequently cited arguments results from the direct observation and analysis of what can be considered as (methane) gas release features in the sediment, at the seafloor, or in the water column. Nevertheless, we note that these features are indicative of gas release, yet they do not necessarily need to be a result of the active decomposition of hydrate deposits (e.g. Knies et al., 2004; Rajan et al., 2012). Therefore below features should be regarded as indicators of the possibility that hydrates have been or are actively dissociating, rather than unambiguous proxies for hydrate dissociation.

\subsubsection{Gas seeps, authigenic carbonates and pockmarks}


Gas bubbles in the water column can be detected with echosounder systems. As such, hydroacoustic surveying has led to the discovery of gas seep sites worldwide, for example off Svalbard (Westbrook et al., 2009; Berndt et al., 2014), on the Cascadia margin (Johnson et al., 2015), in the Gulf of Mexico (Solomon et al., 2009), on the Hikurangi margin off New Zealand (Greinert et al., 2010), and in the Black Sea (Naudts et al., 2006). Westbrook et al. (2009) claim that the methane seeps off Svalbard are at least partly connected to a downslope retreat of the feather edge of the gas hydrate stability zone, because of the melting of hydrates as a response to a $1{ }^{\circ} \mathrm{C}$ bottom water temperature rise since the late 1970 's. However, this late $20^{\text {th }}$ century timing for the onset of hydrate-controlled methane seepage off Svalbard is opposed by Berndt et al. (2014). By U/Th dating of carbonate crusts at the seafloor, resulting from authigenic precipitation driven by anaerobic oxidation of methane at the seep sites, these authors show that methane seepage has been ongoing (though not necessarily in a continuous mode) since at least 3 kyr. Similarly, Crémière et al. (2016) use U/Th dating of carbonate crusts to constrain the timescales of methane seepage on the Norwegian margin, supposedly resulting from the melting of the Scandinavian Ice Sheet during the last deglaciation. Indeed, they find that the seeps started being active during the last deglaciation, and continued to release methane for 7 to $10 \mathrm{kyr}$.

Gas flow through the seabed may also generate (sub)circular depressions, or so-called pockmarks (Judd and Hovland, 2007), and hence analysis of inactive pockmarks at the seabed or buried in the sediment (identified on reflection seismic profiles) constitutes another way to trace past episodes of gas release. Davy et al. (2010) use this method to show that massive gas escape, presumably from dissociating hydrates, might have been a widespread phenomenon on the Chatham Rise off NewZealand at the peak of glaciations, potentially triggering or facilitating the transition to warmer interglacial conditions (in support of the hydrocarbon pump hypothesis and clathrate gun hypothesis).

\subsubsection{Submarine slides}


The transition of gas hydrate to free gas and water involves a volume expansion, and can therefore lead to the build-up of excess pore pressure and eventually sediment failure (Sultan et al., 2004; Xu and Germanovich, 2006). Hence, analysis of submarine slides can also be used as an indicator of potential hydrate destabilization. In the clathrate gun hypothesis, Kennett et al. (2003) argue that periods of elevated atmospheric methane levels coincide with episodes of continental slope-failure, and that this mechanism thus facilitates large and rapid transfers of methane from the dissociating hydrate reservoirs to the atmosphere. To test this assertion, Maslin et al. (2004) have collected the ages of known submarine sediment failures in the North Atlantic, and tried to correlate them with climatic variations over the last $45 \mathrm{kyr}$. They found that the age of a large fraction of the slides correlates with rising sea level and peaks in atmospheric $\mathrm{CH}_{4}$ levels during the deglaciation following the LGM, which supports the clathrate gun hypothesis for glacial to interglacial transitions. However, a significant number of slides does oppositely correlate with Heinrich events, i.e. intervals characterized by low sea level and, most notably, low atmospheric methane concentrations. This implies that the clathrate gun hypothesis does not hold true for stadial-interstadial climatic oscillations, and questions the significance of the methane transfers from hydrate reservoirs to the atmosphere through catastrophic submarine sediment failure.

\subsection{Modelling}

An important limitation of the above "evidences" is that gas escape features or shifts in the isotopic signal cannot be unequivocally linked to the dissociation of gas hydrates, especially when studying the past where direct observation of the hydrate reservoirs is not possible. Modelling can help to resolve this issue, and has therefore become indispensable in the assessment of the stability of hydrates.

A first set of models has focused on the formation of hydrates and the parameters that determine their stability, with the goal to learn where and how much gas hydrates can be found on Earth. This is important knowledge when assessing the role of hydrates in global climate. These early models were 
also a response to the need to expand the promising (in terms of energy resource potential), but very fragmented record of gas hydrate discoveries through drilling or interpretation of bottom simulating reflections (BSR) on seismic profiles. The studies of Rempel and Buffett (1997) and Xu and Ruppel (1999) were among the first to derive analytical models for the accumulation and distribution of gas hydrates, and to apply them to the natural (marine) environment. Whereas these models account for advection and diffusion as the way to supply gas to the gas hydrate system, the numerical model of Davie and Buffett (2001) considers in-situ production of methane through microbial conversion of organic matter in the sediment. They find that gas hydrate reservoirs in marine settings, if their methane supply is solely controlled by in-situ biogenic production of methane, reach a steady state within five to ten millions of years, with average hydrate saturations not exceeding $7 \%$ of the pore space. Later studies have extended this model to estimate the global volume of methane hydrate in marine sediments, and to evaluate how this volume may have fluctuated through time (Buffett and Archer, 2004; Archer and Buffett, 2005). The formation model of Garg et al. (2008) constitutes a further generalization of enumerated studies, while others have focused on more specific aspects of marine gas hydrate systems, like the influence of host sediment properties (Clennell et al., 1999), the significance of capillary effects (Liu and Flemings, 2011) and the build-up of excess pore pressure during hydrate dissociation (Sultan et al., 2004; Xu and Germanovich, 2006). In contrast, much less research has been done on the stability and formation of hydrates associated with onshore and relic subsea permafrost. Observations and measurements in wells on the Alaska North Slope indicate that conversion of conventional free gas accumulations to gas hydrate during (Pleistocene) climate cooling is the most likely formation mechanism for hydrate deposits in this region (Collett, 1993; Boswell et al., 2011; Collett et al., 2011; Ruppel, 2015). This mode of formation was modelled by Behseresht and Bryant (2012).

Along with the growing understanding of the potential climate impact of melting hydrates came a second set of models, which essentially try to assess how certain climate change scenarios cause fluctuations in the size of the hydrate inventory and in atmospheric greenhouse gas levels. A variety 
of studies have modelled the response of marine hydrate reservoirs to present-day climate warming (see table 1). On a global scale, Archer et al. (2009) predict a potential release of 35 - 940 Gton of C over a protracted period of thousands of years, whereas the model of Hunter et al. (2013) anticipates a more catastrophic scenario with possible fluxes of 1 to 50 Mton $\mathrm{CH}_{4}$ per year already during the coming century. One of the main reasons for this discrepancy is the difference in the assumed initial gas hydrate distribution (i.e. hydrate saturation and vertical and horizontal extent of the gas hydrate reservoirs before a change in climatic conditions starts to affect hydrate stability). Archer et al. (2009) adopt an initial distribution without gas hydrates in the upper tens of meters below the seafloor, based on the above described formation model of Davie and Buffett (2001). On the other hand, Hunter et al. (2013) don't consider the supply of methane into the system and assume that the entire hydrate stability zone (HSZ) is occupied by gas hydrates (except for the upper $10 \mathrm{~m}$ below the seafloor). The latter initial situation with larger volumes of hydrate at shallower subsurface depths leads to a faster and more severe predicted response to contemporary climate change. Other studies have adopted a similar approach as Hunter et al. (2013), but focused on marine hydrate reservoirs in the Arctic (e.g. Biastoch et al., 2011; Reagan et al., 2011; Marín-Moreno et al., 2013). Although using comparable initial hydrate distributions, these models still differ in the way they assess the sinks of methane after it evolves from the dissociating hydrate structure. In a first step, the liberated gas has to migrate through the sediment column, where methane bubbles can remain trapped by the effects of surface tension, dissolve in the pore water, and get recycled to form methane hydrate when passing through a HSZ (Davie and Buffett, 2001; Ruppel, 2011), and get consumed by microbes during the anaerobic oxidation of methane (Knittel and Boetius, 2009). In the case of decomposing submarine hydrate reservoirs, replacement of methane by other gases like oxygen and nitrogen (McGinnis et al., 2006), and dissolution and oxidation by aerobic microbes (Boetius and Wenzhöfer, 2013) in the water column further prevent the methane from reaching the atmosphere. MarínMoreno et al. (2013) and Reagan et al. (2011) use the TOUGH+HYDRATE code (Moridis et al., 2008), which incorporates multiphase flow of fluids and heat transport in porous hydrate-bearing geologic 
media to simulate how sediment properties determine the migration of methane through the sediment column. Biastoch et al. (2011) account for anerobic oxidation of methane by assuming that a fixed fraction ( $50 \%)$ of the liberated methane is consumed by microbes along its way up to the overlying ocean. Dissociation of Arctic permafrost and associated hydrates under present-day climate warming has also been addressed (e.g. Delisle, 2007; Frederick and Buffett, 2014; Frederick and Buffett, 2015), but not really from a general perspective. For example, Delisle (2007) models the evolution of terrestrial Arctic permafrost and discusses the implications for potential release of methane during the coming century, without actually integrating gas hydrates in the model, whereas the studies of Frederick and Buffett (2014) and Frederick and Buffett (2015) quantify specific aspects of submarine permafrost-related gas hydrate systems (the role of taliks below palaeo-river channels and submarine groundwater discharge respectively). Other models focus on the response of hydrate reservoirs and permafrost to climatic variation over longer timescales, for example during the last deglaciation and the Holocene (e.g. Tipenko et al., 1999; Mienert et al., 2000; Milkov and Sassen, 2003a; Poort et al., 2005; Phrampus and Hornbach, 2012), or over the most recent glacial-interglacial cycle(s) (Romanovskii et al., 2005; Taylor et al., 2013). As illustrated in table 1, the results of these modelling efforts are equally liable to variations, for the same reasons as discussed above (differences in initial hydrate distributions, consideration of methane sinks, site-specific factors and parameters, ...). For example, Phrampus and Hornbach (2012), in their study of the western North Atlantic margin, don't explicitly model the above discussed methane supply and sinks. Therefore, their estimated value of 2.5 Gton potentially destabilizing methane hydrate along a $300-\mathrm{km}$ span of the North American margin, because of recent (Holocene) changes in the Gulf Stream flow path and temperature, should be considered as a worst-case estimate. The importance of the basic assumptions, considered parameters and model approach when simulating the response of gas hydrate reservoirs to changing climate is further discussed in chapters 3 and 5 . 


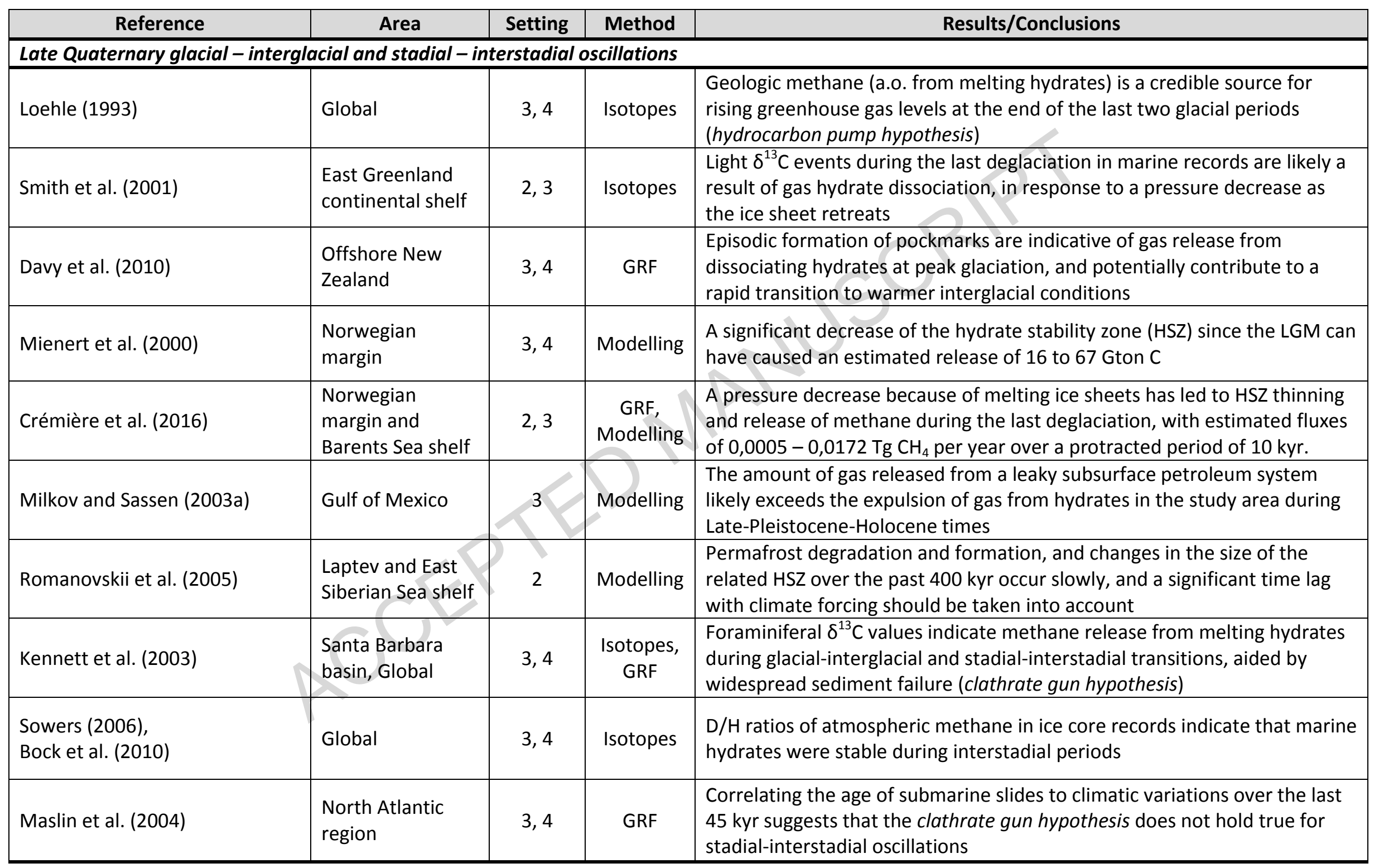




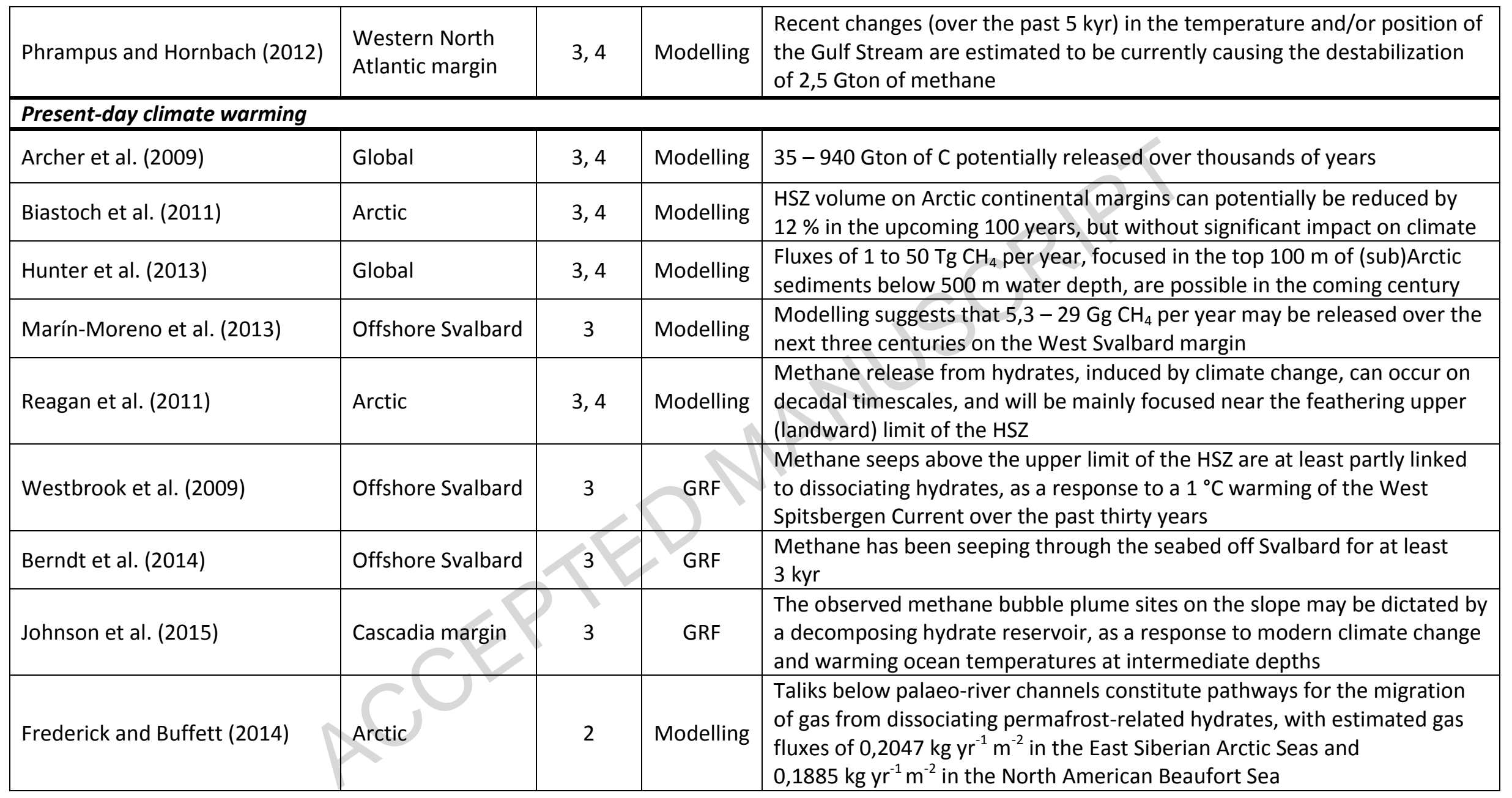

Table 1. List of studies on the dissociation of gas hydrate and its potential role in the Earth's climate, with indication of the study area, hydrate-bearing setting (numbered according to figure 2 : 1 = onshore permafrost, 2 = subsea permafrost, 3 = upper continental slope, $4=$ lower continental slope), methodology and most important results or conclusions. GRF = gas release features
(i.e. gas
seeps,
authigenic
carbonates
or pockmarks);
HSZ = hydrate
stability
zone;
LGM
Last
Glacial
Maximum 


\section{Modelling gas hydrate reservoir response to climatic variations}

In this study, we seek to develop a relatively simple, but robust numerical model, that is applicable in any study area and in both permafrost-related and marine environments. We opted for a onedimensional model because most hydrates occur in stratigraphically constrained hydrate reservoirs which lack significant lateral variation (Archer et al., 2009). The parameters used in the model are summarized in table 2 . Methane is assumed to be the only gas component in the system, so that all values apply to pure methane hydrate.

\subsection{Defining initial hydrate saturation profiles}

Two existing formation models (one for permafrost-related hydrates, and one for the formation of marine hydrate reservoirs) are implemented in order to constrain realistic initial methane hydrate saturation profiles. The studied sediment columns are considered to be homogenous, with a uniform and constant porosity $(\varnothing)$ and permeability $(k)$.

For the marine sediment columns on the upper and lower continental slope (i.e. setting 3 and 4 in figure 2), the analytical formation model of Xu and Ruppel (1999) is adopted. In accordance with their model, the positions of the top and the base of the hydrate stability zone (HSZ) are determined by coupling in-situ pressures and temperatures to an empirical methane hydrate stability curve, which was obtained from the CSMHYD software of Sloan (1998) for a fixed salinity of $35 \%$. We acknowledge that the pore water will freshen during hydrate dissociation, since the hydrate structure only incorporates fresh water. However, this effect is expected to be limited, since the initial hydrate saturations are low (Xu and Germanovich, 2006). Importantly, Xu and Ruppel (1999) differentiate the levels of the top and base of the HSZ from the top and the base of the zone of actual hydrate occurrence ( $\mathrm{HOZ}$ ), which are bound to the additional constraint that the availability of methane in the pore water (curve $M$ in figure 3B) must be equal to or exceed its solubility (curve $M_{s l}$ in figure 3B). This extra requirement is largely controlled by the fluxes of total mass $\left(\mathrm{q}_{\mathrm{f}}\right)$ and energy $\left(q_{e}\right)$, by the flux of methane $q_{m}$ (supplied through advection and/or diffusion), and by the methane 
mass fraction in seawater at the seafloor, which is assumed to be negligible $\left(M_{0}=0\right)$. To be able to solve the equations, the solubility of methane gas in seawater $\left(\mathrm{M}_{\mathrm{sl}}\right)$ as a function of temperature and pressure has to be known, and was determined in agreement with the method proposed by Davie et al. (2004). For average parameter values, the top of the HOZ generally occurs tens of meters below the seafloor, even when a sulfate reduction zone is absent, and the base of the $\mathrm{HOZ}$ can be at a shallower depth than the base of the HSZ (figure 3B). In the end an equilibrium situation is created, and the hydrate saturation can be calculated at any depth in the $\mathrm{HOZ}$ (figure 4B).

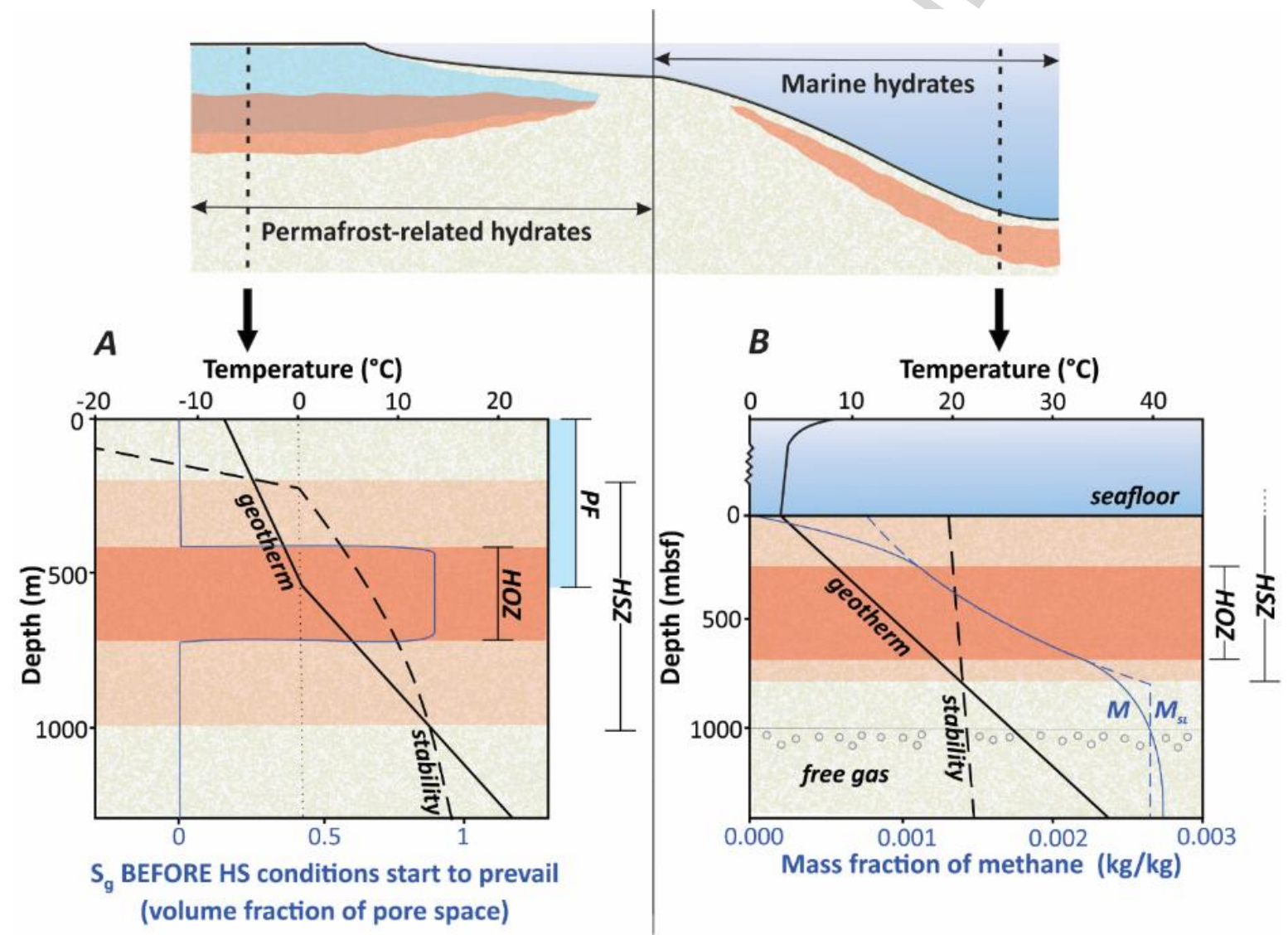

Figure 3. Hydrate stability zone (HSZ) versus hydrate occurrence zone (HOZ) in permafrost-related methane hydrate systems (A) and submarine hydrate systems (B). (A) The HSZ spans the interval between the intersections of the geotherm (solid black curve) with the hydrate - free gas stability boundary (dashed black curve). The position of the HOZ is dependent on the availability of free methane gas (solid blue line) prior to the imposition of hydrate stability (HS) conditions, as further explained in figure $4 A$. Permafrost occurs from the surface to the depth where the temperature starts to exceed the melting temperature of ice (dotted black curve). (B) The HSZ in the submarine environment is again defined by the intersection of the geotherm and the hydrate - free gas stability boundary. Note that the top of the HSZ in this case locates at a depth above the seafloor, so that the HSZ extends into the ocean. The HOZ is bound to the additional constraint that the mass fraction of dissolved methane ( $M$ - solid blue curve) should be equal to or exceed the solubility of methane in the pore water $\left(M_{s l}-\right.$ dashed blue curve). Similarly, free gas only exists below the HSZ at depths where M exceeds $M_{s l}$. The pressure at the seafloor is assumed to correspond to a water depth of $2500 \mathrm{~m}$. Modified from Xu and Ruppel (1999). 
The above approach cannot be applied to methane hydrate systems in on- and offshore permafrostbearing sediment columns (i.e. settings 1 and 2 in figure 2), since these settings require consideration of an extra solid ice phase. The same principles can be used for onshore and subsea permafrost, as the latter is generally accepted to represent relic onshore permafrost, formed during cold periods of sea level lowstand and later flooded during subsequent warming and sea level rise (Ruppel, 2015). Few studies have focused on how gas hydrates form in these environments. Research on hydrate deposits on the Alaska North Slope has indicated that conversion of free gas accumulations is a likely formation mechanism (Boswell et al., 2011). This mechanism is also adopted in this study, and modelled according to the work of Behseresht and Bryant (2012). The extent of the HOZ is in this case dependent on the presence of an accumulation of initially free gas (pure methane in this study), occupying a fraction $S_{g, i}$ of the pore space and presumed to be sealed at its top and isolated from the gas source (figure $3 \mathrm{~A}$ and $4 \mathrm{~A}$ ). We assume that the gas accumulation is located at a depth between $600-670 \mathrm{~m}$, in accordance with observations on the Alaska North Slope (Boswell et al., 2011; Collett et al., 2011; Behseresht and Bryant, 2012). The base of the HSZ (as in the marine columns defined by linking in-situ pressures and temperatures to an empirical methane hydrate stability curve, but now for a fixed salinity of $0 \%$ o) starts to move down to, and eventually through this free gas accumulation after the imposition of temperature and pressure conditions that promote hydrate formation. As a result of the migration of the base of the HSZ, gas hydrates begin to form, which is accompanied by a volume reduction. This is compensated by the influx of a volume of free gas $\left(\Delta \mathrm{V}_{\mathrm{g}}\right)$ and a volume of pore water $\left(\Delta \mathrm{V}_{\mathrm{w}}\right)$, which causes the gas-water contact $(\mathrm{GWC})$ at the base of the gas column to rise. It is assumed that excess water is provided to convert all the available gas to gas hydrate, so that after conversion the pore space is occupied by gas hydrate and water (figure $4 \mathrm{~A})$. This process continues until the base of the HSZ eventually descends below the position of the GWC, where only a small amount of residual gas (with saturation $\mathrm{S}_{\mathrm{g}, \mathrm{r}}$ ) remains to be converted to gas hydrate. In the end a hydrate saturation $\left(S_{h}\right)$ profile as shown in figure $4 \mathrm{~A}$ is established. At subsurface depths where the newly imposed temperature eventually also falls below the freezing temperature of water, the pore 
water starts to freeze and permafrost forms, so that methane hydrates coexist with ice. The ice is assumed to occupy a fraction $S_{1}$, equal to $\left(1-S_{h}\right)$, of the pore space. The gas accumulations considered in this study are located at subsurface depths where, upon cooling, first gas hydrates crystallize and afterwards ice starts to form (i.e. at depths where the equilibrium temperature of methane hydrate exceeds the freezing temperature of the pore water). Field observations of gas and gas hydrates on the Alaska North Slope confirm that this is a likely situation in nature (Boswell et al., 2011; Collett et al., 2011; Behseresht and Bryant, 2012).
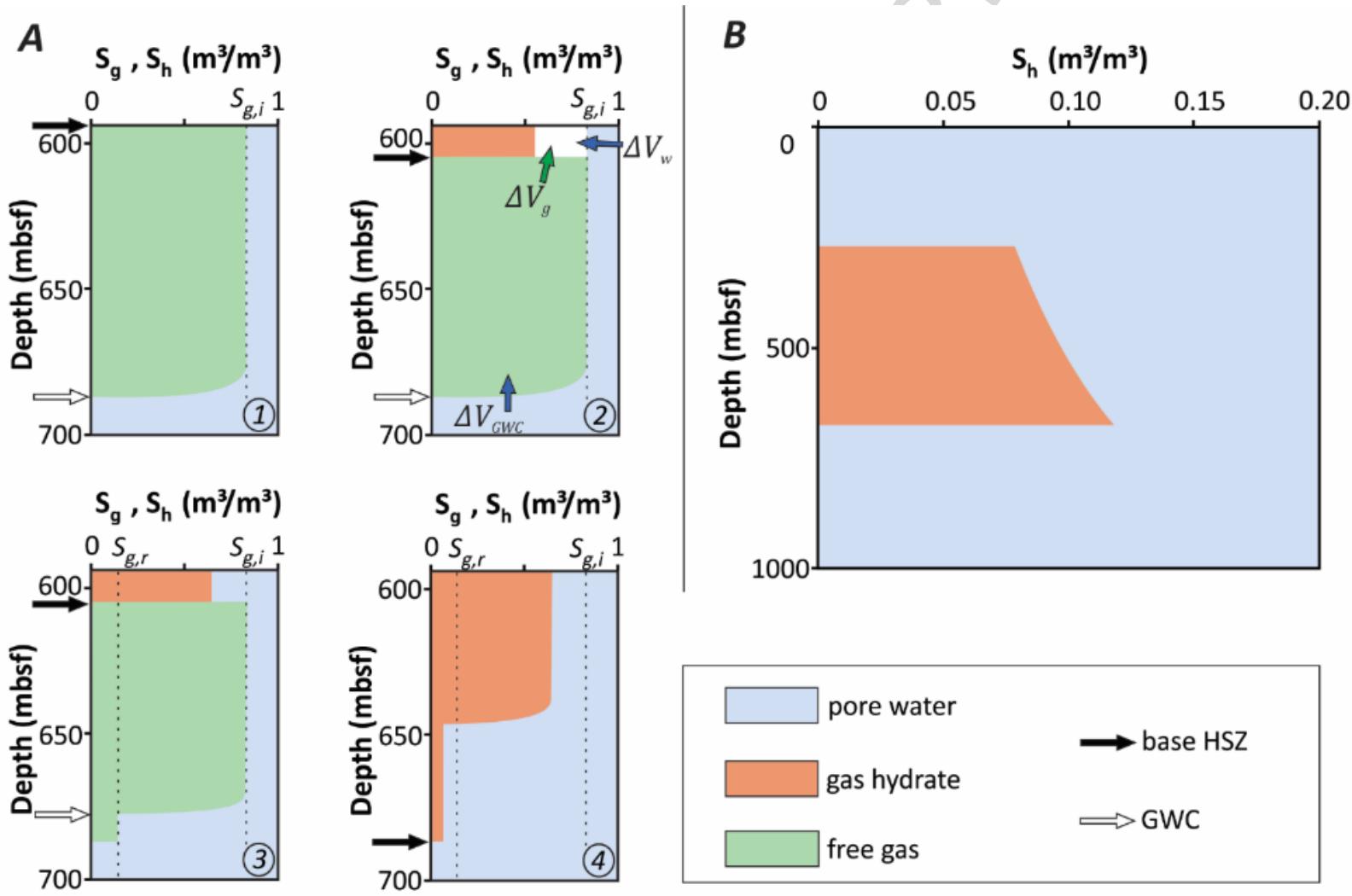

Figure 4. Initial methane hydrate saturation profiles for permafrost-related hydrate systems $(A)$ and marine hydrate systems (B). (A) The hydrate saturation profile (4) is the result of the conversion of a free gas accumulation with an initial gas saturation profile $S_{g, i}(1)$. The base of the HSZ starts to move down after the imposition of $T$ - $P$ conditions favouring hydrate formation. As a result, methane hydrates form and the accompanying volume reduction is compensated by the influx of a volume of gas $\Delta V_{g}$ and a volume of water $\Delta V_{w}$. This causes the gas-water contact (GWC) to rise as a volume of water $\Delta V_{G W C}$ imbibes from below. The gas saturation in the imbibed volume at the base decreases to the residual gas saturation $S_{g, r}(2$ 3). Modified from Behseresht and Bryant (2012). (B) Example of an initial hydrate saturation profile in accordance with the formation model of Xu and Ruppel (1999). 


\subsection{Modelling the subsurface temperature and pressure regime}

\subsubsection{Temperature}

The subsurface temperature and pressure regime control the stability of the hydrate-bearing sediment columns. A change in bottom water temperature (BWT) or temperature at the Earth's surface will disrupt the subsurface temperature profile, which is assumed to be originally in equilibrium with the geothermal heat flow at the specific location of the column. The temporal evolution of the temperature profile towards a new equilibrium situation is described by the onedimensional heat conduction equation:

$$
\frac{\partial T(z, t)}{\partial t}=\kappa \frac{\partial^{2} T}{\partial z^{2}}
$$

where $T$ is temperature (in $\mathrm{K}$ ), $\mathrm{z}$ is the spatial coordinate (in $\mathrm{m}$ ), pointing downwards and with origin at the seafloor (for the marine settings) or the earth's surface (for the onshore settings), $t$ is time (in $\mathrm{s})$, and $\mathrm{k}$ is the effective thermal diffusivity (in $\mathrm{m}^{2} / \mathrm{s}$ ), which is proportional to the effective thermal conductivity. Since hydrate concentrations are relatively low and since the thermal conductivity of methane hydrate is close to that of water ( $<10 \%$ difference; Waite et al., 2007), we assume a constant value for $\mathrm{k}$. Equation [1] is numerically solved using the explicit version of the finite difference method:

$$
T_{n k}=T_{(n-1) k}+\frac{\kappa \Delta t}{\Delta z^{2}}\left(T_{(n-1)(k-1)}-2 T_{(n-1) k}+T_{(n-1)(k+1)}\right)
$$

The temperature at time $\mathrm{n}$ and depth $\mathrm{k}$ is thus calculated based on the temperature at the previous time step $(n-1)$ at depths $k,(k-1)$ and $(k+1) . \Delta t$ and $\Delta z$ represent the time step and depth step respectively, and are bound to the following condition for the numerical solution to be stable:

$$
\Delta t \leq \frac{\Delta z^{2}}{2 \kappa}
$$


A set of boundary conditions needs to be defined to solve equation [2]. The initial (equilibrium) temperature profile (at $t=0$ ) is determined according to the formation model of $\mathrm{Xu}$ and Ruppel (1999) for the continental slope settings, or in case of the permafrost settings, set by defining the temperature at the top of the column $\left(T_{0}\right)$ and the geothermal gradient for both ice-free and icebearing sediments ( $G$ and $G_{p f}$ respectively). The temperature evolution through time at the top boundary, i.e. the seafloor (or Earth's surface in the onshore permafrost setting), is determined by the considered climate change scenario. A constant heat flux is adopted at the bottom boundary.

\subsubsection{Pressure}

The subsurface pressure regime is assumed to be hydrostatic at any time, and variations because of sea level changes are supposed to propagate instantaneously throughout the sediment column. We acknowledge that the latter condition is not evident in permafrost, but can, however, be met under certain conditions, e.g. when open taliks are present in faults zones and below large rivers or lakes (Romanovskii et al., 2005).

\subsection{Modelling gas hydrate dissociation under changing temperature and pressure}

Hydrate stability is verified after each time step by comparing the newly calculated temperature at each depth $\left(T_{n k}\right)$ with the dissociation temperature of hydrates at that depth $\left(T_{\text {diss,k }}\right)$, which is obtained from the CSMHYD software of Sloan (1998). Hydrates start to dissociate when $T_{n k}$ exceeds $T_{\text {diss,k- }}$ Similarly, ice in permafrost starts to melt as soon as $T_{n k}$ exceeds the pressure- (and salinity-) dependent melting temperature of ice $\left(T_{\text {melt,k }}\right)$, which is determined using the formula of Millero and Leung (1976). Importantly, the dissociation of gas hydrates and melting of ice involves a phase transition, and consequently consumes latent heat. This implies that heat is added while the temperature remains constant at $\mathrm{T}_{\text {diss }}$ (for dissociating hydrates) or $\mathrm{T}_{\text {melt }}$ (for melting ice), which delays the propagation of a temperature pulse through the column (figure 5). Accounting for this heat sink demands adding a term $s(z, t)$ to the one-dimensional heat conduction equation: 


$$
\frac{\partial T(z, t)}{\partial t}=\kappa \frac{\partial^{2} T}{\partial z^{2}}+s(z, t)
$$

The solution to [4] requires resolving a moving phase boundary problem, or so-called Stefan problem. In this study a simplified approach is adopted to account for the consumption of latent heat, known as the heat integration method or post-iterative method (Hu and Argyropoulos, 1996). As described above, the temperature at each time and depth step $\left(T_{n k}\right)$ is first calculated according to [2], but afterwards corrected to $T_{\text {diss,k }}$ at depths where hydrates are present but supposed to be dissociating. At these depths an amount of heat, equal to the product of $\left(T_{n k}-T_{\text {diss, }}\right)$ and the specific heat capacity of methane hydrate $\left(C_{p h}\right)$, is added to the heat that has accumulated over previous time steps since the start of the phase transition $\left(Q_{a c c}\right)$. $Q_{a c c}$ is updated after each time step, and once it exceeds the latent heat required for the melting of methane hydrate $\left(L_{h}\right)$, the phase transition is complete and temperature can resume to rise according to [2] (cfr. figure 5). The evolution of the hydrate saturation $S_{h}$ during this process (i.e. the volume percentage of the pore space occupied by hydrate) is approximated as follows:

$$
S_{h}=S_{h, i} \times \frac{L_{h}-Q_{a c c}}{L_{h}}
$$

where $S_{h, i}$ is the hydrate saturation before hydrates start to destabilize. An identical approach is applied to account for the consumption of latent heat during the melting of ice in permafrost.

To test above described method, we applied our model to the well-studied hydrate reservoir on the continental slope of the Nankai Trough offshore Japan. It has been suggested that the base of the HSZ in this area has migrated upwards over the past $10 \mathrm{kyr}$ as a response to a $1-2{ }^{\circ} \mathrm{C}$ BWT rise (Foucher et al., 2002). Golmshtok and Soloviev (2006) analyzed this hypothesis based on a thermal model with an alternative mathematical formulation of the phase boundary displacement. For a case where the base of the HSZ is initially at $300 \mathrm{~m}$ depth below seafloor, they anticipitate an upward displacement in the range of 5 to $10 \mathrm{~m}$ in response to a $1.5{ }^{\circ} \mathrm{C}$ BWT increase, whereas the here presented model predicts $4 \mathrm{~m}$. Although slightly lower, this value is still in the same order of 
magnitude as the values anticipated by Golmshtok and Soloviev (2006), proving the applicability of the approach adopted in this study.

$\boldsymbol{A}$

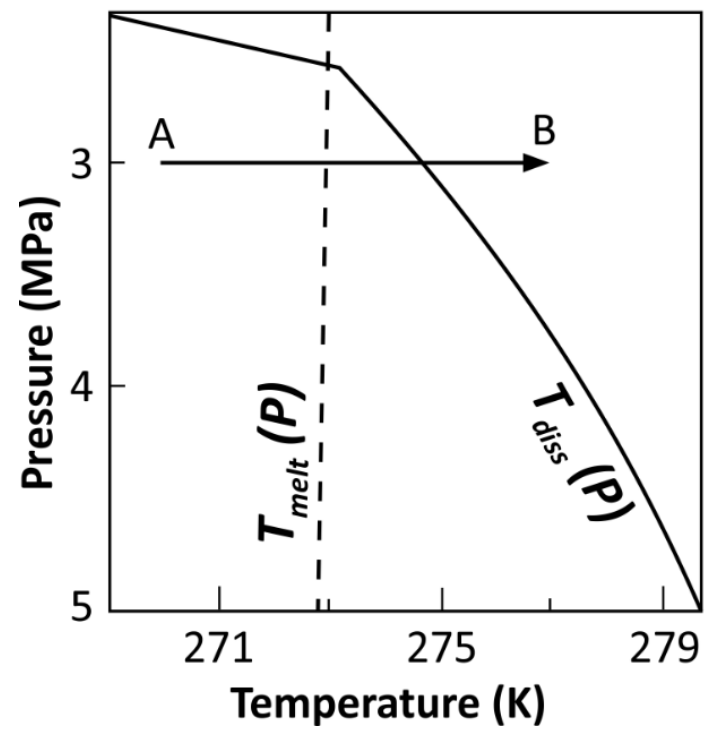

B

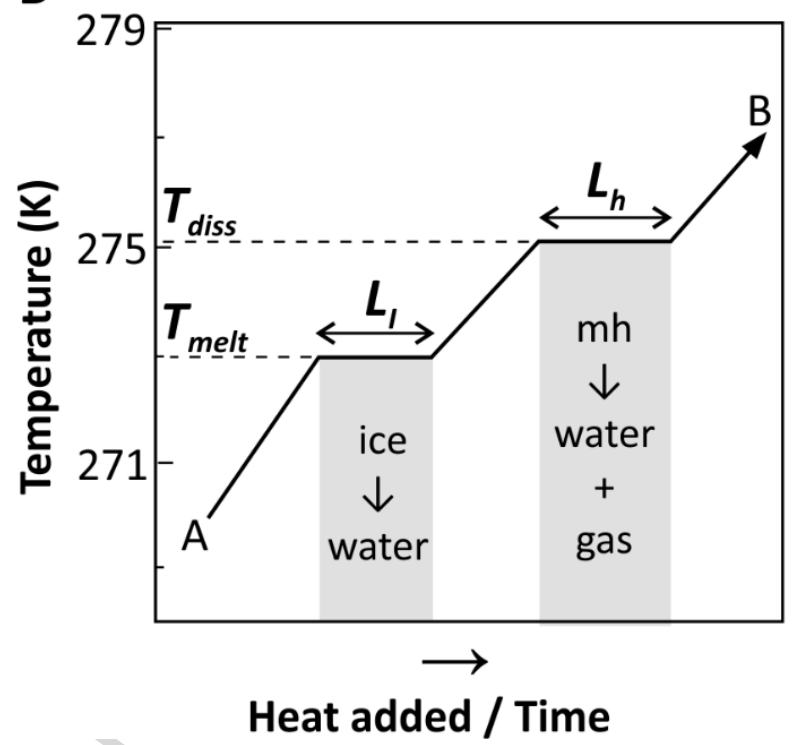

Figure 5. (A) Dissociation temperature of methane hydrate (solid line, $T_{\text {diss}}$ ) and melting temperature of ice (dashed line, $T_{\text {melt }}$ ) as a function of pressure (in the case of fresh pore water). The hypothetic temperature path $A \rightarrow B$ is discussed in the right figure. (B) Temperature path $A \rightarrow B$ plotted through time. The temperature first increases until ice starts to melt at $T_{\text {melt. }}$ During this phase transition, the temperature remains constant until the added heat equals the latent heat for the melting of ice $\left(L_{1}\right)$. At this point all ice is melted and the temperature can resume to rise again. Once $T_{\text {diss }}$ is reached, methane hydrates $(\mathrm{mh})$ start to dissociate and heat is accumulated at a constant temperature $T_{\text {diss. }}$. All hydrate is converted to free gas and water when the added heat equals the latent heat of hydrate dissociation $\left(L_{h}\right)$. Hereafter the temperature can further increase to the final temperature.

The model outlined above describes the decomposition of hydrate reservoirs through dissociation, which is a different process from that of hydrate dissolution. The latter also causes hydrates to disappear, provided that the concentration of dissolved methane is lower than the solubility of methane in the pore water (cfr. figure 3B). However, as opposed to hydrate dissociation, this does generally not result in the generation of free gas bubbles ( $\mathrm{Xu}$ and Germanovich, 2006). Since this review focuses on the liberation of free greenhouse gas bubbles from melting hydrate reservoirs, dissolution is not modelled here. Nevertheless, it is acknowledged that increased dissolved $\mathrm{CH}_{4}$ and $\mathrm{CO}_{2}$ concentrations in the pore water can eventually increase the acidification of the oceans, which could have indirect implications for the global carbon cycle and climate (e.g. Dickens et al., 1997; Boudreau et al., 2015). Another aspect of the dissociation of methane hydrate to free gas and water 
is the involved volume expansion, which can generate excess pore pressure ( $\mathrm{Xu}$ and Germanovich, 2006). It has been shown that hydrate dissolution can also generate excess pore pressure (Sultan, 2007), though in natural settings probably to a much smaller extent than hydrate dissociation (Xu and Germanovich, 2007). Anyhow, increasing the internal pressure tends to stabilize hydrates and impede further dissociation (Kwon et al., 2008). On the other hand, the buildup of excess pore pressure also reduces the sediment strength, which can induce slope failure and a subsequent catastrophic release of large volumes of hydrate. However, for the average permeability value used in this study, the excess pore pressure is inferred to be small and to dissipate sufficiently fast (Roose, 2006; Xu and Germanovich, 2006). The pressure regime is therefore assumed to remain hydrostatic at any time. We do not consider ongoing sedimentation in the model, which actually changes the position of the seafloor while the model runs. This affects the porosity, temperature and pressure profiles of the considered sediment column. Nevertheless, with sedimentation rates generally being in the range of centimeters per kyr, we assume that these changes are negligible compared to the variations in temperature and pressure (sea level) caused by climatic changes.

\begin{tabular}{|c|c|c|c|}
\hline Parameter & Definition & Value (*) & Unit \\
\hline \multicolumn{4}{|c|}{ General parameters } \\
\hline$z$ & $\begin{array}{l}\text { Depth, origin at seafloor or Earth's surface, } \\
\text { downwards increasing positive values }\end{array}$ & & $m$ \\
\hline$t$ & Time & & $s$ \\
\hline$\Delta z$ & Depth interval & 5 & $m$ \\
\hline$\Delta t$ & Time interval & $3.1557 \times 10^{7}$ & $s$ \\
\hline$P$ & Pressure & & $P a$ \\
\hline$T$ & Temperature & & $K$ \\
\hline$S$ & Salinity & 0 (onshore) & \\
\hline & & $35{\text { (marine })^{[1]}}^{[1}$ & $\% 0$ \\
\hline$\varnothing$ & Porosity & $0.5^{[1]}$ & $m^{3} / m^{3}$ \\
\hline$\kappa$ & Effective thermal diffusivity & $3.9 \times 10^{-7[2]}$ & $m^{2} / s$ \\
\hline$\rho$ & Bulk density & & $\mathrm{kg} / \mathrm{m}^{3}$ \\
\hline$C_{p}$ & Effective isobaric specific heat capacity & & $J /(k g \cdot K)$ \\
\hline$C_{p h}$ & Isobaric specific heat capacity of gas hydrate & $2.16 \times 10^{3[3]}$ & $J /(k g \cdot K)$ \\
\hline
\end{tabular}




\begin{tabular}{|c|c|c|c|}
\hline$C_{p I}$ & Isobaric specific heat capacity of ice & $2.03 \times 10^{3[4]}$ & $J /(k g \cdot K)$ \\
\hline$L_{h}$ & Latent heat of melting gas hydrate & $4.30 \times 10^{5[5]}$ & $J / k g$ \\
\hline$L_{I}$ & Latent heat of melting ice & $3.34 \times 10^{5[4]}$ & $J / k g$ \\
\hline$Q, Q_{a c c}$ & Heat, heat accumulated during phase transition & & $J$ \\
\hline$S_{h}, S_{g}, S_{I}$ & $\begin{array}{l}\text { Saturation, i.e. volume fraction of pore space } \\
\text { occupied by gas hydrate, free gas, ice }\end{array}$ & & $m^{3} / m^{3}$ \\
\hline \multicolumn{4}{|c|}{ Parameters used to implement the marine formation model of Xu and Ruppel (1999) } \\
\hline$k$ & Permeability & $1 \times 10^{-14}$ & $m^{2}$ \\
\hline$M$ & Mass fraction of methane in the liquid & & $\mathrm{kg} / \mathrm{kg}$ \\
\hline$M_{s l}$ & Solubility of methane in the liquid phase & & $\mathrm{kg} / \mathrm{kg}$ \\
\hline$\lambda$ & Effective thermal conductivity & & $W /(m \cdot K)$ \\
\hline$q_{e}$ & Flux of energy & & $W / m^{2}$ \\
\hline$q_{m}$ & Flux of methane & $6 \times 10^{-11[1]}$ & $\mathrm{kg} /(\mathrm{m} \cdot \mathrm{s})$ \\
\hline$q_{f}$ & Flux of total mass & $4 \times 10^{-8[1]}$ & $\mathrm{kg} /(\mathrm{m} \cdot \mathrm{s})$ \\
\hline \multicolumn{4}{|c|}{$\begin{array}{l}\text { Parameters used to implement the formation model for permafrost-related hydrates of Behseresht and } \\
\text { Bryant (2012) }\end{array}$} \\
\hline \multirow{3}{*}{$\begin{array}{c}G \\
G_{p f} \\
\Delta V_{w}, \Delta V_{g}\end{array}$} & Geothermal gradient & $0.05^{[1]}$ & $K / m$ \\
\hline & Geothermal gradient in permafrost & $0.02^{[7]}$ & $K / m$ \\
\hline & $\begin{array}{l}\text { Transported volume of water, transported } \\
\text { volume of gas }\end{array}$ & & $m^{3}$ \\
\hline
\end{tabular}

$(*)$ the listed values are used as standard value in the parametric analysis and case studies

\begin{tabular}{|c|l|}
\hline \multicolumn{2}{|l|}{ Subscripts } \\
\hline$i, f$ & Initial, final conditions \\
$h, I, w, g, s$ & $\begin{array}{l}\text { Components of the system: methane hydrate, ice, pore water, free methane gas, } \\
\text { sediment matrix }\end{array}$ \\
$o$ & Seafloor/surface conditions \\
$r$ & Residual \\
$G W C$ & Gas-water contact \\
\hline
\end{tabular}

Table 2. Summary of parameters and units used in this manuscript. The choice of the fixed parameter values is based on previous modelling studies: ${ }^{[1]}$ Xu and Ruppel (1999) ; ${ }^{[2]}$ Biastoch et al. (2011) ; ${ }^{[3]}$ Waite et al. (2007) ; ${ }^{[4]}$ Haynes et al. (20132014) ; ${ }^{[5]}$ Xu and Germanovich (2006) ; ${ }^{[6]}$ Goto and Matsubayashi (2009) ; ${ }^{[7]}$ Collett et al. (2011).

\subsection{Sensitivity analysis}

We performed a sensitivity analysis to quantify how the numerical predictions change when the most important modelling parameters are varied. We consider a simple example (an instantaneous 1 to $5{ }^{\circ} \mathrm{C}$ BWT rise) in an upper continental slope setting (400 $\mathrm{m}$ water depth), with parameter values that reflect a general average of values reported in literature (listed in table 2). Figure 6A shows the initial 
position of the base and top of the $\mathrm{HSZ}$ and $\mathrm{HOZ}$, as well as the evolution of the subsurface temperature profile over a period of $100 \mathrm{kyr}$. Figures $6 \mathrm{~B}$ and $6 \mathrm{C}$ respectively demonstrate how the model anticipates the changes in the hydrate saturation profile and the positions of the top and base of the HOZ. Essentially, the two main controlling factors in these simulations are (i) the effective thermal diffusivity $\mathrm{k}$ (as suggested by equations [1] and [2]), and (ii) the initial subsurface depth, thickness and hydrate concentrations of the gas hydrate reservoir (Archer, 2007), which in marine settings (besides the seafloor temperature and water depth) are principally controlled by the geothermal gradient, methane mass fraction in seawater at the seafloor, methane flux and porosity (Xu and Ruppel, 1999). The sensitivity of the standard case model (presented in figure 6) to changes in each of these parameters is discussed below (figures $7-11$ ). 

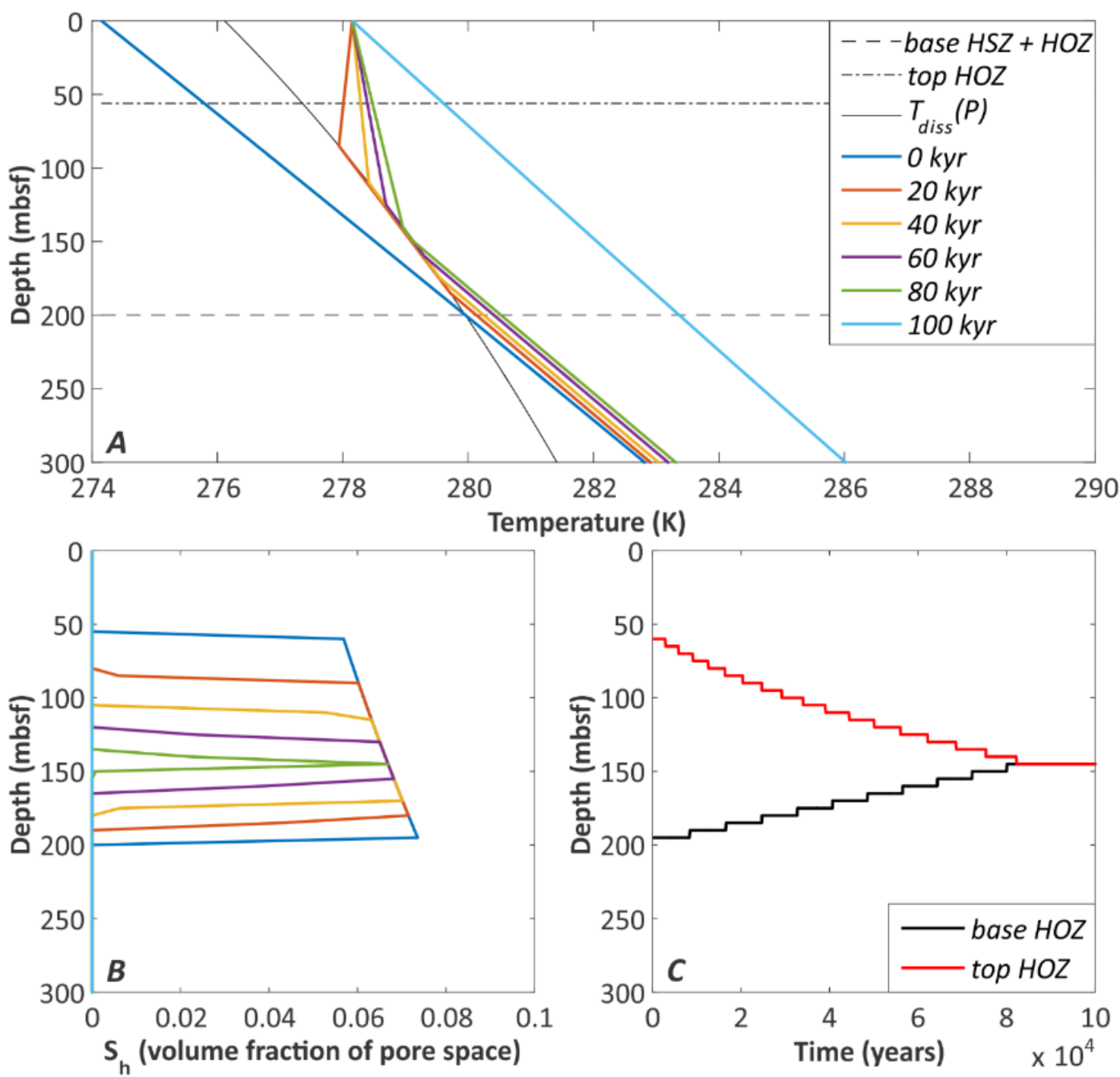

Figure 6. Simulation of the response of a marine gas hydrate reservoir (400 $\mathrm{m}$ water depth) to an instantaneous 1 to $5{ }^{\circ} \mathrm{C}$ BWT rise. The used parameter values are listed in table 2. (A) Evolution of the temperature profile and indication of the initial position of the base of the HOZ (coinciding with the base of the HSZ) and top of the HOZ. (B) Evolution of the hydrate saturation profile. (C) Evolution of the base and top of the HOZ. The legend in (A) also applies to (B).

\subsubsection{Effective thermal diffusivity}

Equation [2] suggests that the effective thermal diffusivity $\mathrm{k}$ directly controls the evolution of the subsurface temperature profile towards a new equilibrium after a temperature disturbance at the seabed. As such, $\mathrm{k}$ also determines how fast the gas hydrate reservoir dissociates. Measured thermal diffusivity values range between $2-5 \times 10^{-7} \mathrm{~m}^{2} / \mathrm{s}$ for marine sediments in the upper hundreds of meters below seafloor (e.g. Lin et al., 2014), and a similar interval is reported for hydrate-sediment mixtures (Kumar et al., 2004). Figure 7 illustrates the evolution of the top and base of the HOZ for the 
average thermal diffusivity assumed in this study (equal to $3.9 \times 10^{-7} \mathrm{~m}^{2} / \mathrm{s}$ ), and compares it to simulations in which this reference value was doubled or halved.
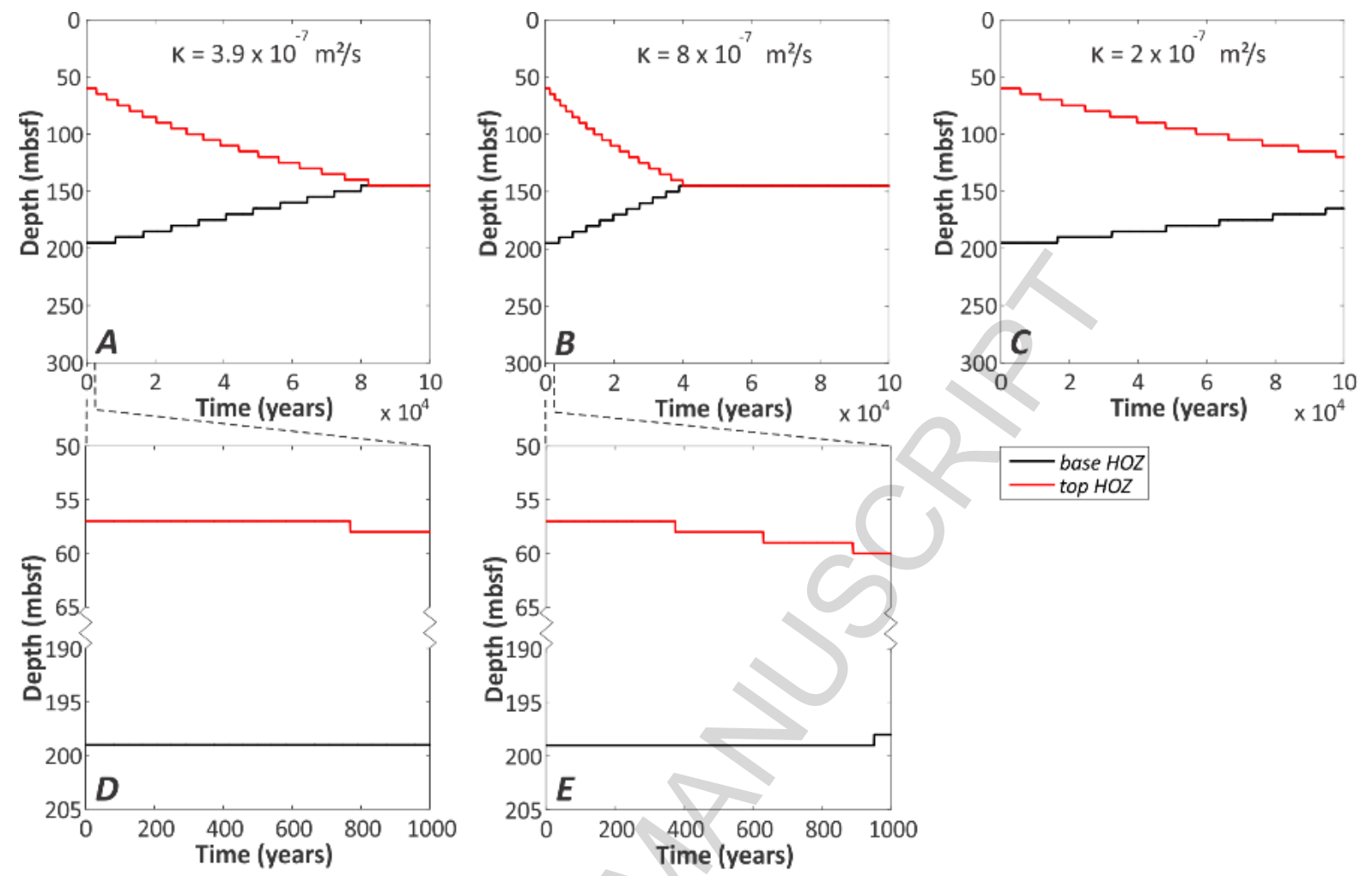

Figure 7. Simulation of the position of the top and base of a marine gas hydrate reservoir (400 $\mathrm{m}$ water depth) after an instantaneous 1 to $5^{\circ} \mathrm{CBWT}$ rise, for three different effective thermal diffusivity values: $(\boldsymbol{A}) \mathrm{K}=3.9 \times 10^{-7} \mathrm{~m}^{2} / \mathrm{s},(\boldsymbol{B}) \mathrm{K}=8 \times 10^{-}$ ${ }^{7} \mathrm{~m}^{2} / \mathrm{s},(C) \mathrm{K}=2 \times 10^{-7} \mathrm{~m}^{2} / \mathrm{s}$. The values of the other parameters are identical in $(A),(B)$ and $(C)$ and listed in table 2. (D) Detail of the initial 1000 years of the simulation shown in (A). (E) Detail of the initial 1000 years of the simulation shown in (B).

The initial position of the top and base of the $\mathrm{HOZ}$ are identical in all three cases, while the dissociation rates show large variations. When $\mathrm{k}$ is doubled, the entire gas hydrates reservoir dissociates within app. $40 \mathrm{kyr}$ (figure 7B), in contrast to app. $80 \mathrm{kyr}$ in the standard example (figure 7A). Within the first 1000 years of the simulation, $3 \mathrm{~m}$ of hydrates melt at the top of the reservoir and $1 \mathrm{~m}$ at the base when $\mathrm{K}$ equals $8 \times 10^{-7} \mathrm{~m}^{2} / \mathrm{s}$ (figure $7 \mathrm{E}$ ), as opposed to $1 \mathrm{~m}$ and $0 \mathrm{~m}$ at respectively the top and base when $\mathrm{K}$ is $3.9 \times 10^{-7} \mathrm{~m}^{2} / \mathrm{s}$ (figure 7D). Decreasing $\mathrm{k}$ to $2 \times 10^{-7} \mathrm{~m}^{2} / \mathrm{s}$ lowers the propagation speed of the thermal signal and hence also decreases the dissociation rate, as shown in figure 7C.

It should be noted that $\mathrm{k}$ is defined as $\lambda /\left(\rho \mathrm{C}_{\mathrm{p}}\right)$, with $\lambda$ being the effective thermal conductivity of the medium and $\rho C_{p}$ the effective volumetric heat capacity of the medium (i.e. the product of bulk 
density $\rho$ and effective isobaric specific heat capacity of the medium $C_{p}$ ). The effective thermal conductivity and volumetric heat capacity can be calculated from the thermal conductivities and volumetric heat capacities of the individual components of the system, the porosity $\varnothing$, and the volume fractions of hydrate, ice and free gas in the pore space (e.g. equations [7] and [4] in respectively Xu and Ruppel, 1999; Sultan et al., 2004). Although the volume fractions of hydrate, ice and free gas in the pore space change throughout the simulation, we adopt a constant value for $\mathrm{k}$. This simplication is justified because (i) the variations in $\mathrm{k}$ are expected to be rather limited when hydrate saturations are low, and (ii) there is less than $10 \%$ difference between the thermal conductivity of water and methane hydrate (Waite et al., 2007). The influence of porosity and gas hydrate saturation on the model predictions is further discussed below.

\subsubsection{Gas hydrate distribution (occurrence and saturation)}

\subsubsection{Geothermal gradient}

The geothermal gradient $\mathrm{G}$ determines the temperature profile at the start of the simulation, and as such exerts an immediate control over the initial gas hydrate distribution. For the marine settings, in accordance with the formation model of Xu and Ruppel (1999), we implicitly define the geothermal gradient through the choice of the effective thermal conductivity $\lambda$ and energy (heat) flux $q_{e}$. Measured values for effective thermal conductivity in marine sediments are in the range of $1.0-2.0$

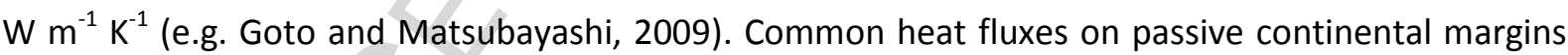
are in the range of $0.05-0.06 \mathrm{~W} / \mathrm{m}^{2}$, although elevated values of $0.085 \mathrm{~W} / \mathrm{m}^{2}$ on young passive margins have been measured as well (e.g. Goutorbe et al., 2011). In the standard case we therefore assume $\lambda=1.7 \mathrm{~W} \mathrm{~m}^{-1} \mathrm{~K}^{-1}$ and $\mathrm{q}_{\mathrm{e}}=0.05 \mathrm{~W} / \mathrm{m}^{2}$, which results in a geothermal gradient of $0.029 \mathrm{~K} / \mathrm{m}$ since $\mathrm{G}=\mathrm{q}_{\mathrm{e}} / \lambda$. This leads to a $150 \mathrm{~m}$ thick $\mathrm{HOZ}$ (figure 6 ). Figure 8 shows the same example, but with a geothermal gradient equal to $0.050 \mathrm{~K} / \mathrm{m}$ (corresponding to $\lambda=1.0 \mathrm{~W} \mathrm{~m}^{-1} \mathrm{~K}^{-1}$ and $\mathrm{q}_{\mathrm{e}}=0.05 \mathrm{~W} / \mathrm{m}^{2}$, or alternatively $\lambda=1.7 \mathrm{~W} \mathrm{~m}^{-1} \mathrm{~K}^{-1}$ and $\mathrm{q}_{\mathrm{e}}=0.085 \mathrm{~W} / \mathrm{m}^{2}$ ). As a consequence, the base of the HOZ shifts to a much shallower position (from 200 mbsf to 70 mbsf), the thickness of the HOZ decreases (figure $8 \mathrm{~A})$, and the gas hydrate saturation in the reservoir slightly increases to $8-10$ volume $\%$ of the pore 
space (figure 8C). With this reduced thickness, it only takes 6130 years to dissociate the entire gas hydrate reservoir (figure 8B). In the initial 1000 years of the simulation, the $\mathrm{HOZ}$ thickness decreases with $2 \mathrm{~m}$ at the top and $1 \mathrm{~m}$ at the base (figure 8D).
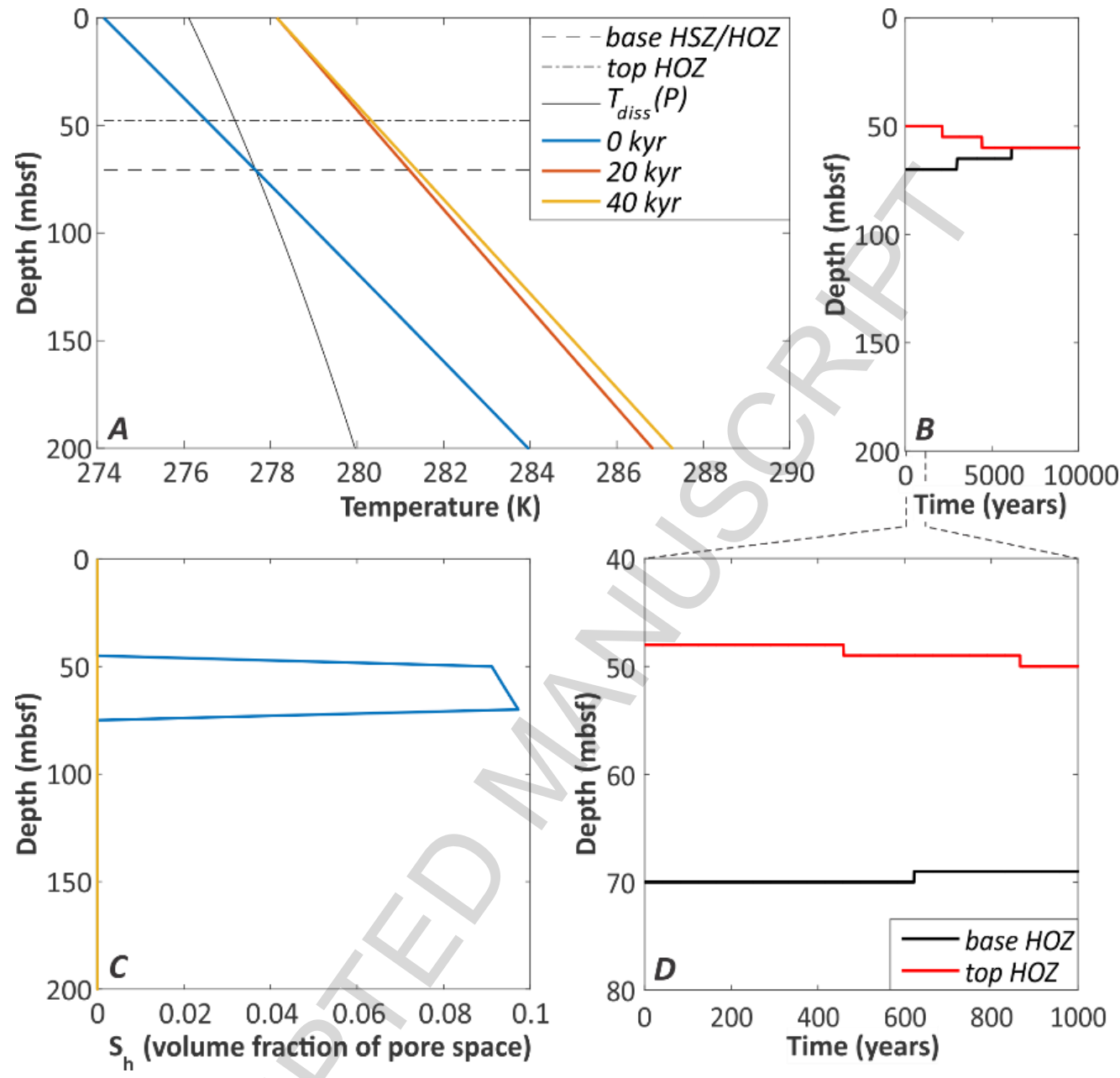

Figure 8. Simulation of the response of a marine gas hydrate reservoir (400 $\mathrm{m}$ water depth) to an instantaneous 1 to $5{ }^{\circ} \mathrm{C}$ BWT rise, for a geothermal gradient equal to $0.05 \mathrm{~K} / \mathrm{m}$. The values used for the other parameters are identical to the values applied in the standard example in figure 6. (A) Evolution of the temperature profile and indication of the initial position of the base of the HOZ (coinciding with the base of the HSZ) and top of the HOZ. (B) Evolution of the base and top of the HOZ. (C) Evolution of the hydrate saturation profile. (D) Detail of the initial 1000 years of the simulation shown in (B). The legend in (A) also applies to (C).

An additional element to take into account is the increased initial methane hydrate saturation (figure 8C), which in theory will affect the thermal diffusivity (as discussed in section 3.4.1). Indeed, Kumar et al. (2004) have experimentally shown that the thermal diffusivity of methane hydrate-sand mixtures increases with increasing hydrate volume fractions, which results in faster hydrate dissociation rates. However, the maximal thermal diffusivities measured by Kumar et al. (2004) are still in the order of $10^{-7} \mathrm{~m}^{2} / \mathrm{s}$, implying that also the dissociation rates will only increase slightly and 
remain in the order of magnitude shown in figures $8 \mathrm{~B}$ and $8 \mathrm{D}$. Using an average constant thermal diffusivity of $3.9 \times 10^{-7} \mathrm{~m}^{2} / \mathrm{s}$ will therefore only slightly underestimate the real response.

\subsubsection{Mass fraction of methane in seawater at the seabed}

In marine hydrate-bearing settings, the mass fraction of methane in seawater at the seafloor, $M_{0}$, is a crucial parameter in determining the proximity of the top of the HOZ to the seabed (Xu and Ruppel, 1999). These authors point out that the concentration of methane in seawater is generally negligible, and therefore we assume $\mathrm{M}_{0}=0 \mathrm{~kg} / \mathrm{kg}$ in the standard case. As a result, the top of the HOZ locates at several tens of meters below the seafloor (figure 6). However, examples are known where gas hydrates do exist at the seafloor (e.g. in the Gulf of Mexico, Sassen et al., 2001). If we assume a value of $M_{0}=6.35 \times 10^{-4} \mathrm{~kg} / \mathrm{kg}$, which is a value close to the solubility of methane in seawater at the seabed, the top of the $\mathrm{HOZ}$ moves to a position right below the seafloor (figure 9). Because of the increased thickness of the $\mathrm{HOZ}$, it takes more time $(90 \mathrm{kyr})$ to destabilize the entire hydrate reservoir (figure 9B). Nevertheless, compared to the standard example (figure 6 and 7D), hydrate dissociation is significantly more severe in the initial 1000 years, as $14 \mathrm{~m}$ of hydrate melts at the top of the $\mathrm{HOZ} \mathrm{(4}$ $m$ in the first 100 year, figure 9D). 

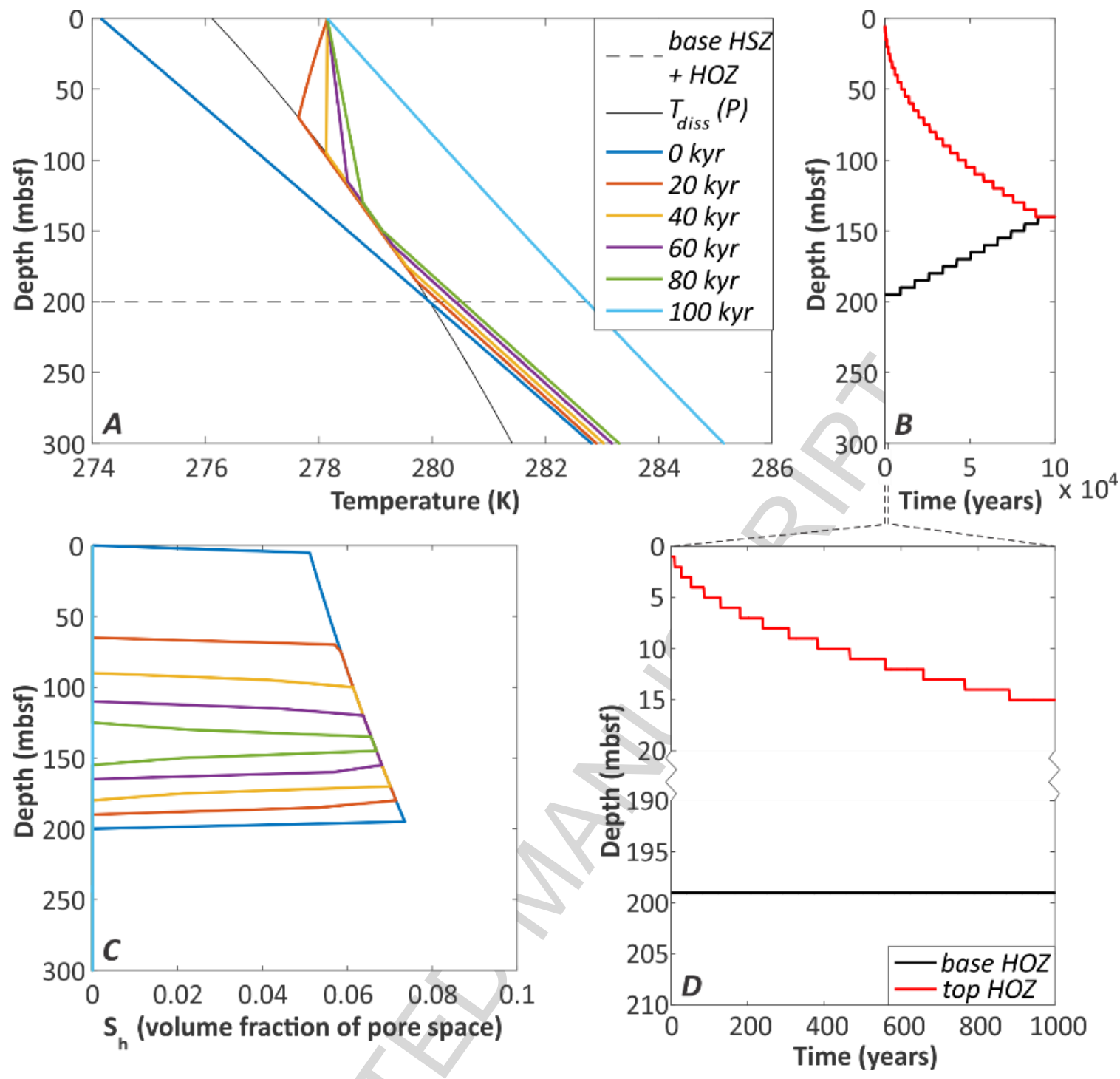

Figure 9. Simulation of the response of a marine gas hydrate reservoir (400 m water depth) to an instantaneous 1 to $5{ }^{\circ} \mathrm{C}$ $B W T$ rise, for a methane concentration in the bottom water equal to $6.35 \times 10^{-4} \mathrm{~kg} / \mathrm{kg}$. The values used for the other parameters are identical to the values applied in the standard example in figure 6. (A) Evolution of the temperature profile and indication of the initial position of the base of the HOZ (coinciding with the base of the HSZ). The top of the HOZ is situated at 1 mbsf. (B) Evolution of the base and top of the HOZ. (C) Evolution of the hydrate saturation profile. (D) Detail of the initial 1000 years of the simulation shown in (B). The legend in (A) also applies to (C).

\subsubsection{Methane flux}

The methane flux $q_{m}$ directly influences the position of the base of the HOZ (Xu and Ruppel, 1999). In the standard example (figure 6), we adopt a value equal to $6 \times 10^{-11} \mathrm{~kg} \mathrm{~m}^{-1} \mathrm{~s}^{-1}$, which is high enough to form stable methane hydrates all the way down to the base of the HSZ. If this value is reduced, the base of the HOZ shifts to a position that is shallower than the base of the HSZ. For example, figure 10 shows the same simulation as figure 6 , but with a reduced methane flux of $3.5 \times 10^{-11} \mathrm{~kg} \mathrm{~m}^{-1} \mathrm{~s}^{-1}$. The hydrate saturation profile remains unaltered (figure 10C), but the initial position of the base of the 
HOZ moves 55 m upward compared to the standard case (from 199 mbsf to 144 mbsf, figure 10). This thinner gas hydrate reservoir degrades completely within $46 \mathrm{kyr}$, but the dissociation pattern during the inititial 1000 years of the simulation remains similar (cfr. figure 7D and 10D).
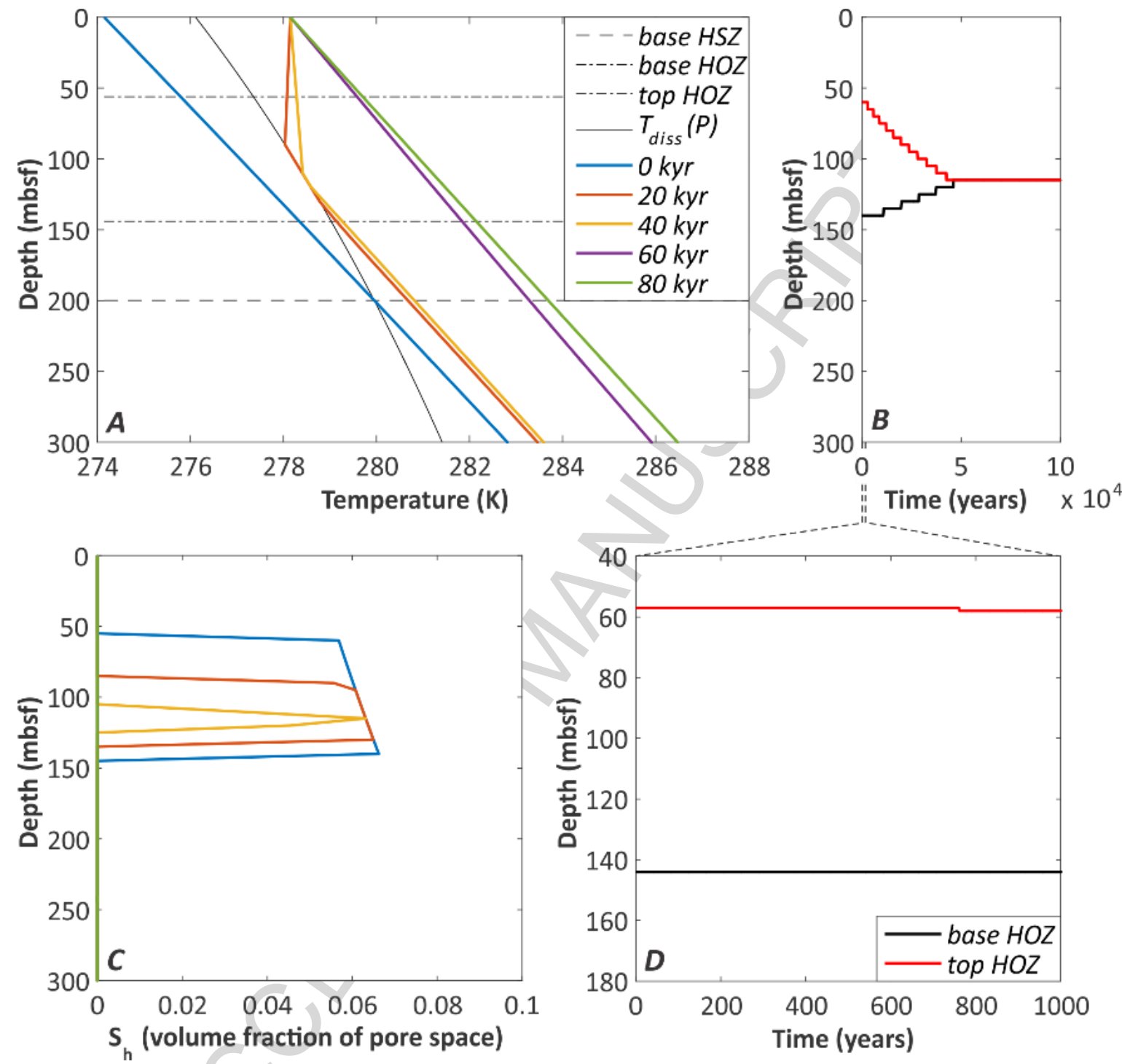

Figure 10. Simulation of the response of a marine gas hydrate reservoir (400 m water depth) to an instantaneous 1 to $5{ }^{\circ} \mathrm{C}$ $B W T$ rise, for a methane flux equal to $3.5 \times 10^{-11} \mathrm{~kg} \mathrm{~m}^{-1} \mathrm{~s}^{-1}$. The values used for the other parameters are identical to the values applied in the standard example in figure 6. (A) Evolution of the temperature profile and indication of the initial position of the base of the HSZ, and base and top of the HOZ. (B) Evolution of the base and top of the HOZ. (C) Evolution of the hydrate saturation profile. (D) Detail of the initial 1000 years of the simulation shown in (B). The legend in $(A)$ also applies to (C).

\subsubsection{Porosity}

Another parameter influencing the initial gas hydrate occurence and saturation is the porosity of the sediment column (Xu and Ruppel, 1999). The average porosity in marine sediments was assumed to 
be 0.5 for the standard case (figure 6). Nevertheless, the porosity of sediments close to the seafloor may reach up to 0.8 (e.g. Borowski et al., 1996; Burwicz et al., 2011). We therefore repeated the base simulation with a porosity equal to 0.8 (figure 11 ).
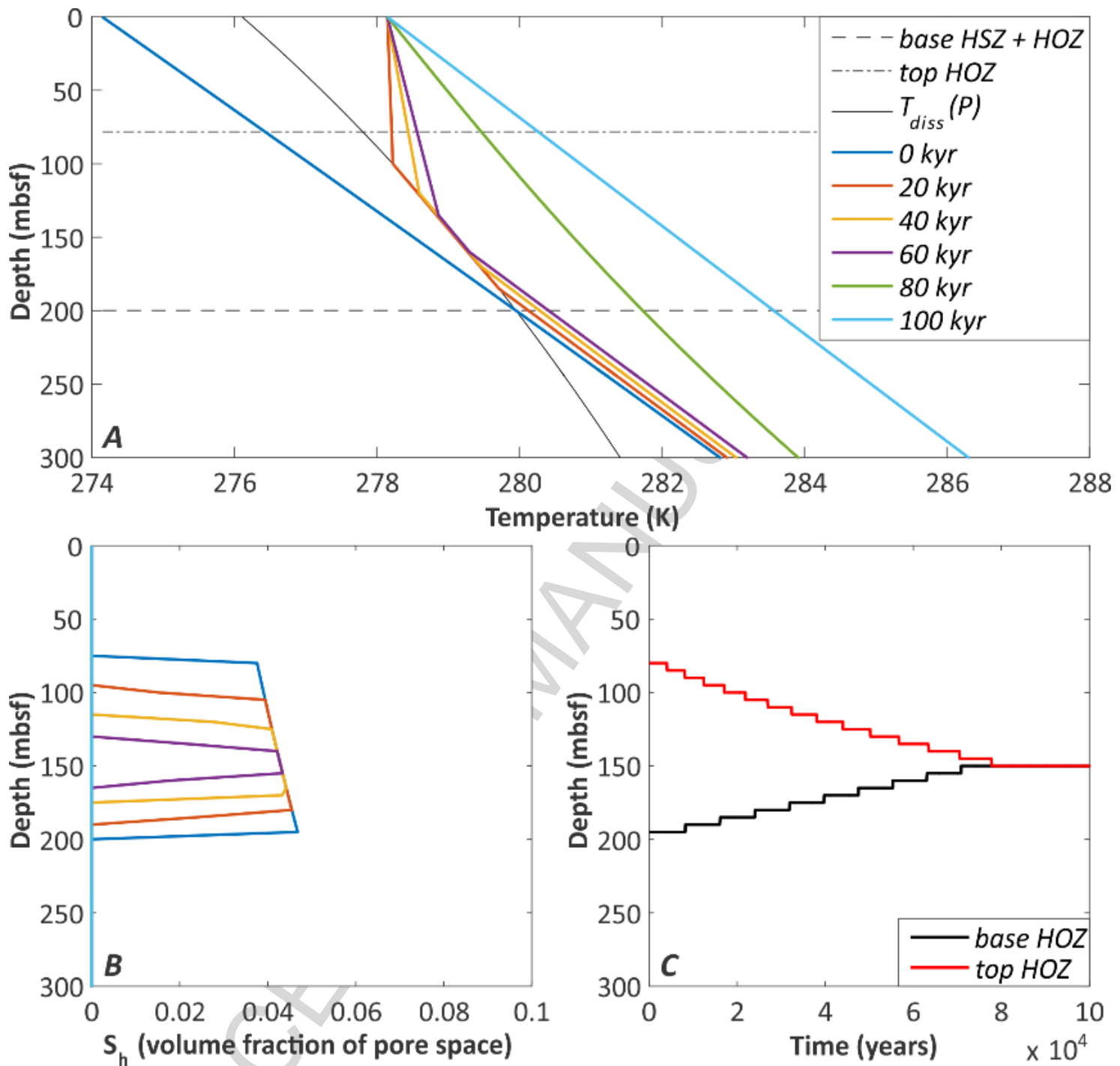

Figure 11. Simulation of the response of a marine gas hydrate reservoir (400 m water depth) to an instantaneous 1 to $5{ }^{\circ} \mathrm{C}$ BWT rise, for a porosity equal to $0.8 \mathrm{~m}^{3} / \mathrm{m}^{3}$. The values used for the other parameters are identical to the values applied in the standard example in figure 6. (A) Evolution of the temperature profile and indication of the initial position of the base of the $\mathrm{HOZ}$ (coinciding with the base of the HSZ) and top of the HOZ. (B) Evolution of the hydrate saturation profile. (C) Evolution of the base and top of the HOZ. The legend in (A) also applies to (B).

The initial gas hydrate saturation in the reservoir decreases to app. $4 \%$ of the pore space (figure 11B), and the initial position of the top of the HOZ moves to a deeper position (from 57 mbsf in figure $6 \mathrm{~A}$ to $78 \mathrm{mbsf}$ in figure $11 \mathrm{~A})$. Apart from these changes in the initial hydrate occurrence, the model anticipates a dissociation pattern that is similar to the one predicted for a 0.5 porosity sediment 
column (cfr. figure 6C and $11 \mathrm{C}$ ). However, a change in porosity and decrease in initial methane hydrate saturations will also have an impact on the thermal diffusivity (see section 3.4.1). Experimental results suggest that a decrease in hydrate saturation generally leads to a lower thermal diffusivity (Kumar et al., 2004), and so does an increase in porosity (Goto and Matsubayashi, 2009). As discussed above, a lower thermal diffusivity implies that the dissociation rate might in reality be slower than predicted in figure $11 \mathrm{C}$, for which the standard constant thermal diffusivity of $3.9 \times 10^{-7}$ $\mathrm{m}^{2} / \mathrm{s}$ was adopted. 


\section{Case studies}

The model is used to simulate the hydrate stability response to two specific cases of environmental change: (i) the deglaciation following the LGM, which happened on a timescale of several thousands of years, and (ii) present-day anthropogenic climate warming, occurring on a shorter timescale of a few tens to hundreds of years. We specifically focus on hydrate reservoirs across a high-latitude continental margin which are inferred to be the most sensitive to environmental changes (e.g. Archer et al., 2009; Hunter et al., 2013), although the model is equally applicable to low-latitude hydrate reservoirs.

\subsection{CASE LGM: deglaciation following the Last Glacial Maximum}

The adopted initial and final temperatures and water depths in this simulation of the post-LGM deglactiation are summarized in table 3 . These changes are assumed to have occurred gradually and linearly, over a period of approximately 3 kyr for the temperature changes (Landvik et al., 1998) and a period of $10 \mathrm{kyr}$ for the sea level change (Bard et al., 1990). The values used for the other parameters are listed in table 2.

\begin{tabular}{|c|cc|cc|}
\hline \multirow{2}{*}{ CASE LGM } & \multicolumn{2}{|c|}{ Tat ocean floor or surface (in ${ }^{\circ} \mathrm{C}$ ) } & \multicolumn{2}{|c|}{ Water depth (in $\mathrm{m}$ ) } \\
\cline { 2 - 5 } & Initial & Final & Initial & Final \\
\hline $\begin{array}{c}\text { Onshore } \\
\text { permafrost }\end{array}$ & -15 & $2^{[1]}$ & 0 & 0 \\
\hline $\begin{array}{c}\text { Offshore } \\
\text { permafrost }\end{array}$ & -10 & $2^{[1]}$ & 0 & $120^{[3]}$ \\
\hline $\begin{array}{c}\text { Upper } \\
\text { continental slope }\end{array}$ & -1 & $2^{[2]}$ & 300 & $420^{[3]}$ \\
\hline $\begin{array}{c}\text { Lower } \\
\text { continental slope }\end{array}$ & -1 & $2^{[2]}$ & 1000 & $1120^{[3]}$ \\
\hline
\end{tabular}

Table 3. Summary of the in this study adopted temperature and sea level changes for the deglaciation following the LGM, in four hydrate-bearing settings across a high-latitude continental margin (see figure 2). Initial and final temperatures and water depths from ${ }^{[1]}$ Miller et al. (2010), ${ }^{[2]}$ Waelbroeck et al. (2002) and ${ }^{[3]}$ Bard et al. (1990).

Figure 12 provides a schematic overview of the distribution of permafrost and methane hydrate across a hypothetic high-latitude continental margin at the start of the simulation, and after running 
the model for $100 \mathrm{kyr}$. Figure $13-16$ show the change in the temperature profile and the evolution of the subsurface hydrate (and ice) distribution and saturation for each hydrate-bearing setting individually. Figure $13 \mathrm{C}$ demonstrates that the environmental changes affect hydrate stability in the onshore permafrost column only after 85 kyr. Permafrost decays both from the top (at a slowing rate) and the base (at a fairly constant rate), and is reduced to $30 \%$ of its original thickness after 100 kyr (figure 13E). Figure 13A suggests that the melting of ice in permafrost significantly delays the evolution of the subsurface temperature profile, which is far from having reached a new equilibrium state after $100 \mathrm{kyr}$. In contrast, a converted free methane gas accumulation at the same depth, but underneath relic subshelf permafrost, does completely dissociate within $95 \mathrm{kyr}$. In this column, hydrate dissociation initiates after $28 \mathrm{kyr}$, at the base of the reservoir (figure 14C). The permafrost thickness below the shelf reduces by $90 \%$ over $100 \mathrm{kyr}$ (figure 14E). The modelled changes have only a minor effect on the hydrate reservoirs on the continental slope. On the upper continental slope, merely $10 \mathrm{~m}$ of hydrates melt within $100 \mathrm{kyr}$ at the base of the $\mathrm{HOZ}$ (figure $15 \mathrm{C}$ ), while the entire HOZ remains stable on the lower continental slope (figure 16C). In the latter setting, a new equilibrium temperature profile is established within $\pm 40 \mathrm{kyr}$ (figure 16A).
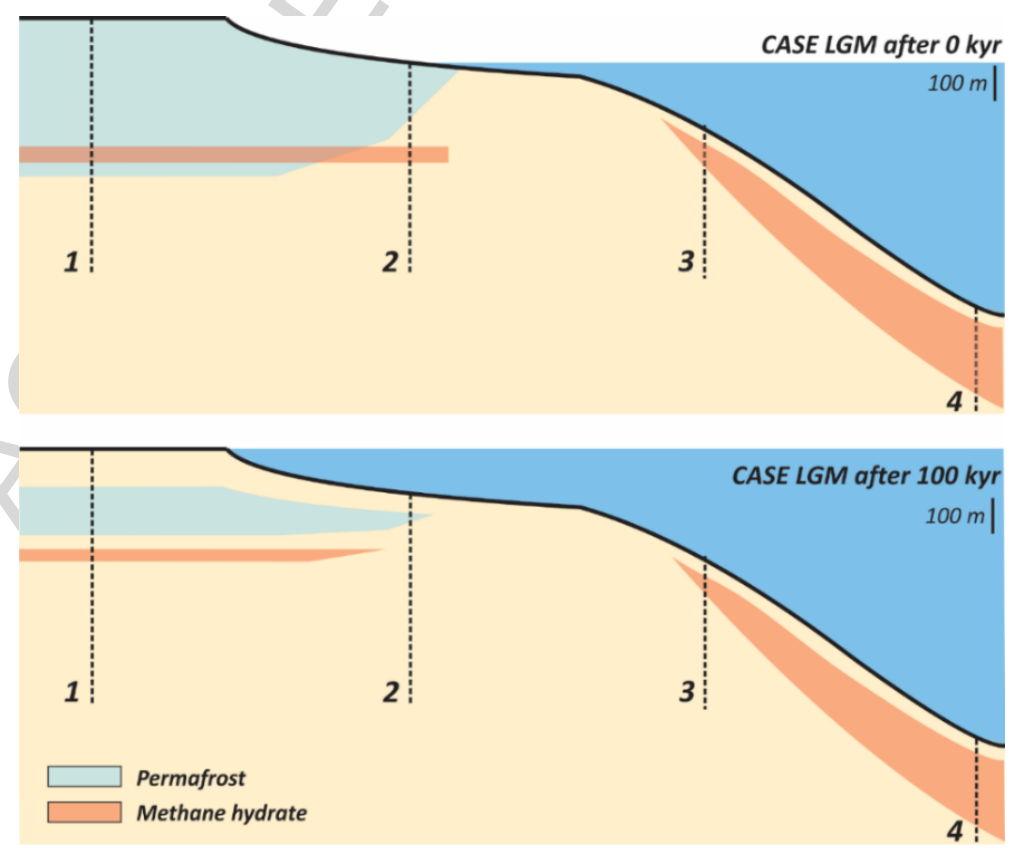

Figure 12. Schematic overview of the subsurface distribution of methane hydrate and ice at the start (top) and at the end (bottom) of the CASE LGM simulation, which summarizes how the modelled environmental changes affect hydrate and permafrost stability across the continental margin. 1 - 4 refer to the hydrate-bearing settings distinguished in figure 2. 
CASE LGM in onshore permafrost (column 1 in fig. 12)
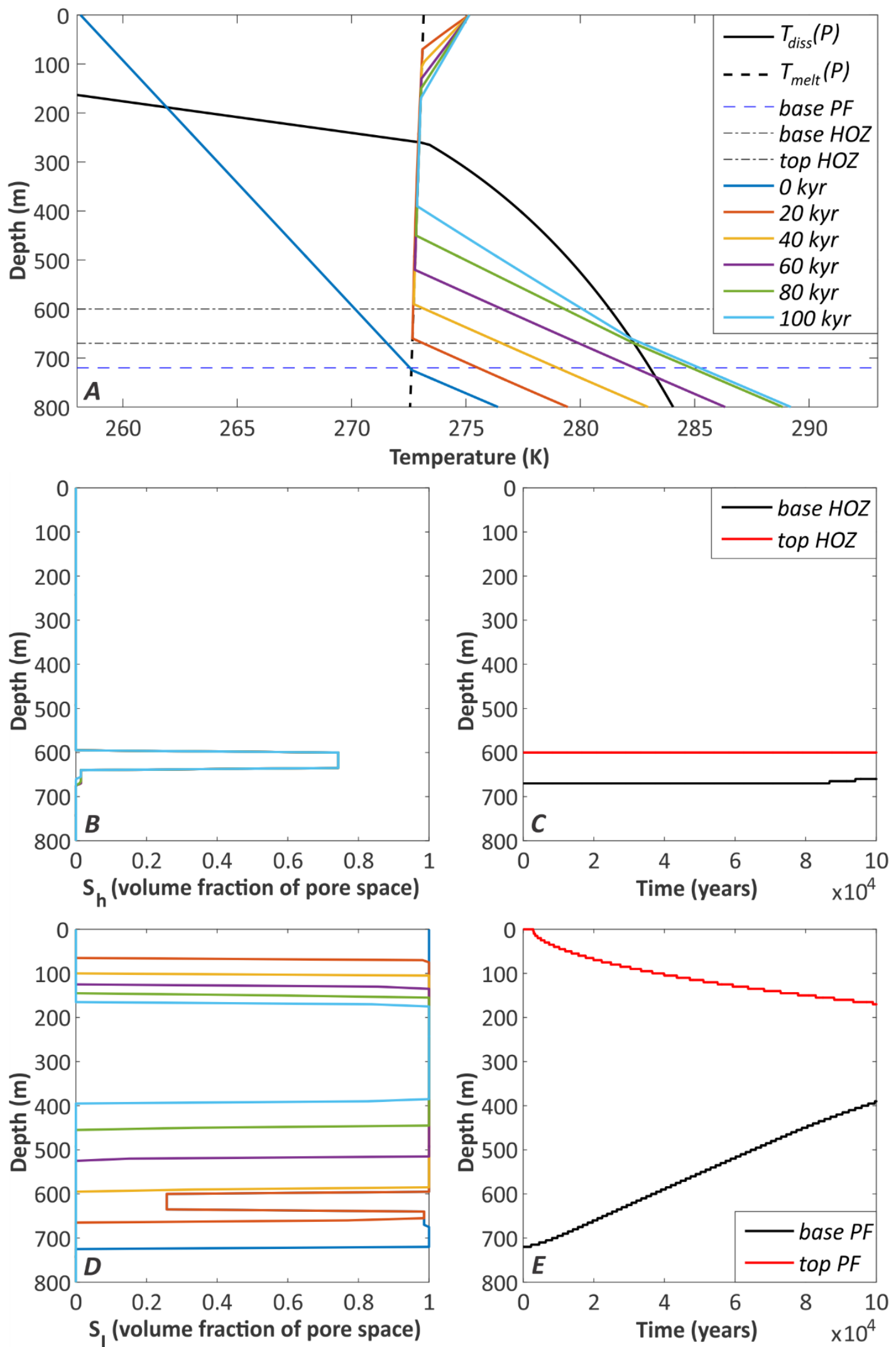

Figure 13. CASE LGM applied to a sediment column in the onshore permafrost setting: evolution of (A) the temperature profile, with indication of the initial position of the base of the permafrost (PF) and base and top of the HOZ, (B) hydrate saturation profile, (C) base and top of the HOZ, (D) ice saturation profile, and (E) base and top of the permafrost (PF). The legend in $(A)$ also applies to $(B)$ and $(D)$. 
CASE LGM in offshore permafrost (column 2 in fig. 12)
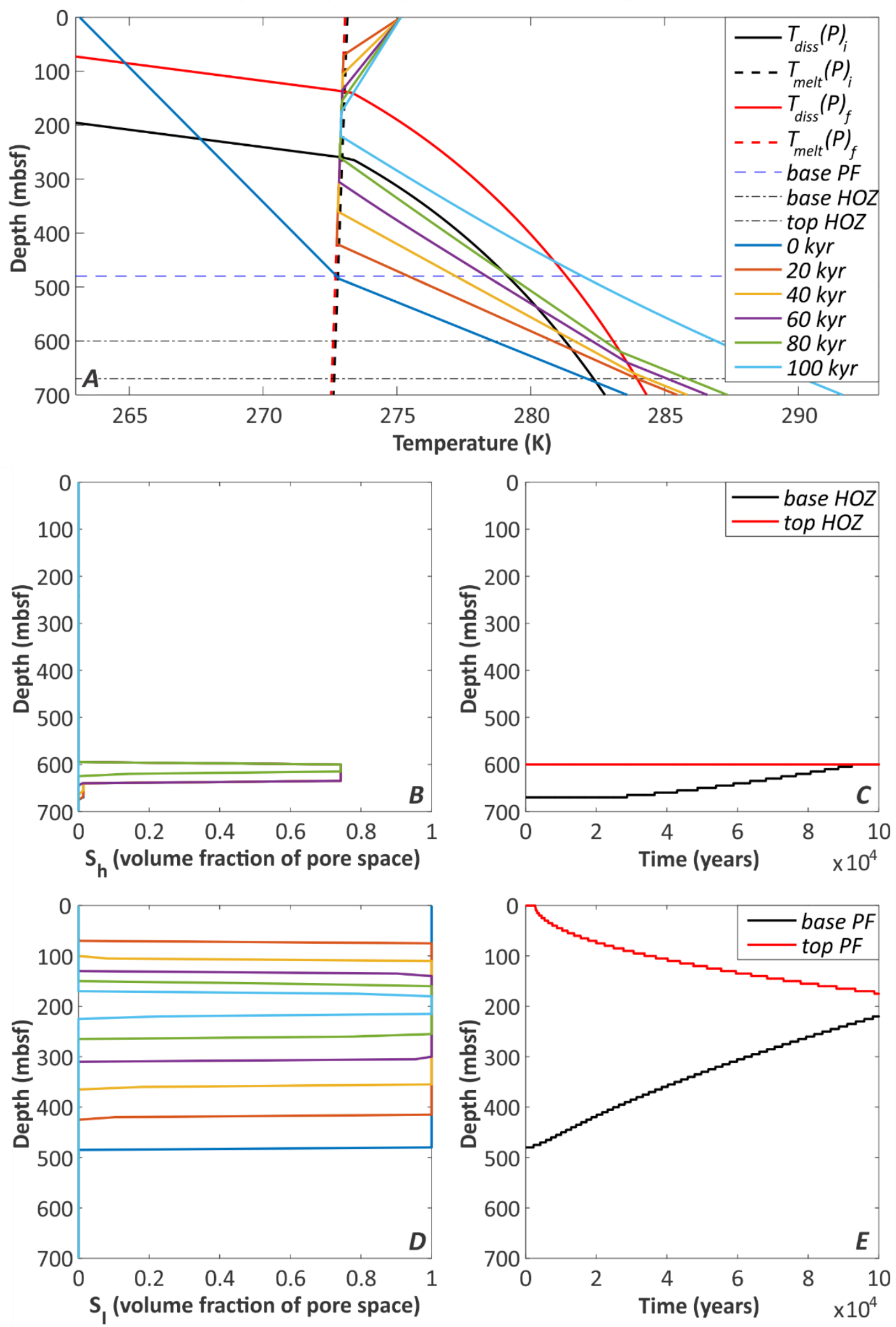

Figure 14. CASE LGM applied to a sediment column in the offshore (subsea) permafrost setting: evolution of $(\boldsymbol{A})$ the temperature profile, with indication of the initial position of the base of the permafrost (PF) and base and top of the HOZ, (B) hydrate saturation profile, (C) base and top of the $\mathrm{HOZ},(D)$ ice saturation profile, and (E) base and top of the permafrost (PF). The legend in (A) also applies to (B) and (D). 
CASE LGM on upper continental slope (column 3 in fig. 12)
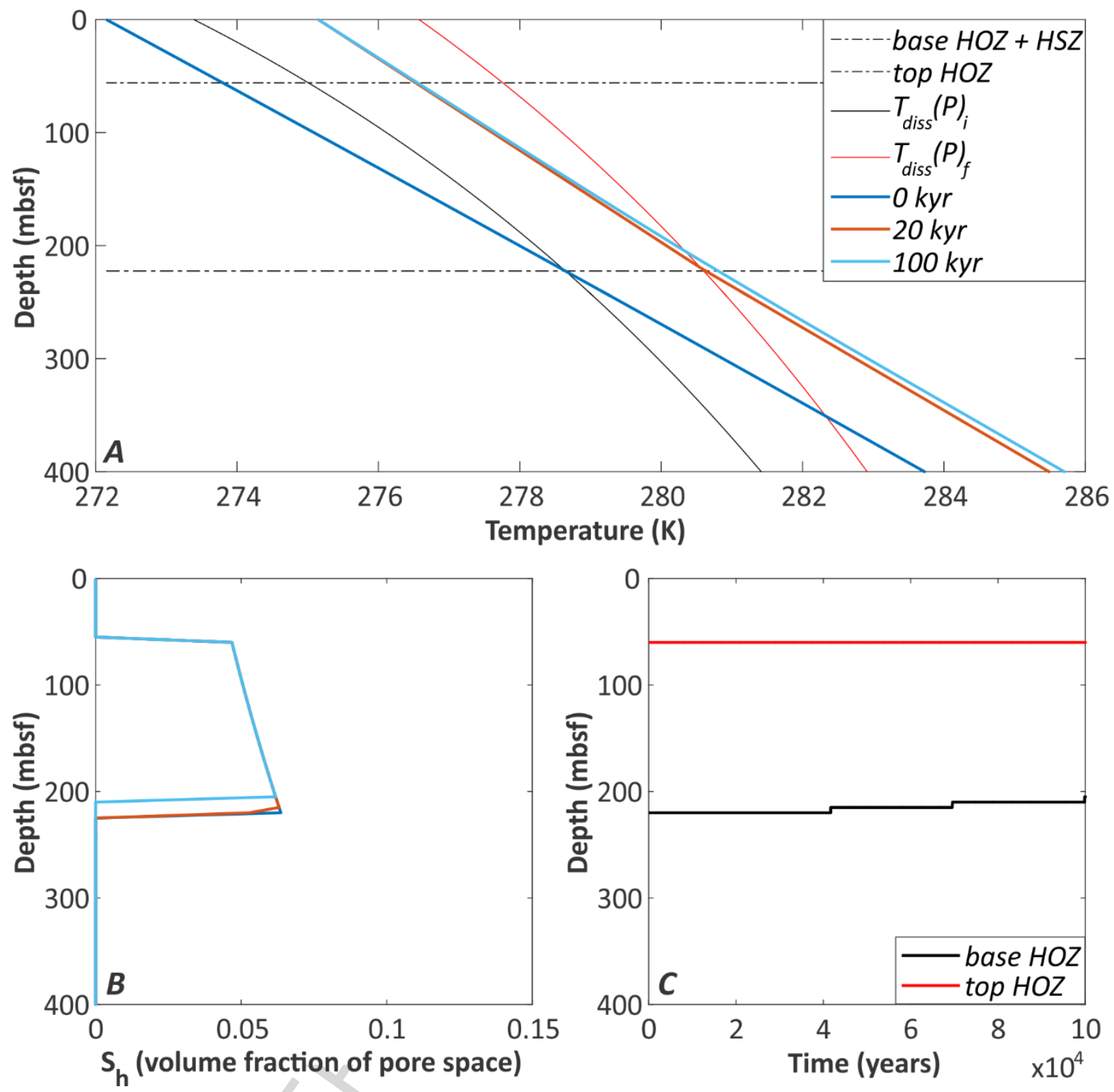

Figure 15. CASE LGM applied to a sediment column on the upper continental slope (300 m initial water depth): evolution of (A) the temperature profile, (B) hydrate saturation profile, and (C) base and top of the HOZ. The initial position of the base of the $\mathrm{HOZ}$ (coinciding with the base of the HSZ) and top of the HOZ are indicated in (A). The legend in (A) also applies to (B). 
CASE LGM on lower continental slope (column 4 in fig. 12)
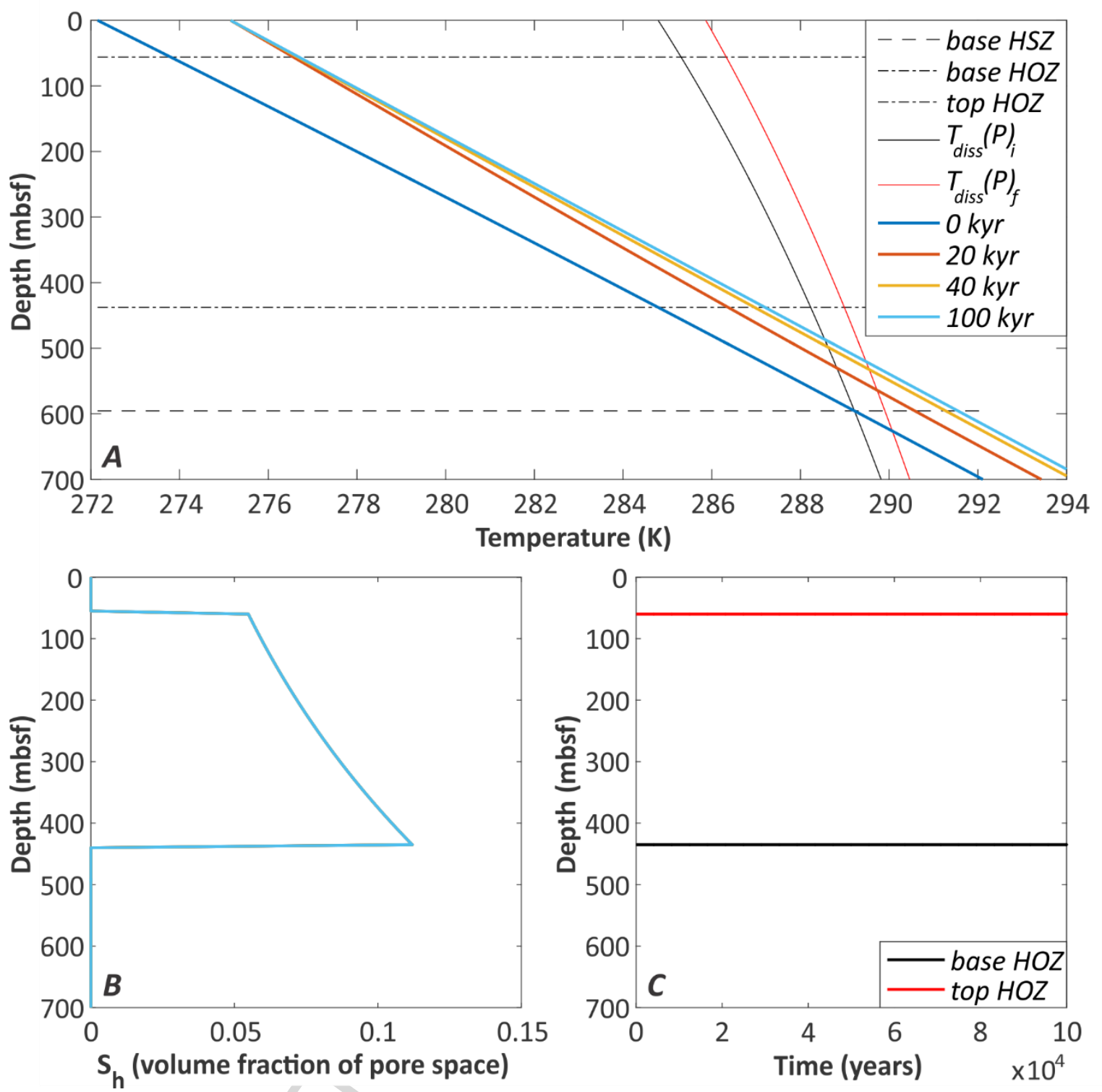

Figure 16. CASE LGM applied to a sediment column on the lower continental slope or continental rise (1000 m initial water depth): evolution of $(\boldsymbol{A})$ the temperature profile, (B) hydrate saturation profile, and (C) base and top of the HOZ. The initial position of the base of the HSZ, the base of the HOZ, and the top of the HOZ are indicated in (A). The legend in (A) also applies to (B). 


\subsection{CASE PRESENT: contemporary climate warming}

This second case (further also referred to as 'CASE PRESENT') simulates the sensitivity of high-latitude methane hydrate reservoirs to contemporary climate change. The adopted changes, summarized in table 4, are assumed to occur over a period of 200 years (IPCC, 2013). Present-day temperature and pressure values don't allow permafrost-related hydrate reservoirs to be initially present in an equilibrium state, which is assumed to be the starting condition in the other examples presented in this study. Therefore, for the onshore and offshore permafrost settings, we adopt the temperature and hydrate saturation profiles of CASE LGM after $10 \mathrm{kyr}$ as the initial situation in this simulation (cfr. figure 13 and 14). The values used for the other parameters are listed in table 2.

\begin{tabular}{|c|cc|cc|}
\hline \multirow{2}{*}{ CASE PRESENT } & \multicolumn{2}{|c|}{ Tat ocean floor or surface (in ${ }^{\circ} \mathrm{C}$ ) } & \multicolumn{2}{|c|}{ Water depth (in $\mathrm{m}$ ) } \\
\cline { 2 - 5 } & Initial & \multicolumn{1}{c|}{ Final } & Initial & Final \\
\hline $\begin{array}{c}\text { Onshore } \\
\text { permafrost }\end{array}$ & $\left(^{*}\right)$ & $3^{[1]}$ & 0 & 0 \\
\hline $\begin{array}{c}\text { Offshore } \\
\text { permafrost }\end{array}$ & $\left(^{*}\right)$ & $3^{[1]}$ & 120 & $401^{[1]}$ \\
\hline $\begin{array}{c}\text { Upper } \\
\text { continental slope }\end{array}$ & 1 & $5^{[2]}$ & 400 & $1001^{[1]}$ \\
\hline $\begin{array}{c}\text { Lower } \\
\text { continental slope }\end{array}$ & 0 & $4^{[2]}$ & 1000 & \\
\hline
\end{tabular}

Table 4. Summary of the changes modelled in CASE PRESENT (present-day climate warming across a high-latitude continental margin). Initial and final temperatures and water depths from ${ }^{[1]}$ IPCC (2013) and ${ }^{[2]}$ Biastoch et al. (2011). (*) The initial temperature profiles in the onshore and offshore permafrost settings are adopted from CASE LGM at 10 kyr (see figures 13 and 14), since present-day conditions don't permit for the assumption of initial equilibrium.

Figure 17 schematically shows the distribution of permafrost and methane hydrate across a hypothetic high-latitude continental margin at the start of the simulation, and after running the model for $100 \mathrm{kyr}$. Figures $18-21$ illustrate the change in the temperature profile and the evolution of the subsurface hydrate (and ice) distribution and saturation for each hydrate-bearing setting individually. The thickness of a hydrate reservoir associated with thick onshore permafrost starts to decrease from the base after $75 \mathrm{kyr}$, and is reduced by $20 \mathrm{~m}$ after $100 \mathrm{kyr}$ (figure 18C). The permafrost thickness declines from $660 \mathrm{~m}$ at the start to $150 \mathrm{~m}$ at the end of the simulation (figure 
18E). Methane hydrates at the same depth, but underneath thinner subsea permafrost, start to melt after $19 \mathrm{kyr}$ and completely dissociate within $83 \mathrm{kyr}$ (figure 19C). Subsea permafrost decays both from the top and the base, and is completely melted after $90 \mathrm{kyr}$ (figure 19E). Figure 20 demonstrates the simulated response of a methane hydrate reservoir on the upper continental slope to contemporary anthropogenic climate forcing. Hydrates, initially occurring between $60 \mathrm{~m}$ and 195 $\mathrm{m}$ depth below the seafloor, dissociate both from the top and the base of the reservoir. The upper 5 m of the HOZ melts within $3 \mathrm{kyr}$, while it takes $8 \mathrm{kyr}$ for the lower $5 \mathrm{~m}$ of the $\mathrm{HOZ}$ to dissociate completely. Hydrates persist longest between $140 \mathrm{~m}$ and $145 \mathrm{~m}$ depth in the column, until all hydrates are dissociated after $84.5 \mathrm{kyr}$ (figure $20 \mathrm{C}$ ). The considered $1 \mathrm{~m}$ sea level rise does not notably alter the $T_{\text {diss }}(P)$ profile, and hence does not have a significant stabilizing effect (only $T_{\text {diss }}(P)$ at the start of the simulation is shown in figure 20A). The model predicts a thick HSZ in the sediment column on the lower continental slope (1000 m water depth), with methane hydrate actually occurring between $56 \mathrm{~m}$ and $400 \mathrm{~m}$ depth below seafloor. This configuration remains stable during the CASE PRESENT simulation (figure 21), since the new temperature profile intersects $T_{\text {diss }}(P)$ below the base of the HOZ. It takes approximately $50 \mathrm{kyr}$ for the temperature profile to reach a new equilibrium. 

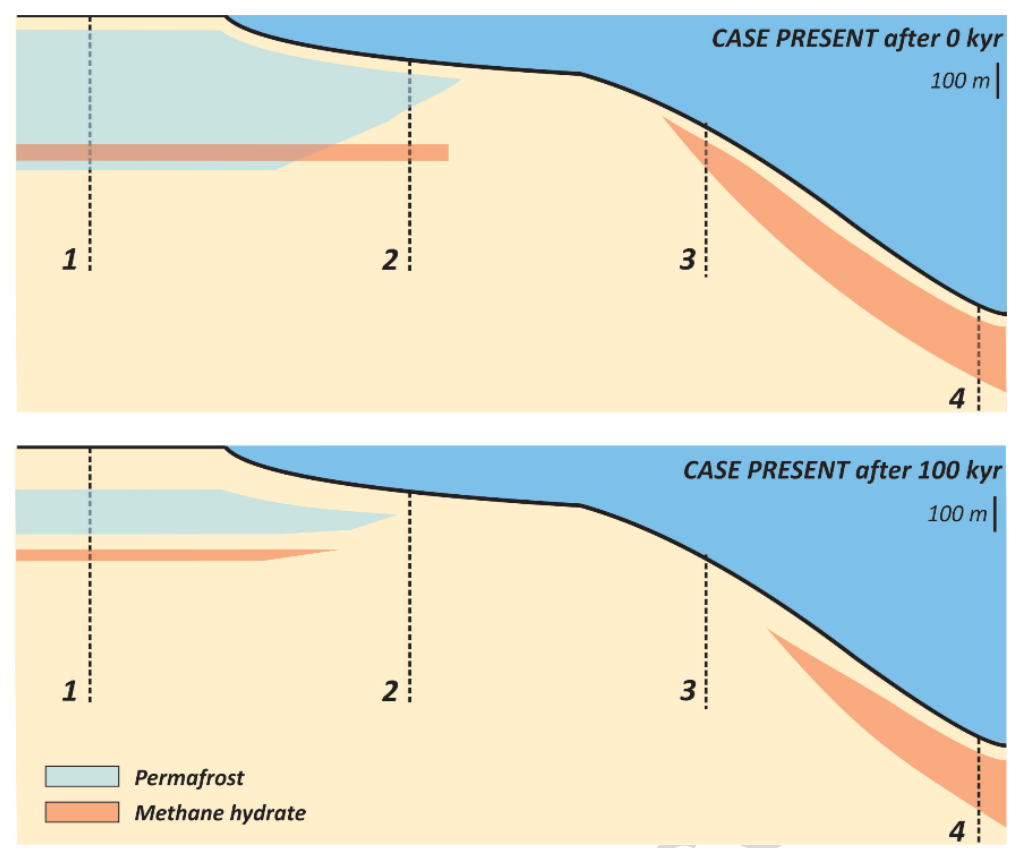

Figure 17. Schematic overview of the subsurface distribution of methane hydrate and ice at the start (top) and at the end (bottom) of the CASE PRESENT simulation, which summarizes how the modelled environmental changes affect hydrate and permafrost stability across the continental margin. 1 - 4 refer to the hydrate-bearing settings distinguished in figure 2. 
CASE PRESENT in onshore permafrost (column 1 in fig. 17)
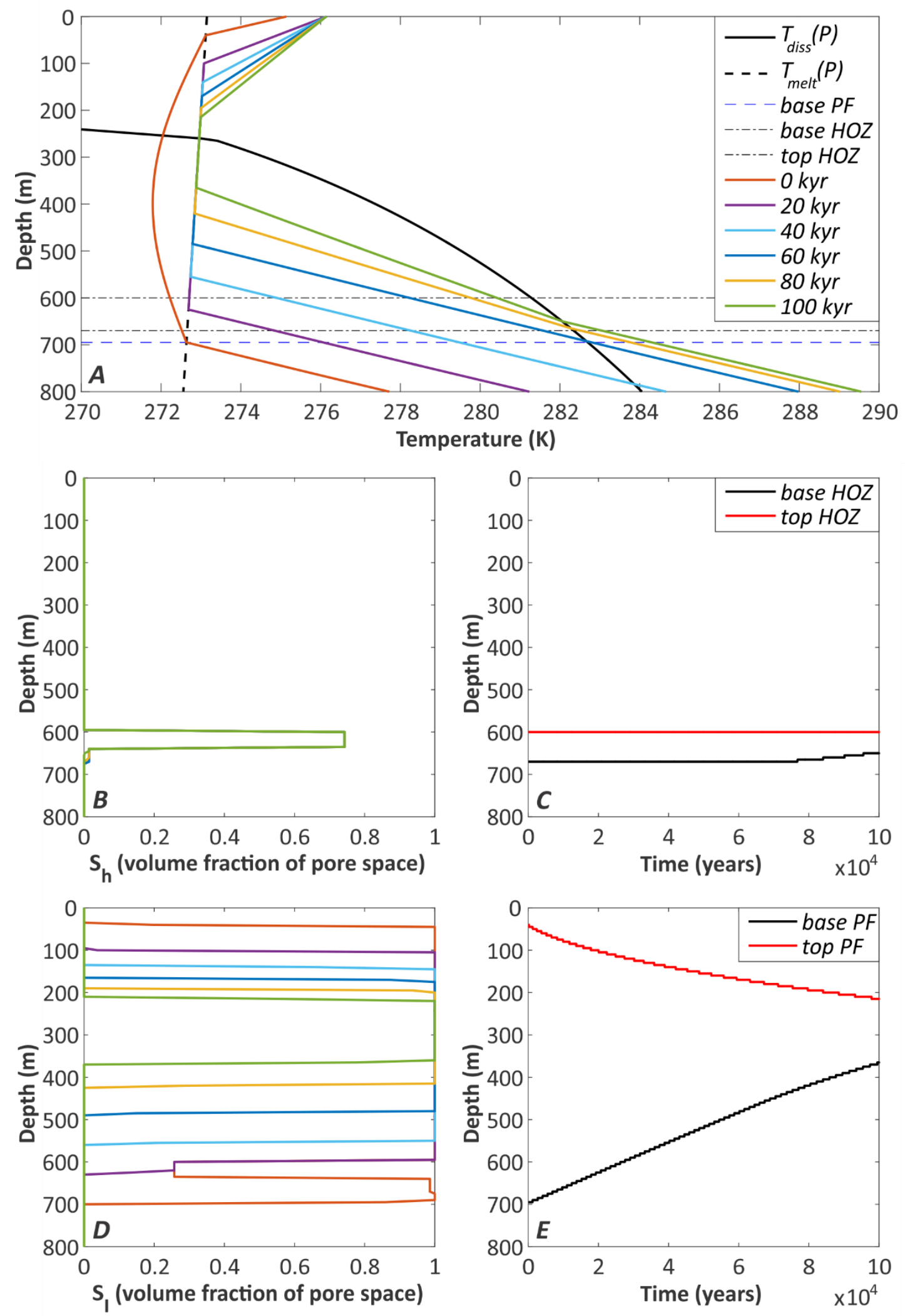

Figure 18. CASE PRESENT applied to a sediment column in the onshore permafrost setting: evolution of (A) the temperature profile, with indication of the initial position of the base of the permafrost (PF) and base and top of the HOZ, (B) hydrate saturation profile, (C) base and top of the HOZ, (D) ice saturation profile, and (E) base and top of the permafrost (PF). The legend in (A) also applies to (B) and (D). 
CASE PRESENT in offshore permafrost (column 2 in fig. 17)
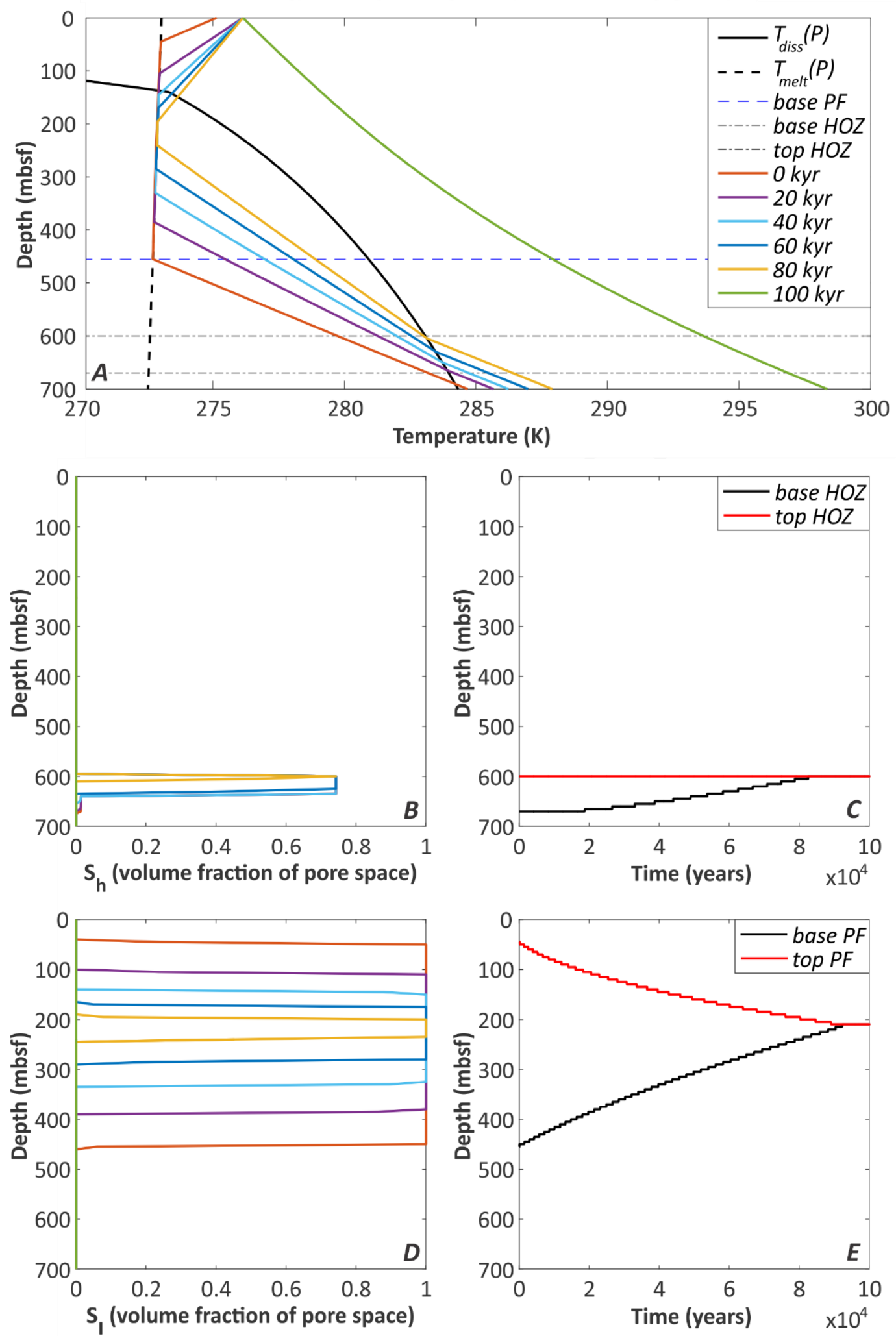

Figure 19. CASE PRESENT applied to a sediment column in the offshore (subsea) permafrost setting: evolution of (A) the temperature profile, with indication of the initial position of the base of the permafrost (PF) and base and top of the HOZ, (B) hydrate saturation profile, (C) base and top of the $\mathrm{HOZ},(D)$ ice saturation profile, and (E) base and top of the permafrost (PF). The considered $1 \mathrm{~m}$ sea level rise does not noticeably alter the $T_{\text {diss }}(P)$ - and $T_{\text {melt }}(P)$ profiles. The legend in $(A)$ also applies to $(B)$ and $(D)$. 
CASE PRESENT on the upper continental slope (column 3 in fig. 17)
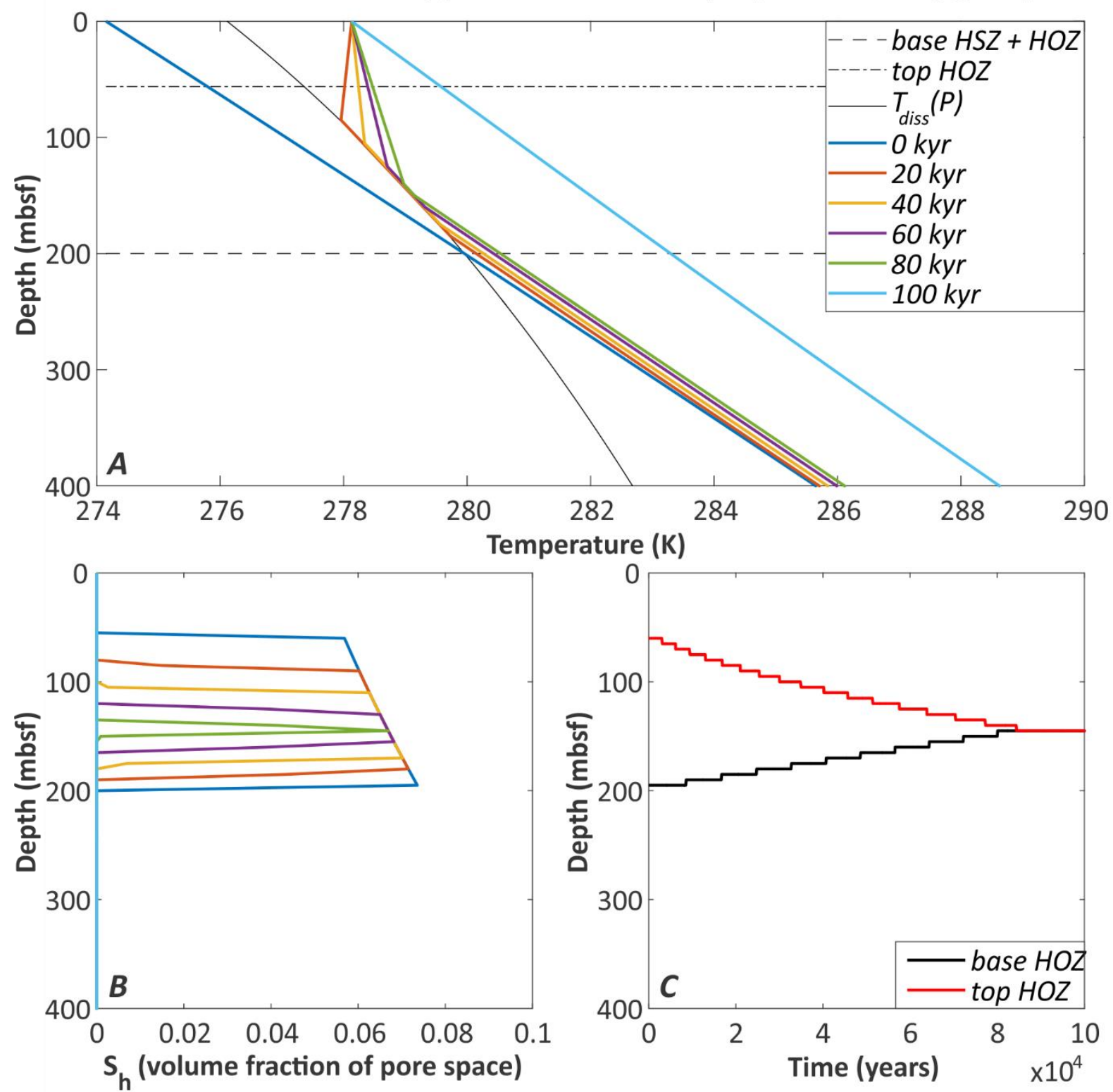

Figure 20. CASE PRESENT applied to a sediment column on the upper continental slope (400 $\mathrm{m}$ initial water depth): evolution of (A) the temperature profile, (B) hydrate saturation profile, and (C) base and top of the HOZ. The initial position of the base of the $\mathrm{HOZ}$ (coinciding with the base of the HSZ) and top of the $\mathrm{HOZ}$ are indicated in (A). The considered $1 \mathrm{~m}$ sea level rise does not noticeably alter the $T_{\text {diss }}(P)$-profile. The legend in (A) also applies to (B). 
CASE PRESENT on lower continental slope (column 4 in fig. 17)
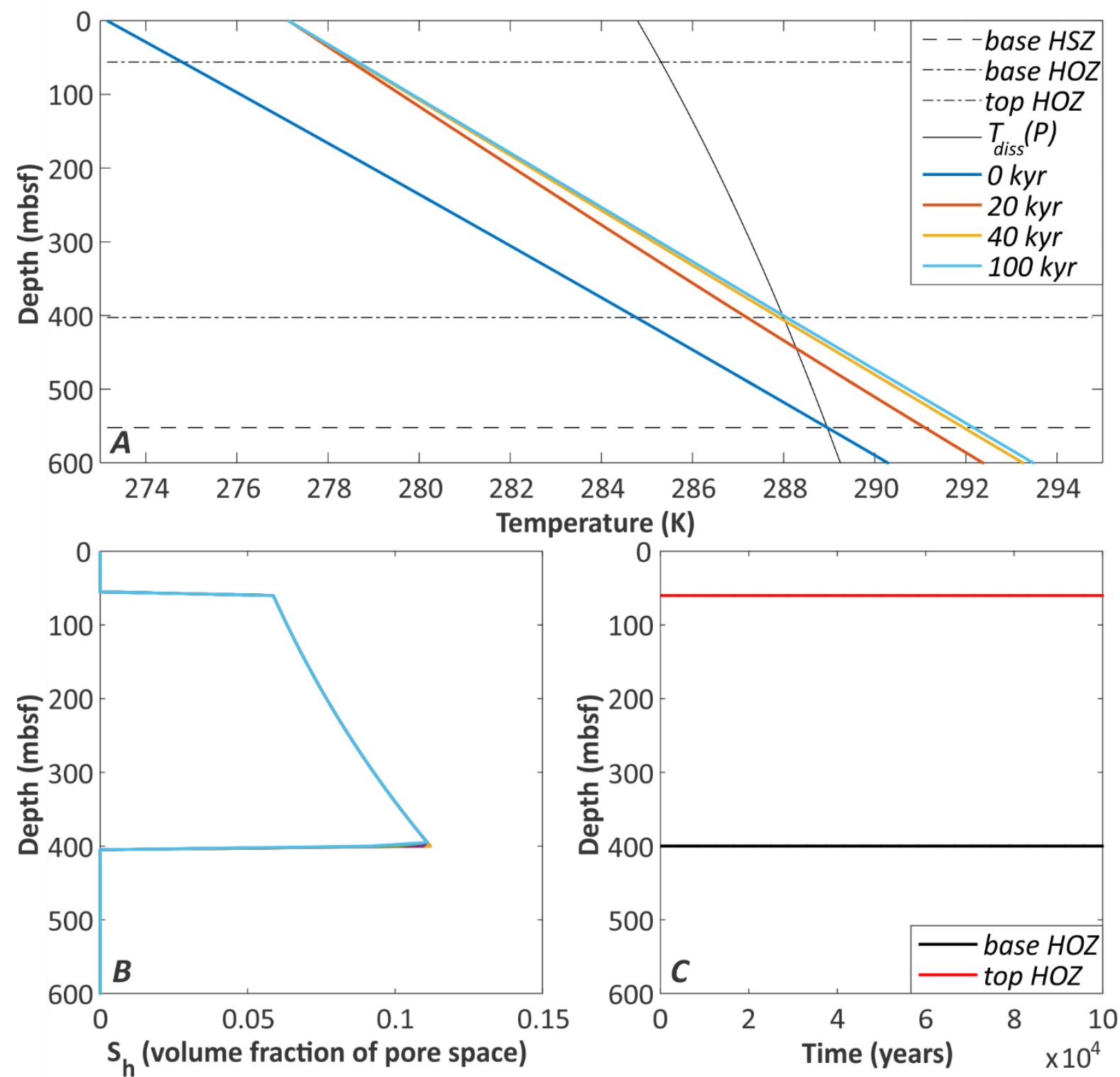

Figure 21. CASE PRESENT applied to a sediment column on the lower continental slope or continental rise (1000 m initial water depth): evolution of (A) the temperature profile, (B) hydrate saturation profile, and (C) base and top of the HOZ. The initial position of the base of the HSZ, the base of the HOZ, and the top of the $\mathrm{HOZ}$ are indicated in (A). The considered $1 \mathrm{~m}$ sea level rise does not noticeably alter the $T_{\text {diss }}(P)$-profile. The legend in $(A)$ also applies to $(B)$. 


\section{Discussion}

\subsection{Evaluation of the sensitivity of gas hydrates to the last deglaciation and Quaternary climatic oscillations}

The results of the simulation of the last deglaciation (CASE LGM) help to shed a light on the hypothesized role of gas hydrates in Quaternary climatic oscillations (see table 1 for a list of previous studies). Most strikingly, in each of the considered geographic settings, the modelled hydrate dissociation timescale is at least in the order of tens of thousands of years. This does not support a rapid feedback with warming climate, as proposed by Nisbet (1990) and Loehle (1993) for the last deglaciation. The size of Arctic hydrate reservoirs is therefore also unlikely to have fluctuated in concert with even higher frequency (millennial-scale) stadial-interstadial climatic oscillations, as suggested in the clathrate gun hypothesis (Kennett et al., 2003). We acknowledge that the here presented model does not account for rapid and massive gas release through continental slope failure and deroofing of gas hydrate reservoirs, which Kennett et al. (2003) assume to be the principal gas release mechanism. However, our simulations show that warming-induced dissociation of hydrates (at the base of the HSZ) and the associated volume expansion, which was proposed to have triggered the sediment failures, only initiates after several (tens of) thousands of years. Hence, build-up of excess pore pressure (if any, given the rate of overpressure dissipation and the considered timescales) and potential slope failure should lag the warming by a comparatively long time interval. Neither did we explicitly model the effect of deglacial melting of ice sheets and associated pressure drop on hydrate stability. Nevertheless, since we assume that pressure changes propagate instantaneously into the subsurface, we infer that modelled timescales of hydrate dissocation in this case would be mainly dictated by the timescale of the melting of the ice sheet, i.e. thousands of years, with a potential extra delay because of the consumption of latent heat. A protracted, millennial timescale ( $7-10 \mathrm{kyr})$ for hydrate dissociation and methane release after ice sheet collapse is corroborated by Crémière et al. (2016) for the Norwegian margin during the last deglaciation (see table 1). These authors also remark that, from a global perspective, the retreat of 
ice sheets over different continental shelves is very asynchronous, hence methane release from this mechanism is not likely to occur as rapid and large outbursts. Another factor that is not taken into account by the CASE LGM simulation, is the intrusion of salty water into the subshelf permafrost and hydrates when the shelf gets flooded during the sea level rise. An increase in salinity depresses the melting temperature of ice and methane hydrate (Dickens and Quinby-Hunt, 1994), and hence will accelerate permafrost degradation and hydrate destabilization. However, in the here presented case study (figure 14), it will take time before the salt water intrusion reaches the deep hydrate deposits, because permafrost capping the hydrates constitutes a relatively impermeable barrier to the saltwater movement (Frederick and Buffett, 2015). Our model anticipates that even with a salinity of $35 \%$, it still takes several tens of thousands of years before the permafrost-cap completely degrades, and hence before the salt water intrusion can affect hydrate stability. Therefore we believe that the hydrate dissociation timescale derived from the CASE LGM simulation (figure 14) will remain in the same order of magnitude after an intrusion of salty water. To conclude, our modelling results suggest slow hydrate destabilization rates in response to the post-LGM warming and sea level rise. To date, hydrate reservoirs are still mostly unaffected by these changes, as reflected by the model outcome at 10 to $20 \mathrm{kyr}$ in figures $13-16$, and it will generally take another (tens of) thousands of years before a noticeable effect appears. The simulations thus do not support the idea of a direct, dynamic link between Quaternary climatic oscillations and changes in the size of high-latitude hydrate reservoirs. This concurs with modelling results of the Black Sea gas hydrate reservoir (Poort et al., 2005) and as indicated in table 1, with findings from slope failure analysis (Maslin et al., 2004), hydrogen isotope measurements on ice core methane (Sowers, 2006; Bock et al., 2010), and deglacial carbon budget balancing (Maslin and Thomas, 2003). The latter studies promote enhanced outgassing from expanding wetlands as the main driver of increased atmospheric methane levels during the last deglaciation and interstadial events.

\subsection{Evaluation of the sensitivity of high-latitude gas hydrates to contemporary climate warming}


The present-day, anthropogenic climate warming is, in addition to Quaternary climatic oscillations, also perceived to be capable of inducing gas hydrate dissociation in the (near) future (see table 1 for a list of studies). Interpretation of the results of the CASE PRESENT simulation in this study can further contribute to this debate. Those results suggest that it takes a few millennia to melt $5 \mathrm{~m}$ of hydrates at the top and the base of the HOZ on the upper continental slope (figure 20). Re-running the model with a $1 \mathrm{~m}$ depth interval to obtain a higher spatial resolution, shows that the top of the HOZ deepens by $1 \mathrm{~m}$ after almost 900 years. This is in agreement with the millennial-scale release scenario predicted by Archer et al. (2009). In the deep marine realm (1000 m water depth), the simulations predict no hydrate dissociation at all, even on timescales as long as hundreds of thousands of years. Permafrost-related hydrates also appear to melt on a very slow timescale of tens to hundreds of thousands of years.

Remarkably, a range of other modelling studies report significant hydrate dissociation in shallow- and mid-depth marine environments in the Arctic on timescales of only a few centuries or decades (Biastoch et al., 2011; Reagan et al., 2011; Hunter et al., 2013; Marín-Moreno et al., 2013). Besides small variations in the choice of parameter values and imposed climate change scenarios, some major differences between the modelling approach of these studies and the model deployed here should be regarded, in order to understand this discrepancy. First, in the above-mentioned models hydrates are assumed to be present over the entire extent of the HSZ, except for the sediments immediately below the seafloor where a sulphate reduction zone with a maximal thickness of $10 \mathrm{~m}$ is assumed to impede hydrate formation. Hence hydrates exist at much shallower subsurface depths than proposed in this study, where the top of the hydrate occurrence zone is modelled to be located at more than $50 \mathrm{~m}$ below the seafloor, according to the formation model of $\mathrm{Xu}$ and Ruppel (1999). It is exactly this section of hydrates in the upper tens of meters below the seafloor that is most susceptible to bottom water warming, because the rate of warming (especially in the first hundreds to thousands of years of the simulation) is largest at the top of the sediment columns and decreases with depth. Consequently, hydrates at very shallow depths will degrade rapidly from the top, given 
that the newly imposed bottom water temperature exceeds $T_{\text {diss }}$ at the seafloor. Indeed, in the parameter sensitivity analysis (section 3.4) it was shown that hydrate deposits at and just below the seafloor can dissociate on decadal to centennial timescales (see figure 9 - this example in fact corresponds to the CASE PRESENT simulation, for an upper continental slope column containing hydrates right below the seafloor). Similarly, the permafrost-associated hydrate reservoirs modelled in this study are protected from rapid warming-induced degradation, because of their large subsurface depth $(600-670 \mathrm{~m})$, in correspondence with the few available field examples from the Alaska North Slope (Boswell et al., 2011; Collett et al., 2011). Regarding the bottom end of the columns, it appears that not differentiating between the base of the HSZ and the base of the HOZ can lead to an over-prediction of the amount and rate of hydrate dissociation from the base of a hydrate reservoir. This is especially important in deep water settings, since the offset between the base of the HSZ and $\mathrm{HOZ}$ is modelled to be largest here. A second point is that the models of Biastoch et al. (2011) and Hunter et al. (2013) do not account for latent heat consumption during hydrate dissociation, which can also be part of the explanation why the predicted hydrate response times differ at least one order of magnitude between their models and this study.

The modelling outcome of this CASE PRESENT simulation further implies that the hypothesis concerning the West Svalbard continental margin seeps (Westbrook et al., 2009 - see table 1 for a summary) probably does not hold true for the deep, stratigraphic-type hydrate deposits considered in this study. Only where hydrates occur at or just below the seafloor can decadal-scale melting be expected and potentially contribute to the observed gas seepage. However, such shallow hydrates generally only occur in so-called structural-type hydrate deposits (Milkov and Sassen, 2002; Archer, 2007). In these spatially confined deposits, high upward fluxes of deeper methane along structural features (e.g. faults, permeable channels) saturate the bottom water and thus prevent the dissolution of hydrate, which normally takes place at such shallow subsurface depths (cfr. figure 3B). Anyhow, it is not inconceivable that in this situation gas can escape through the seabed regardless of the release of gas from melting hydrate. Indeed, Berndt et al. (2014) find that methane has been 
seeping through the seabed off Svalbard for at least $3 \mathrm{kyr}$. The Svalbard case does therefore not provide unambiguous evidence for recent anthropogenic warming-induced hydrate destabilization and enhanced methane emissions, although it neither rules it out. The potential feedback of this and similar systems with presently warming climate will remain speculative as long as the volumes of shallow hydrate in them are not fully constrained.

It can thus be concluded that gas hydrates will generally be protected from contemporary warming and melting, because of their depth in the subsurface. Only very shallow structural-type hydrate accumulations are capable to respond on the proposed decadal to centennial timescales (e.g. figure 9 and studies listed in table 1). However, it remains highly uncertain if the volumes of gas released from this type of hydrate deposits are large enough to stand out against the background flux of deeper thermogenic gas.

\subsection{Variations in the climate sensitivity of high-latitude hydrate reservoirs}

Besides the above discussion of specific Late Quaternary and contemporary climate change examples, the here presented results also provide insights in the dissociation patterns of highlatitude hydrates. Significant differences can be identified in the sensitivity of high-latitude hydratebearing settings to the simulated temperature and sea level changes.

\subsubsection{Permafrost settings}

As for the permafrost settings, it appears that methane hydrates associated with relic subshelf permafrost are more sensitive to warming than methane hydrates within or below continental permafrost. This can be explained by the permafrost thickness: the thicker the permafrost, the thicker the interval in which ice melts and latent heat is consumed, and the longer it takes for a temperature pulse to propagate in the subsurface and initiate hydrate dissociation. The shifts in permafrost thickness found in this study are typically in the order of tens of meters per $10 \mathrm{kyr}$. This is in line with other studies focusing on (subsea) permafrost evolution in high-latitude areas (e.g. Romanovskii et al., 2005; Taylor et al., 2013). 


\subsubsection{Marine settings}

The results regarding the continental slope settings indicate that methane hydrates become less prone to destabilization as the water depth increases, which is corroborated by several previous modelling studies (e.g. Reagan and Moridis, 2007; Reagan and Moridis, 2008; Biastoch et al., 2011; Ruppel, 2011). Importantly, figure 15A suggests that the large $120 \mathrm{~m}$ sea level rise and subsequent pressure increase considered in CASE LGM, has a significant stabilizing effect on the upper continental slope hydrates. Indeed, without accounting for this sea level rise, the hydrate reservoir would shrink by $40 \mathrm{~m}$ at the base, and notably, by $70 \mathrm{~m}$ at the top within $100 \mathrm{kyr}$ (figure 22). A similar dissociation pattern was observed in the simulation of the upper continental slope hydrates under contemporary climate forcing (figure 20), and was also modelled by Reagan and Moridis (2007). Such a dissociation pattern is of interest, since methane evolving from the top of hydrate reservoirs has a higher chance to eventually reach the atmosphere. The reason for this is the shorter migration pathway of these methane bubbles through the sediments to the ocean floor, along which the bubbles can dissolve in the pore water or remain trapped by the effects of surface tension (Davie and Buffett, 2001; Ruppel, 2011). Furthermore, free methane gas released at the top of the HOZ does not need to ascend through the entire HSZ, in which free gas might be recycled and reform hydrates (Archer et al., 2009). The importance of sea level or pressure variations on hydrate stability, as illustrated by the comparison of figure 15 and 22, decreases with increasing water depth, since the shape of the methane hydrate stability curve dictates that the variation in dissociation temperature becomes smaller as pressure increases. Consequently, a sea level change will cause larger shifts in dissociation temperatures in hydrate reservoirs under shallow water than at large water depths. Another noteworthy observation regarding the marine realm is that a significant reduction in the size of the HSZ does not necessarily mean that a large volume of methane hydrate will melt, as illustrated in figure 16 and 21 . This is a result of the large offset between the base of the HSZ and the base of the HOZ, of which the positions were modelled according to $X u$ and Ruppel (1999). Not 
differentiating between the $\mathrm{HSZ}$ and $\mathrm{HOZ}$ can therefore lead to large overestimations of the volume of potentially releasable methane.

CASE LGM on upper continental slope, without sea level rise
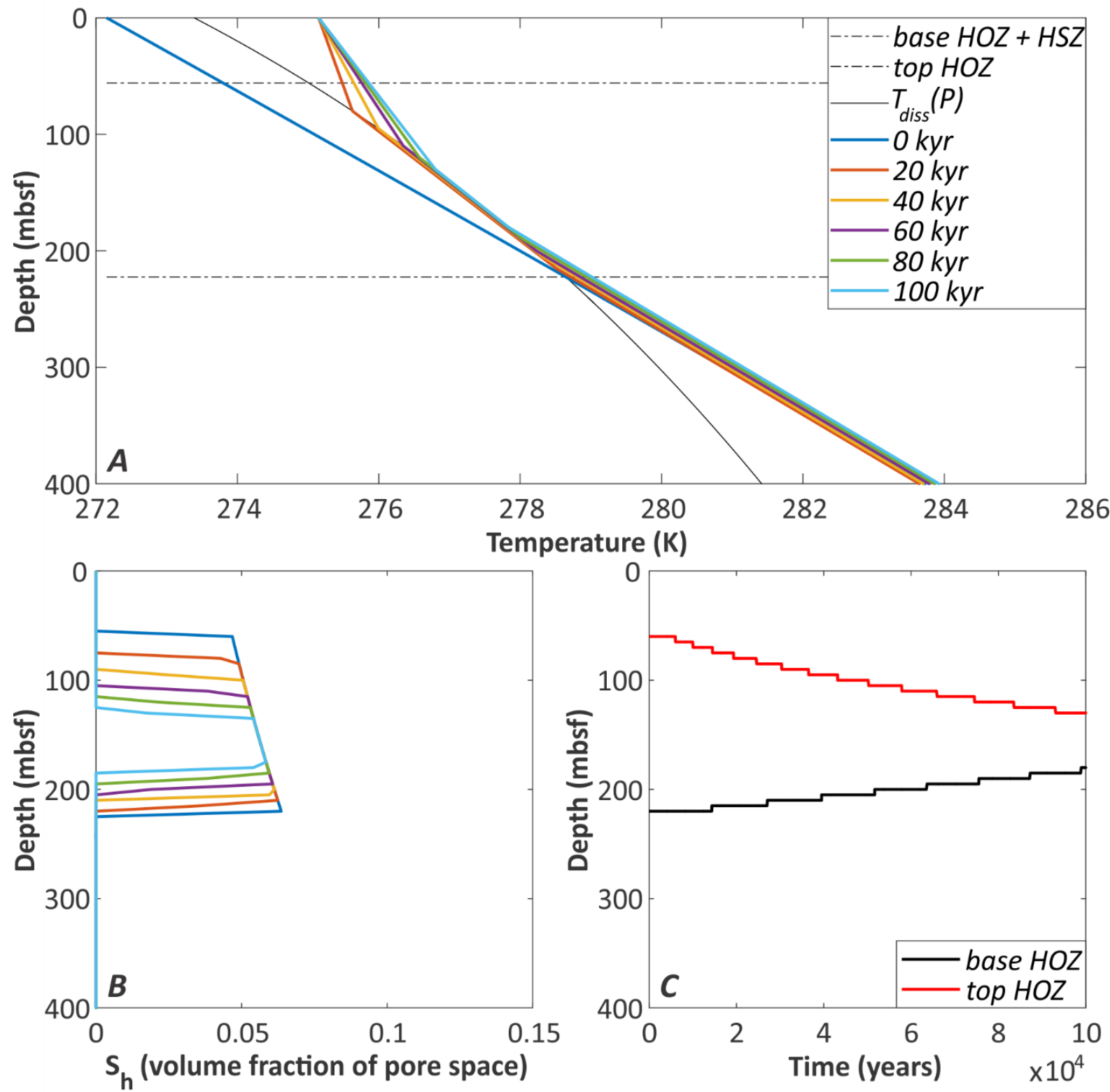

Figure 22. CASE LGM applied to a sediment column on the upper continental slope (300 $\mathrm{m}$ initial water depth), but without accounting for a $120 \mathrm{~m}$ sea level rise: evolution of (A) the temperature profile, (B) hydrate saturation profile, and (C) base and top of the HOZ. The initial position of the base of the HOZ (coinciding with the base of the HSZ) and top of the HOZ are indicated in (A). The legend in (A) also applies to (B). Hydrate dissociation is significantly more severe than if a simultaneous $120 \mathrm{~m}$ sea level rise is accounted for (cfr. figure 15).

\subsubsection{Combined permafrost and marine settings}


Few studies have made a side-by-side comparison of both marine and permafrost-related highlatitude hydrate-bearing settings. This study, in alignment with Ruppel (2011), highlights the contrast between the stable onshore permafrost and deep marine settings on the one hand, and the more unstable upper continental slope and subsea permafrost hydrates on the other. Disregarding continental methane hydrate reservoirs, which are protected from rapid melting because of the thick permafrost, it appears that the hydrate-bearing settings with the shallowest overlying ocean are the most unstable. This is of particular relevance, since the ocean, in addition to the aforementioned role of the sediment column as a buffer for methane release, also impedes the transfer of free methane gas from hydrate reservoirs to the atmosphere. While ascending through the water column, methane bubbles can dissolve and may be oxidized by aerobic microbes (Boetius and Wenzhöfer, 2013) or can be replaced by other gases like oxygen and nitrogen (McGinnis et al., 2006). Evidently, the shallower the overlying ocean, the more likely it becomes that free gas will withstand these processes and eventually reach the atmosphere.

\subsection{General perspectives on the timescales and volumes of gas hydrate dissociation}

Two decisive demands for considering gas hydrate reservoirs as a central component in our climate system are (i) that the hydrate dissociation timescale needs to be sufficiently fast, and (ii) that the involved volumes of methane must be sufficiently large (Buffett and Archer, 2004).

\subsubsection{Stratigraphic-type and permafrost-related hydrates}

Figure 23 illustrates how the dissociation timescales modelled in this study relate to the timescales of climatic variations and the rate of processes that govern atmospheric greenhouse gas levels. This figure shows that climatic cycles generally oscillate faster than the rate at which the size of deep stratigraphic-type and permafrost-related hydrate reservoirs can fluctuate, even in the settings that were identified to be most sensitive (see above). This does not only apply to the degradation of hydrates induced by warming, but even more so to the formation of this type of hydrates upon climate cooling. As a consequence, a primary leading role for this type of hydrate deposits in climate 
change can probably be excluded. Neither is the size of these reservoirs able to closely follow climatic variations, which impedes the creation of a positive feedback mechanism with climate warming. Without such a positive feedback and dynamic response mechanism, deep hydrate reservoirs must be most of the time in a transient, non-equilibrium state, especially when regarding relatively rapid climate change events like those recorded during the Late Quaternary or at present. This implies that deep methane hydrate systems are not stable today, but neither were they before the onset of contemporary anthropogenic climate warming or before the onset of the last deglaciation. Hydrates in these reservoirs continuously melt or form, but not as a reflection of a direct and dynamic interrelationship with the Earth's climate.

\subsubsection{Structural-type hydrates}

In contrast, the dissociation and formation of structural-type hydrate deposits near the seabed can be rapid enough to affect the Earth's carbon budget on timescales similar to those of climatic oscillations (figure 9 and 23). Besides dissociation, Sultan et al. (2014) also underline the importance of dissolution in shallow structural hydrates. These authors describe a complex, heterogenous hydrate distribution pattern within a pockmark field offshore Nigeria, with concurrent fast hydrate growth and relatively slow hydrate dissolution. The dominant process at each location within the pockmark is determined by the balance between gas inflow from below and gas outflow. However, regardless of the timescale of the destabilization process (dissociation or dissolution), up to date it remains highly uncertain if the volumes of methane stored in such structural deposits are large enough to be capable of driving Late Quaternary climatic variations. Estimates of the size of individual structural-type hydrate accumulations are in the range of $4.7 \times 10^{8}$ to $1.3 \times 10^{11} \mathrm{~m}^{3}$ gas at STP in the Gulf of Mexico (Milkov and Sassen, 2003b), $10^{8}$ to $10^{9} \mathrm{~m}^{3}$ gas at STP in the Norwegian, Caspian, Mediterranean and Okhotsk seas (Soloviev, 2002) and $3 \times 10^{8} \mathrm{~m}^{3}$ at the southern summit of Hydrate Ridge (Milkov et al., 2003). Based on their global estimate of $(1-5) \times 10^{15} \mathrm{~m}^{3}$ of hydratebound gas ( $\pm 500-2500$ Gton of methane carbon) in stratigraphic-type reservoirs, Milkov (2004) 
concludes that $10^{4}$ to $10^{7}$ structural hydrate accumulations are needed to come to a significant contribution to the size of the global hydrate inventory. However, the amount of present-day discovered structural-type hydrate deposits is far below this number. Therefore the conclusion, based on the present-day knowledge, is that the volumes of gas in these accumulations are probably insignificant, though further research and exploration in the future may contradict this. It should additionally be noted that only a fraction of structural deposits is located in a temperature-pressure window that is close to the stability boundary of gas hydrate, and thus prone to dissociation upon changing environmental conditions. Secondly, the transfer of methane from melting hydrates to the atmosphere is also strongly mitigated by the buffering effect of the sediments and the ocean (Ruppel and Kessler, 2017). Another question is how large the methane fluxes generated from melting hydrates in structural deposits are, relative to the 'background' seepage of gas from below at those sites. A case study in the Gulf of Mexico suggests that the Late Pleistocene-Holocene gas flux from a leaky petroleum system exceeds the average flux of gas from decomposing structural-type hydrate deposits under changing sea-level and bottom water temperatures (Milkov and Sassen, 2003a). Furthermore, because of the long lifetime of $\mathrm{CO}_{2}$ in the atmosphere and the rapid oxidation of $\mathrm{CH}_{4}$ to $\mathrm{CO}_{2}$ both in the ocean and the atmosphere (figure 23 ), it is $\mathrm{CO}_{2}$ and not $\mathrm{CH}_{4}$ that will persist in nature (Archer, 2007). Methane transfer from hydrate reservoirs to the ocean-atmosphere system will thus rather indirectly impact on the global carbon budget and climate, for example through enhanced ocean acidification (Dickens et al., 1997; Boudreau et al., 2015). 


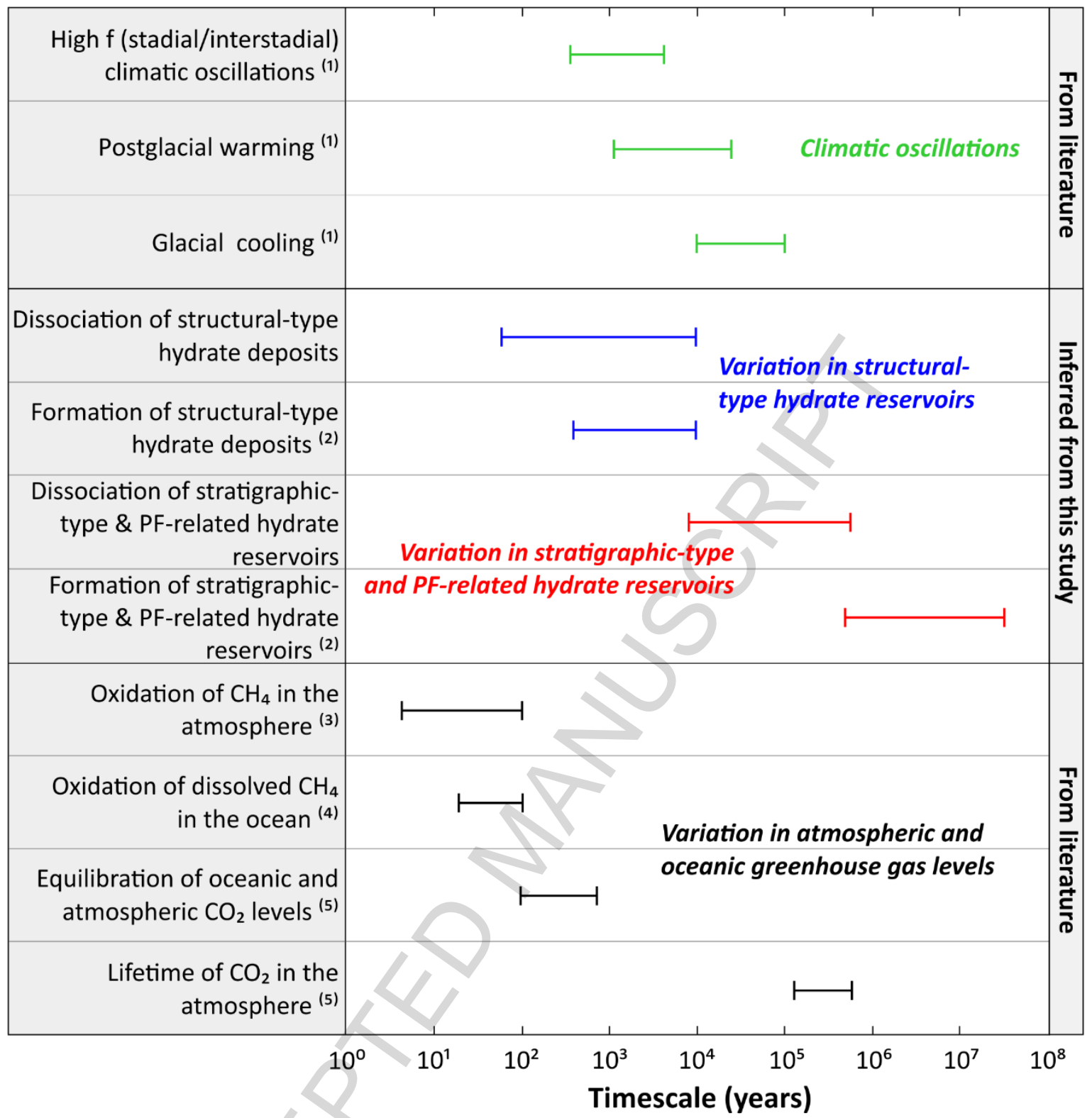

Figure 23. Compilation of the timescales of climatic oscillations, the dissociation and formation timescale of permafrost (PF)related and marine hydrate reservoirs (both deep stratigraphic-type and shallow structural-type), and the rates of processes governing $\mathrm{CH}_{4}$ and $\mathrm{CO}_{2}$ levels in the atmosphere and ocean. Values from ${ }^{[1]}$ Broecker (2000), ${ }^{[2]}$ Xu and Ruppel (1999), ${ }^{[3]}$ Archer (2007), ${ }^{[4]}$ Rehder et al. (1999), ${ }^{[5]}$ Archer (2005). 


\section{Conclusions}

During the past decades, the potential role of gas hydrate systems in global climate has been the motive of extensive, international research. The large volumes of methane contained in gas hydrate reservoirs and the dependence of their stability on pressure and temperature suggest that perturbations in the size of the global gas hydrate inventory could drive variations in atmospheric greenhouse gas levels, and thus impact on the Earth's climate. However, to date there is little consensus on the significance of this process. Central to the discussion is the climate sensitivity of gas hydrate systems, which determines where, how much, in what mode, and (most importantly) how fast gas hydrates are able to melt in response to environmental changes.

In this study we reviewed the scientific base of the argumentation used in the debate, and developed a new one-dimensional, numerical model to evaluate the response of gas hydrate reservoirs to climatic variations. The quality of the model is that it is (i) relatively simple, though based on a large set of parameters, incorporating realistic starting conditions through the implementation of hydrate formation models, and accounting for the most decisive processes (e.g. consumption of latent heat), and (ii) widely applicable, as both marine and permafrost-related (on- and offshore) hydrate-bearing settings in any kind of study area can be analyzed. In a parameter sensitivity analysis, we identified the thermal diffusivity and the depth and thickness of the hydrate occurrence zone as the most important controlling factors for the model outcome.

Focussing on a transect across a high-latitude continental margin, two specific cases of climate change were modelled (the last deglaciation following the LGM and contemporary climate warming). These simulations reveal that there are significant differences in the susceptibility of the considered hydrate-bearing settings to changing temperatures and sea level. Hydrates below shallow water depths (i.e. on the upper continental slope or in association with thin, subsea permafrost) are found to be the most prone to dissociation when bottom water temperatures rise, and are strongly affected by large sea level changes. In contrast, hydrate reservoirs in association with thick onshore 
permafrost and in the deep marine realm are more stable under warming temperature conditions, and (in the latter setting) less influenced by sea level variations.

However, even in the most sensitive environments the dissociation timescales are generally long. The here considered stratigraphic-type hydrate reservoirs, which contain by far the largest fraction of the global gas hydrate volume, melt on timescales of thousands to hunderds of thousands of years. Oppositely, shallow structural-type hydrate accumulations can dissociate on faster, sub-millennial timescales, but their significance to the size of the global hydrate inventory is highly questionable. Quantifying the global volumes of methane in these shallow hydrate accumulations should therefore be considered as one of the major challenges in future gas hydrate research. Without fast response timescales and large releasable gas volumes, it is not likely that dissociating gas hydrates can create a dynamic positive feedback with changing climate, especially when geologically rapid climatic oscillations as those recorded during the late Quaternary or today are regarded. Therefore, based on the present-day knowledge, the overall conclusion is that the destabilization of gas hydrate reservoirs is generally too inefficient to closely follow, interfere with, or dictate rapid Quaternary or contemporary climate change. 


\section{Acknowledgements}

TM is supported by a doctoral scholarship of the Ghent University Special Research Fund (BOF). The authors wish to thank Dr. Nabil Sultan and one anonymous reviewer for constructive reviews which significantly enhanced the quality of this manuscript. This research did not receive any specific grant from funding agencies in the public, commercial, or not-for-profit sectors. 


\section{References}

Archer, D., 2005. Fate of fossil fuel $\mathrm{CO}_{2}$ in geologic time. Journal of Geophysical Research, 110 : C09S05.

Archer, D., 2007. Methane hydrate stability and antropogenic climate change. Biogeosciences, 4: 521-544.

Archer, D. and Buffett, B., 2005. Time-dependent response of the global ocean clathrate reservoir to climatic and anthropogenic forcing. Geochemistry, Geophysics, Geosystems, 6(3).

Archer, D., Buffett, B. and Brovkin, V., 2009. Ocean methane hydrates as a slow tipping point in the global carbon cycle. Proceedings of the National Academy of Sciences of the United States of America, 106(49): 20596-20601.

Bard, E., Hamelin, B. and Fairbanks, R.G., 1990. U-Th ages obtained by mass-spectrometry in corals from Barbados - Sea-level during the past 130,000 years. Nature, 346: 456-458.

Behseresht, J. and Bryant, S.L., 2012. Sedimentological control on saturation distribution in Arctic gas-hydrate-bearing sands. Earth and Planetary Science Letters, 341: 114-127.

Berndt, C., Feseker, T., Treude, T., Krastel, S., Liebetrau, V., Niemann, H., Bertics, V.J., Dumke, I., Dunnbier, K., Ferre, B., Graves, C., Gross, F., Hissmann, K., Huhnerbach, V., Krause, S., Lieser, K., Schauer, J. and Steinle, L., 2014. Temporal constraints on hydrate-controlled methane seepage off Svalbard. Science, 343: 284-287.

Biastoch, A., Treude, T., Rüpke, L.H., Riebesell, U., Roth, C., Burwicz, E.B., Park, W., Latif, M., Böning, C.W., Madec, G. and Wallmann, K., 2011. Rising Arctic Ocean temperatures cause gas hydrate destabilization and ocean acidification. Geophysical Research Letters, 38: L08602.

Bock, M., Schmitt, J., Möller, L., Spahni, R., Blunier, T. and Fischer, H., 2010. Hydrogen Isotopes Preclude Marine Hydrate $\mathrm{CH}_{4}$ Emissions at the Onset of Dansgaard-Oeschger Events. Science, 328(5986): 1686-1689.

Boetius, A. and Wenzhöfer, F., 2013. Seafloor oxygen consumption fuelled by methane from cold seeps. Nature Geoscience, 6(9): 725-734.

Borowski, W.S., Paull, C.K. and Ussler, W., 1996. Marine pore-water sulfate profiles indicate in situ methane flux from underlying gas hydrate. Geology, 24(7): 655-658.

Boswell, R., Rose, K., Collett, T.S., Lee, M., Winters, W., Lewis, K.A. and Agena, W., 2011. Geologic controls on gas hydrate occurrence in the Mount Elbert prospect, Alaska North Slope. Marine and Petroleum Geology, 28(2): 589-607.

Boudreau, B.P., Luo, Y., Meysman, F.J.R., Middelburg, J.J. and Dickens, G.R., 2015. Gas hydrate dissociation prolongs acidification of the Anthropocene oceans. Geophysical Research Letters, 42: 9337-9344.

Broecker, W.S., 2000. Abrupt climate change: causal constraints provided by the paleoclimate record. Earth-Science Reviews, 51: 137-154.

Buffett, B. and Archer, D., 2004. Global inventory of methane clathrate: sensitivity to changes in the deep ocean. Earth and Planetary Science Letters, 227(3-4): 185-199.

Burwicz, E.B., Rüpke, L.H. and Wallmann, K., 2011. Estimation of the global amount of submarine gas hydrates formed via microbial methane formation based on numerical reaction-transport modeling and a novel parameterization of Holocene sedimentation. Geochimica et Cosmochimica Acta, 75(16): 4562-4576. 
Clennell, M.B., Hovland, M., Booth, J.S., Henry, P. and Winters, W.J., 1999. Formation of natural gas hydrates in marine sediments: 1 . Conceptual model of gas hydrate growth conditioned by host sediment properties. Journal of Geophysical Research, 104(B10): 22985-23003.

Collett, T.S., 1993. Natural gas hydrates of the Prudhoe Bay and Kuparuk River area, North Slope, Alaska. AAPG Bulletin, 77(5): 793-812.

Collett, T.S., Johnson, A.H., Knapp, C.C. and Boswell, R., 2009. Natural Gas Hydrates: A Review. In: T.S. Collett, A.H. Johnson, C.C. Knapp and R. Boswell (Editors), Natural gas hydrates - Energy resource potential and associated geologic hazards: AAPG Memoir 89, pp. 146-219.

Collett, T.S., Lee, M.W., Agena, W.F., Miller, J.J., Lewis, K.A., Zyrianova, M.V., Boswell, R. and Inks, T.L., 2011. Permafrost-associated natural gas hydrate occurrences on the Alaska North Slope. Marine and Petroleum Geology, 28(2): 279-294.

Crémière, A., Lepland, A., Chand, S., Sahy, D., Condon, D.J., Noble, S.R., Martma, T., Thorsnes, T., Sauer, S. and Brunstad, H., 2016. Timescales of methane seepage on the Norwegian margin following collapse of the Scandinavian Ice Sheet. Nature Communications, 7: 11509.

Davie, M.K. and Buffett, B., 2001. A numerical model for the formation of gas hydrate below the seafloor. Journal of Geophysical Research, 106(B1): 497-514.

Davie, M.K., Zatsepina, O.Y. and Buffett, B.A., 2004. Methane solubility in marine hydrate environments. Marine Geology, 203(1-2): 177-184.

Davy, B., Pecher, I., Wood, R., Carter, L. and Gohl, K., 2010. Gas escape features off New Zealand: Evidence of massive release of methane from hydrates. Geophysical Research Letters, 37 : L21309.

Delisle, G., 2007. Near-surface permafrost degradation: How severe during the 21st century? Geophysical Research Letters, 34: L09503.

Dickens, G.R., 2011. Down the Rabbit Hole: toward appropriate discussion of methane release from gas hydrate systems during the Paleocene-Eocene thermal maximum and other past hyperthermal events. Climate of the Past, 7(3): 831-846.

Dickens, G.R., Castillo, M.M. and Walker, J.C.G., 1997. A blast of gas in the latest Paleocene: Simulating first-order effects of massive dissociation of oceanic methane hydrate. Geology, 25(3): 259-262.

Dickens, G.R., O'Neil, J.R., Rea, D.K. and Owen, R.M., 1995. Dissociation of oceanic methane hydrate as a cause of the carbon isotope excursion at the end of the Paleocene. Paleoceanography, 10(6): 965-971.

Dickens, G.R. and Quinby-Hunt, M.S., 1994. Methane hydrate stability in seawater. Geophysical Research Letters, 21(19): 2115-2118.

Foucher, J.P., Nouzé, H. and Henry, P., 2002. Observation and tentarive interpretation of a double BSR on the Nankai slope. Marine Geology, 187(1-2): 161-175.

Frederick, J.M. and Buffett, B.A., 2014. Taliks in relict submarine permafrost and methane hydrate deposits: Pathways for gas escape under present and future conditions. Journal of Geophysical Research: Earth Surface, 119(2): 106-122.

Frederick, J.M. and Buffett, B.A., 2015. Effects of submarine groundwater discharge on the presentday extent of relict submarine permafrost and gas hydrate stability on the Beaufort Sea continental shelf. Journal of Geophysical Research: Earth Surface, 120(3): 417-432. 
Garg, S.K., Pritchett, J.W., Katoh, A., Baba, K. and Fujii, T., 2008. A mathematical model for the formation and dissociation of methane hydrates in the marine environment. Journal of Geophysical Research, 113: B01201.

Golmshtok, A.Y. and Soloviev, V.A., 2006. Some remarks on the thermal nature of the double BSR. Marine Geology, 229(3-4): 187-198.

Goto, S. and Matsubayashi, O., 2009. Relations between the thermal properties and porosity of sediments in the eastern flank of the Juan de Fuca Ridge. Earth Planets Space, 61: 863-870.

Goutorbe, B., Poort, J., Lucazeau, F. and Raillard, S., 2011. Global heat flow trends resolved from multiple geological and geophysical proxies. Geophysical Journal International, 187(3): 14051419.

Greinert, J., Lewis, K.B., Bialas, J., Pecher, I.A., Rowden, A., Bowden, D.A., De Batist, M. and Linke, P., 2010. Methane seepage along the Hikurangi Margin, New Zealand: Overview of studies in 2006 and 2007 and new evidence from visual, bathymetric and hydroacoustic investigations. Marine Geology, 272(1-4): 6-25.

Haynes, W.M., Lide, D.R. and Bruno, T.J., 2013-2014. CRC handbook of chemistry and physics: a ready-reference book of chemical and physical data, 94th edition. CRC Press LLC, Boca Raton, Florida.

Hu, H. and Argyropoulos, S.A., 1996. Mathematical modelling of solidification and melting: a review. Modelling and Simulation in Materials Science and Engineering, 4: 371-396.

Hunter, S.J., Goldobin, D.S., Haywood, A.M., Ridgwell, A. and Rees, J.G., 2013. Sensitivity of the global submarine hydrate inventory to scenarios of future climate change. Earth and Planetary Science Letters, 367: 105-115.

IPCC, 2013. Climate Change 2013: The Physical Science Basis. Contribution of Working Group I to the Fifth Assessment Report of the Intergovernmental Panel on Climate Change. In: T.F. Stocker, D. Qin, G.-K. Plattner, M. Tignor, S.K. Allen, J. Boschung, A. Nauels, Y. Xia, V. Bex and P.M. Midgley (Editors), Cambridge University Press, Cambridge, United Kingdom and New York, NY, USA, pp. 1535.

Johnson, H.P., Miller, U.K., Salmi, M.S. and Solomon, E.A., 2015. Analysis of bubble plume distributions to evaluate methane hydrate decomposition on the continental slope. Geochemistry, Geophysics, Geosystems, 16(11): 3825-3839.

Judd, A. and Hovland, M., 2007. Seabed fluid flow: the impact on geology, biology, and the marine environment. Cambridge University Press, Cambridge, U.K.

Kennett, J.P., Cannariato, K.G., Hendy, I.L. and Behl, R.J., 2003. Methane Hydrates in Quaternary Climate Change: The Clathrate Gun Hypothesis. In: J.P. Kennett, K.G. Cannariato, I.L. Hendy and R.J. Behl (Editors), Methane Hydrates in Quaternary Climate Change: The Clathrate Gun Hypothesis, American Geophysical Union, Washington, D.C.

Knies, J., Damm, E., Gutt, J., Mann, U. and Pinturier, L., 2004. Near-surface hydrocarbon anomalies in shelf sediments off Spitsbergen: Evidences for past seepages. Geochemistry, Geophysics, Geosystems, 5(6).

Knittel, K. and Boetius, A., 2009. Anaerobic oxidation of methane: progress with an unknown process. Annual Review of Microbiology, 63: 311-34.

Koh, C.A., Sum, A.K. and Sloan, E.D., 2012. State of the art: Natural gas hydrates as a natural resource. Journal of Natural Gas Science and Engineering, 8: 132-138. 
Kumar, P., Turner, D. and Sloan, E.D., 2004. Thermal diffusivity measurements of porous methane hydrate and hydrate-sediment mixtures. Journal of Geophysical Research: Solid Earth, 109(B1).

Kvenvolden, K.A., 1988. Methane hydrate - a major reservoir of carbon in the shallow geosphere. Chemical Geology, 71: 41-51.

Kvenvolden, K.A., 1993. Gas hydrates: Geological perspective and global change. Reviews of Geophysics, 31(2): 173-187.

Kvenvolden, K.A., 2002. Methane hydrate in the global carbon cycle. Terra Nova, 14(5): 302-306.

Kwon, T.-H., Cho, G.-C. and Santamarina, J.C., 2008. Gas hydrate dissociation in sediments: Pressuretemperature evolution. Geochemistry, Geophysics, Geosystems, 9: Q03019.

Landvik, J.Y., Bondevik, S., Elverhøi, A., Fjeldskaar, W., Mangerud, J., Salvigsen, O., Siegert, M.J., Svendsen, J.-I. and Vorren, T.O., 1998. The Last Glacial Maximum of Svalbard and the Barents Sea area: ice sheet extent and configuration. Quaternary Science Reviews, 17: 43-75.

Lin, W., Fulton, P.M., Harris, R.N., Tadai, O., Matsubayashi, O., Tanikawa, W. and Kinoshita, M., 2014. Thermal conductivities, thermal diffusivities, and volumetric heat capacities of core samples obtained from the Japan Trench Fast Drilling Project (JFAST). Earth, Planets and Space, 66(1): 48.

Liu, X. and Flemings, P.B., 2011. Capillary effects on hydrate stability in marine sediments. Journal of Geophysical Research, 116: B07102.

Loehle, C., 1993. Geologic methane as a source for post-glacial $\mathrm{CO}_{2}$ increases: The hydrocarbon pump hypothesis. Geophysical Research Letters, 20(14): 1415-1418.

MacDonald, G.J., 1990. Role of methane clathrates in past and future climates. Climatic Change, 16(3): 247-281.

Marín-Moreno, H., Minshull, T.A., Westbrook, G.K., Sinha, B. and Sarkar, S., 2013. The response of methane hydrate beneath the seabed offshore Svalbard to ocean warming during the next three centuries. Geophysical Research Letters, 40: 5159-5163.

Maslin, M., Owen, M., Day, S. and Long, D., 2004. Linking continental-slope failures and climate change: Testing the clathrate gun hypothesis. Geology, 32(1): 53-56.

Maslin, M.A. and Thomas, E., 2003. Balancing the deglacial global carbon budget: the hydrate factor. Quaternary Science Reviews, 22: 1729-1736.

McGinnis, D.F., Greinert, J., Artemov, Y., Beaubien, S.E. and Wüest, A., 2006. Fate of rising methane bubbles in stratified waters: How much methane reaches the atmosphere? Journal of Geophysical Research, 111: C09007.

Mienert, J., Andreassen, K., Posewang, J. and Lukas, D., 2000. Changes in the hydrate stability zone of the Norwegian margin from glacial to interglacial times. In: G.D. Holder and P.R. Bishnoi (Editors), Gas hydrates: challenges for the future. Annals of the New York Academy of Sciences, pp. 200-210.

Milkov, A., Claypool, G.E., Lee, Y.-J., Xu, W., Dickens, G.R., Borowski, W.S. and ODP Leg 204 Scientific Party, 2003. In situ methane concentrations, at Hydrate Ridge, offshore Oregon: New constraints on the global gas hydrate inventory from an active margin. Geology, 31(10): 833836.

Milkov, A. and Sassen, R., 2002. Economic geology of offshore gas hydrate accumulations and provinces. Marine and Petroleum Geology, 19: 1-11. 
Milkov, A.V., 2004. Global estimates of hydrate-bound gas in marine sediments: how much is really out there? Earth-Science Reviews, 66: 183-197.

Milkov, A.V., 2005. Molecular and stable isotope compositions of natural gas hydrates: A revised global dataset and basic interpretations in the context of geological settings. Organic Geochemistry, 36(5): 681-702.

Milkov, A.V. and Sassen, R., 2003a. Two-dimensional modeling of gas hydrate decomposition in the northwestern Gulf of Mexico: significance to global change assessment. Global and Planetary Change, 36(1-2): 31-46.

Milkov, A.V. and Sassen, R., 2003b. Preliminary assessment of resources and economic potential of individual gas hydrate accumulations in the Gulf of Mexico continental slope. Marine and Petroleum Geology, 20(2): 111-128.

Miller, G.H., Brigham-Grette, J., Alley, R.B., Anderson, L., Bauch, H.A., Douglas, M.S.V., Edwards, M.E., Elias, S.A., Finney, B.P., Fitzpatrick, J.J., Funder, S.V., Herbert, T.D., Hinzman, L.D., Kaufman, D.S., MacDonald, G.M., Polyak, L., Robock, A., Serreze, M.C., Smol, J.P., Spielhagen, R., White, J.W.C., Wolfe, A.P. and Wolff, E.W., 2010. Temperature and precipitation history of the Arctic. Quaternary Science Reviews, 29: 1679-1715.

Millero, F.J. and Leung, W.H., 1976. The thermodynamics of seawater at one atmosphere. American Journal of Science, 276(9): 1035-1077.

Moridis, G.J., Kowalsky, M.B. and Pruess, K., 2008. TOUGH+HYDRATE v1.0 user's manual: A code for the simulation of system behavior in hydrate-bearing geologic media, Rep. LBNL-0149E, Lawrence Berkeley Natl. Lab., Berkeley, California.

Naudts, L., Greinert, J., Artemov, Y., Staelens, P., Poort, J., Van Rensbergen, P. and De Batist, M., 2006. Geological and morphological setting of 2778 methane seeps in the Dnepr paleo-delta, northwestern Black Sea. Marine Geology, 227(3-4): 177-199.

Nisbet, E.G., 1990. The end of the ice age. Canadian Journal of Earth Sciences, 27(1): 148-157.

Paull, C.K., Ussler, W. and Dillon, W.P., 1991. Is the extent of glaciation limited by marine gashydrates? Geophysical Research Letters, 18(3): 432-434.

Phrampus, B.J. and Hornbach, M.J., 2012. Recent changes to the Gulf Stream causing widespread gas hydrate destabilization. Nature, 490(7421): 527-30.

Poort, J., Vassilev, A. and Dimitrov, L., 2005. Did postglacial catastrophic flooding trigger massive changes in the Black Sea gas hydrate reservoir? Terra Nova, 17(2): 135-140.

Rajan, A., Mienert, J. and Bünz, S., 2012. Acoustic evidence for a gas migration and release system in Arctic glaciated continental margins offshore NW-Svalbard. Marine and Petroleum Geology, 32(1): 36-49.

Reagan, M.T. and Moridis, G.J., 2007. Oceanic gas hydrate instability and dissociation under climate change scenarios. Geophysical Research Letters, 34(22).

Reagan, M.T. and Moridis, G.J., 2008. Dynamic response of oceanic hydrate deposits to ocean temperature change. Journal of Geophysical Research, 113(C12): C12023.

Reagan, M.T., Moridis, G.J., Elliott, S.M. and Maltrud, M., 2011. Contribution of oceanic gas hydrate dissociation to the formation of Arctic Ocean methane plumes. Journal of Geophysical Research, 116: C09014.

Rehder, G., Keir, R.S., Suess, E. and Rhein, M., 1999. Methane in the northern Atlantic controlled by microbial oxidation and atmospheric history. Geophysical Research Letters, 26(5): 587-590. 
Rempel, A.W. and Buffett, B., 1997. Formation and accumulation of gas hydrate in porous media. Journal of Geophysical Research, 102(B5): 10151-10164.

Romanovskii, N.N., Hubberten, H.W., Gavrilov, A.V., Eliseeva, A.A. and Tipenko, G.S., 2005. Offshore permafrost and gas hydrate stability zone on the shelf of East Siberian Seas. Geo-Marine Letters, 25(2-3): 167-182.

Roose, F., 2006. Hydrate dissociation and slope stability on continental margins in response to changes in environmental parameters. Msc. thesis GGS Marine and Lacustrine Sciences, Ghent University. 20 pp.

Ruppel, C., 2015. Permafrost-Associated Gas Hydrate: Is It Really Approximately $1 \%$ of the Global System? Journal of Chemical \& Engineering Data, 60(2): 429-436.

Ruppel, C.D., 2011. Methane Hydrates and Contemporary Climate Change. Nature Education Knowledge, 2(12): 12.

Ruppel, C.D. and Kessler, J.D., 2017. The interaction of climate change and methane hydrates. Reviews of Geophysics.

Sassen, R., Sweet, S.T., Milkov, A., DeFreitas, D.A. and Kennicut II, M.A., 2001. Thermogenic vent gas and gas hydrate in the Gulf of Mexico slope: Is gas hydrate decomposition significant? Geology, 29: 107-110.

Sloan, E.D., 1998. Clathrate Hydrate of Natural Gases, 2nd Edition. Marcel Dekker Inc., New York.

Smith, L.M., Sachs, J.P., Jennings, A.E., Anderson, D.M. and deVernal, A., 2001. Light $\delta^{13}$ C events during deglaciation of the East Greenland continental shelf attributed to methane release from gas hydrates. Geophysical Research Letters, 28(11): 2217-2220.

Solomon, E.A., Kastner, M., MacDonald, I.R. and Leifer, I., 2009. Considerable methane fluxes to the atmosphere from hydrocarbon seeps in the Gulf of Mexico. Nature Geoscience, 2: 561-565.

Soloviev, V.A., 2002. Global estimation of gas content in submarine gas hydrate accumulations. Russian Geology and Geophysics, 43: 609-624.

Sowers, $\mathrm{T}$., 2006. Late Quaternary atmospheric $\mathrm{CH}_{4}$ isotope record suggests marine clathrates are stable. Science, 311: 838-840.

Sultan, N., 2007. Comment on "Excess pore pressure resulting from methane hydrate dissociation in marine sediments: A theoretical approach" by Wenyue Xu and Leonid N. Germanovich. Journal of Geophysical Research, 112: B02103.

Sultan, N., Bohrmann, G., Ruffine, L., Pape, T., Riboulot, V., Colliat, J.-L., De Prunelé, A., Dennielou, B., Garziglia, S., Himmler, T., Marsset, T., Peters, C.A., Rabiu, A. and Wei, J., 2014. Pockmark formation and evolution in deep water Nigeria: Rapid hydrate growth versus slow hydrate dissolution. Journal of Geophysical Research: Solid Earth, 119: 2679-2694.

Sultan, N., Cochonat, P., Foucher, J.P. and Mienert, J., 2004. Effect of gas hydrates melting on seafloor slope instability. Marine Geology, 213(1-4): 379-401.

Taylor, A.E., Dallimore, S.R., Hill, P.R., Issler, D.R., Blasco, S. and Wright, F., 2013. Numerical model of the geothermal regime on the Beaufort Shelf, arctic Canada since the Last Interglacial. Journal of Geophysical Research: Earth Surface, 118(4): 2365-2379.

Tipenko, G.S., Romanovskii, N.N. and Kholodov, A.L., 1999. Simulation of the Offshore Permafrost and Gashydrate Stability Zone: Mathematical Solution, Numerical Realization and Preliminary Results. Polarforschung, 69: 229-233. 
Waelbroeck, C., Labeyrie, L., Michel, E., Duplessy, J.C., McManus, J.F., Lambeck, K., Balbon, E. and Labracherie, M., 2002. Sea-level and deep water temperature changes derived from benthic foraminifera isotopic records. Quaternary Science Reviews, 21: 295-305.

Waite, W.F., Stern, L.A., Kirby, S.H., Winters, W.J. and Mason, D.H., 2007. Simultaneous determination of thermal conductivity, thermal diffusivity and specific heat in sl methane hydrate. Geophysical Journal International, 169(2): 767-774.

Westbrook, G.K., Thatcher, K.E., Rohling, E.J., Piotrowski, A.M., Pälike, H., Osborne, A.H., Nisbet, E.G., Minshull, T.A., Lanoisellé, M., James, R.H., Hühnerbach, V., Green, D., Fisher, R.E., Crocker, A.J., Chabert, A., Bolton, C., Beszczynska-Möller, A., Berndt, C. and Aquilina, A., 2009. Escape of methane gas from the seabed along the West Spitsbergen continental margin. Geophysical Research Letters, 36: L15608.

Xu, W. and Germanovich, L.N., 2006. Excess pore pressure resulting from methane hydrate dissociation in marine sediments: A theoretical approach. Journal of Geophysical Research, 111: B01104.

Xu, W. and Germanovich, L.N., 2007. Reply to comment by Nabil Sultan on "Excess pore pressure resulting from methane hydrate dissociation in marine sediments: A theoretical approach". Journal of Geophysical Research, 112: B02104.

Xu, W. and Ruppel, C., 1999. Predicting the occurrence, distribution, and evolution of methane gas hydrate in porous marine sediments. Journal of Geophysical Research, 104(B3): 5081-5095. 